\title{
METHODS, FORMULAS, AND TABLES FOR THE CALCULATION OF ANTENNA CAPACITY
}

\author{
By Frederick W. Grover
}

\begin{abstract}
To calculate the capacity of an antenna a certain charge is assumed upon the antenna and the resulting potential is calculated.

In carrying out this method the difficulty is met that, in general, the law of distribution of the charge is not known. Howe made the assumption that sufficient accuracy is attained if first a uniform distribution of charge is supposed to exist and the potential calculated at various points of the antenna, the average of these potentials being taken as the final equilibrium potential. Howe called attention to discrepancies between the values obtained by his method and published values for the same antennas by the inductance method. The present paper shows that the two methods agree if appropriate inductance formulas are employed. The Howe method is more general, and it is believed to give sufficient accuracy for engineering requirements.

Formulas are given for the common types of single and multiple wire antennas in a form convenient for numerical computation, together with tables of constants which will be found useful in such calculations. In addition, tables of the capacities of both horizontal and vertical single-wire antennas and horizontal two-wire antennas have been included, which should render all calculation unnecessary in many inportant practical cases.
\end{abstract}

\section{CONTENTS}

I. Introduction

II. General method used for calculating the capacity

III. Single horizontal wire

IV. Howe's approximation.

V. Method of successive numerical approximations

VI. Treatment of combinations of wires

VII. Derivation of working formulas for the capacity.

VIII. Working formulas for calculating capacity of various practical forms of antennas

1. Single horizontal wire

2. Single vertical wire

586

3. Single-wire inverted $L$ antenna

4. Single-wire T antenna_...

5. Parallel horizontal wires in the same horizontal plane...-

6. Antenna of parallel wires equally spaced in a vertical



7. Parallel wire inverted $L$ antenna

8. Parallel wire T antenna.......

9. Horizontal "cage" antenna.

10. Vertical "cage" antenna

11. Single $V$ antenna..........

586

587

588

588 
VIII. Working formulas for calculating capacity of various practical forms of antennas-Continued.

12. Two horizontal wires inclined to one another

13. Single-wire inclined to the earth's surface

14. Parallel wire $V$ antenna

15. Antenna of parallel wires in a plane inclined to ground... -

16. Conical antenna_...... 602

17. Umbrella antenna

18. Fan or harp antenna......... 604

IX. Use of tables for three common forms of antennas

X. Calculation of capacity of lead-in wires_...... 607

XI. Tables for antenna capacity calculation

Table 1.- Values of the constant $K$ for use in formula (18) and for horizontal wires in general........

Table 2.-Constants for single-wire horizontal antennas......

Table 3.-Values of the constant $k$ for use in formula (19) and



Table 4.-Constants for single-wire vertical antennas 609 609

Table 5.- Values of the constant $X$ for the mutual effect of wires at right angles

Table 6.-Values of the constant $K_{\mathrm{n}}$ for use in formula (22)

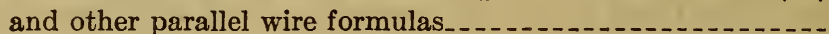

Table 7.- Values of the constant $Y_{1}$ for wires intersecting at an angle.

Table 8.- Values of the constant $Y_{2}$ for wires in parallel planes and inclined at an angle

Table 9.-Constants for two-wire horizontal antennas.

XII. Appendixes_...

Appendix 1.-Formula for the capacity of a solid-top antenna

Appendix 2.-Formulas for potential coefficients of various wire

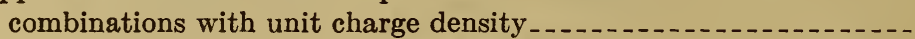

Appendix 3.-An alternative or mathematical statement of Howe's assumption................

\section{INTRODUCTION}

Formulas for the calculation of the capacity between two parallel wires of infinite length have long been known. The case of a single wire of infinite length, stretched parallel with the surface of the earth at a distance which is small, compared with its length, may be treated by the same formulas, since, by the theory of electric images, the effect of the induced charge on the earth may be taken into account by supposing the earth to be replaced by a wire of the same dimensions as the given wire and carrying a charge of opposite sign. This image wire is assumed to lie as far below the surface of the earth as the actual wire is above the surface of the earth. A very complete treatment of the whole subject for wires of infinite length, together with a bibliography, is given in a paper by Kennelly ${ }^{1}$ who has also in a later article ${ }^{2}$ published curves for simplifying the calculations. 
The formulas for wires of infinite length suffice for calculations with transmission lines, but in the very important case of an antenna, the wires of which it is composed are seldom of such a length that their distances from one another and from the earth, can be neglected in comparison with their lengths. A correction for the lack of uniformity of distribution of the charge along the wires has to be taken into account. The capacity of a single wire has sometimes been calculated from the formula for a very long thin ellipsoid, isolated in space, but only in recent years have formulas for the more common forms of antenna been derived.

Of these, especial mention may be made of the work of Cohen, ${ }^{3}$ who derived formulas for the capacity of an antenna consisting of a number of wires, arranged parallel to one another and to the surface of the earth (flat-top antenna) by assuming the reciprocal of the capacity per unit length to be equal to the inductance per unit length of the system of wires, assumed to be joined in parallel with the earth as return. This reciprocal relation holds exactly only when the wires are of infinite length.

The most extensive contribution is, however, furnished by the papers of Howe, ${ }^{4}$ who has obtained formulas for a number of common forms of antenna from electrostatic considerations. The distinguishing feature of his treatment is the method used to take into account the lack of uniformity of distribution of the charge along the wires. Howe called attention to the considerable difference in the value of the capacity calculated by Cohen for a certain flat-top antenna and the value obtained by his own formula for the same case, but gave no explanation of the discrepancy.

In 1917 formulas derived by the author of the present paper were published by the Bureau of Standards. ${ }^{5}$ In these account was taken of the finite length of the wire, but the lack of uniformity of charge distribution was only imperfectly taken into account. The method of Cohen was employed, but with a considerable simplification in the mathematical work.

An approximate formula by Austin ${ }^{6}$ for the capacity of multiplewire flat-top antennas has the advantage of simplicity, with an accuracy which is greater the greater the number of wires in the antenna top; that is, for close distribution of the wires.

The present paper has grown out of an examination of the difference between the results of Cohen and Howe. It will be shown that although neither method is exact, the method of Cohen leads to the same formulas as the method of Howe in those cases where the former method is applicable.

2 L. Cohen, Alternating-current Problems, McGraw-Hill Publishing Co., 1913.

' G. W. O. Howe, Lond. Elect., 73, p. 829; 1914. Lond. Elect., 77, p. 761; 1916. Proc. Lond. Phys. Soc., 29, p. 339; 1916-17.

- Circular No. 74, Radio Instruments and Measurements, Bureau of Standards. pp. 237-241; 1917.

- L. W. Austin, J. Wash. Acad. of Sci., 9, p. 393; 1919 
Finally, the Howe method of approximation has been used to derive formulas for the capacity of the more usual types of antenna. Some of these cases have already been treated by Howe, but for the most part with further simplifying assumptions. The attempt has been made here to avoid, as far as possible, approximations other than that involved in Howe's fundamental assumption. Especial attention has been paid to putting the formulas in a form convenient for numerical calculation, and to unifying the mode of expression, so that a few tables suffice for all the principal cases.

The formulas of this paper apply strictly only to the electrostatic capacity. For the case of alternating currents, provided that the length of the antenna is small compared with the wave length, the value of the quotient of charge by potential may be regarded as the effective capacity of the antenna.

\section{GENERAL METHOD USED FOR CALCULATING THE CAPACITY}

The electrostatic capacity of a conductor is defined as the quotient of its charge by its potential. The potential is the algebraic sum of the values of potential given it by its own charge and by the charges on all the other conductors of the system. The effect of the induced charges on the earth may be taken into account by including with each conductor an image conductor which is supposed to carry an equal and opposite charge to that on the conductor to which it corresponds.

Accordingly, the capacity of an infinite straight wire placed parallel to the surface of the earth is the same as that of an infinite straight wire, placed parallel to an equal wire, bearing an equal charge of the opposite sign. The exact formula for the capacity in this last case is well known. If $d$ is the diameter of cross section of the wire, and $h$ is its height above the earth, the capacity of the wire per unit length is

$$
C_{1}=\frac{1}{2 \cosh ^{-1} \frac{2 h}{d}}=\frac{1}{2 \log \left[\frac{2 h+\sqrt{4 h^{2}-d^{2}}}{d}\right]}
$$

For a wire 0.01 foot $(0.12$ inch) in diameter, placed 25 feet above the ground, the formula

$$
\mathrm{C}_{1}=\frac{1}{2 \operatorname{logn} \frac{4 h}{d}}
$$

differs from the exact formula (1) by only 1 part in $10^{\circ}$. The exact formula takes into account the fact that the surface density of the charge is not quite uniform around the perimeter of the elements of the wire, as a result of the attraction between the charge on the wire and that on the earth. This disturbance is neglected in equation (2), and the smallness of the error thus committed in the example in question shows that this effect does not need to be taken into account with the sizes of wire and the heights common in antennas. 
For an infinite wire the distribution of charge is uniform along the axis; that is, the quantity of charge is everywhere the same for portions of the cylindrical surface intercepted between planes drawn perpendicular to the axis and $1 \mathrm{~cm}$ apart. Neglecting the slight variation of the surface density around the perimeter of the cross section, the potential at external points and at points on the surface of the wire, is the same as would be produced by a uniform distribution of charge on the axis itself, if the quantity of charge $q$ per centimeter, measured along the axis, be taken equal to the charge on the cylindrical surface between planes perpendicular to the axis and $1 \mathrm{~cm}$ apart.

\section{SINGLE HORIZONTAL WIRE}

For a horizontal antenna wire the height above the earth can not be regarded as negligible in comparison with the length of the wire; on the contrary, these two dimensions are, as a rule, of the same order of magnitude. No exact formula for the calculation of the capacity of such a wire is known. In fact, the simpler problem of the calculation of the capacity of an isolated cylinder has not yet been solved and seems to offer great difficulties. Fortunately, the smallness of the diameter of the wires used for antennas, as compared with their length, allows an approximation to the capacity to be obtained. The following possibilities may be considered for the case of a single horizontal wire.

We may, first, assume that the capacity per centimeter is the same as for an infinite wire of the same diameter and height above the earth, and may thus write for the capacity

$$
C=\frac{l}{2 \log n \frac{4 h}{d}}
$$

$l$ being the length of the wire in centimeters. This formula, however, does not take into account the fact that the charge density on the wire increases as the ends of the wire are approached, and must become infinite for an infinitesimal area of the surface at the extreme ends of the wires.

Let us suppose that a charge distribution of $q$ units per centimeter be placed along the axis of the wire. (Fig. 1.) The potential at any point $P(a, D)$ is readily found to be

$$
v=q\left[\sinh ^{-1} \frac{\frac{l}{2}+a}{D}+\sinh ^{-1} \frac{\frac{l}{2}-a}{D}\right]
$$


and taking the point $P$ on the surface of the wire; that is, putting $D=\frac{d}{2}$, the potential of the wire due to the charge is

$$
v_{1}=q\left[\sinh ^{-1} \frac{\frac{l}{2}+a}{d / 2}+\sinh ^{-1} \frac{\frac{l}{2}-a}{d / 2}\right]
$$

The similar distribution of charge of $-q$ per centimeter on the image wire will give to the wire at the point $P$ the potential

$$
v_{2}=-q\left[\sinh ^{-1} \frac{\frac{l}{2}+a}{2 h}+\sinh ^{-1} \frac{\frac{l}{2}-a}{2 h}\right]
$$

The potential values calculated from equations (5) and (5) are plotted in Figure 2 for a wire 50 feet long, 0.01 foot in diameter,



Fig. 1.-Potential due to a uniform line charge at an external point

placed 25 feet above the ground. Curve $A$ shows the potential variation along the wire, due to the assumed uniform distribution of charge on the wire. The potential has a maximum value of 18.420 $q$ at the center, and decreases only very slightly until the ends are nearly reached, when the value drops suddenly to $9.903 q$. The potential due to the charge on the image wire, curve $B$, is also largest at the center, and is quite uniform over the wire, decreasing somewhat toward the ends. The value at the center is $-0.962 q$, and at the ends $-0.881 q$. The resultant potential, curve $C$, which is the sum of the curves $A$ and $B$, has, therefore, a maximum value of $17.458 q$ at the center and $9.022 q$ at the ends, but the changes are small, excepting within the last few inches of wire at the ends.

Thus, the value of potential at the center may be taken as representing approximately the actual potential of the wire, and this approximation is a closer one than the value $18.420 q$ given by the infinite wire formula for in the latter is included the potential which would be contributed by uniform axial charges of density $q$ per centimeter reaching from the ends of the wire to infinity. 


\section{HOWE'S APPROXIMATION}

The assumed uniformly distributed charge on the wire would not be in equilibrium. The potential variation shown in curve $C$ (fig. 2) would cause charge to move from the center toward the ends. Thus, the potential at the middle would fall, and that at the ends would rise, until the whole wire would reach a uniform potential. It is thus evident that the potential value calculated for the middle of the wire on the assumption of uniform charge density is too large, and the value similarly calculated for the ends is too small. As an approximation to the true equilibrium potential, Howe calculated the average of the potentials taken over the length of the wire. The expression for this average is readily obtained by integrating equations (5) and (6) over the wire, and dividing the result by the length of the wire. The average potential due to the charge on the wire is thus found to be $17.807 q\left(D D^{\prime}\right.$, fig. 2 ), and that due to the image charge $-0.934 q$. Their
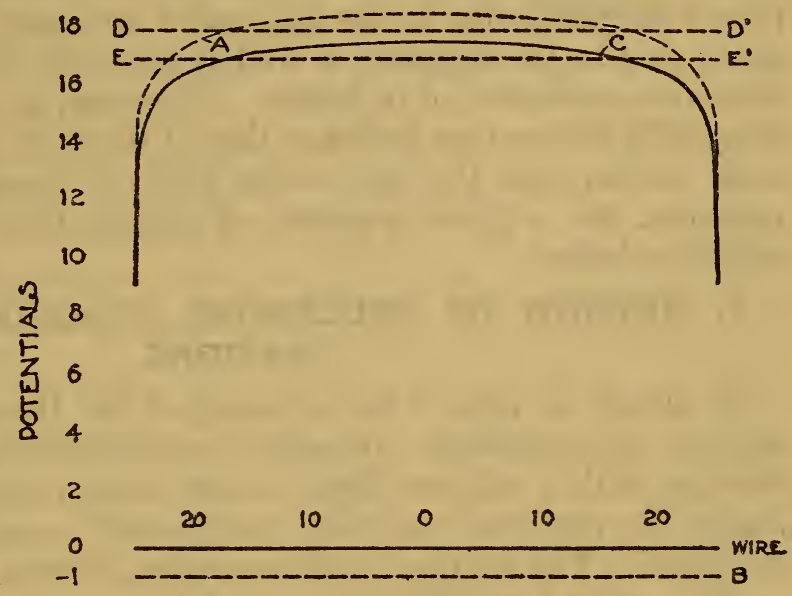
sum is $16.874 q$ ( $E E^{\prime}$, fig. 2). If, instead of supposing an axial distribution of charge, the distribution were supposed uniform over the cylindrical surface of the wire, and the average of the potentials taken over the surface of the wire, the result found would differ in this example by only 5 parts in 100,000 . Thus, for the dimensions common with antenna wires, the assumption of an axial distribution in carrying out the Howe method of approximation is justified.

The different approximations to the potential of the wire considered may be summarized as follows:

Infinite wire formula, $\mathrm{v}=18.420 \mathrm{q}$

Uniform axial distribution (middle point), $\mathrm{v}=17.458 q$

Howe's approximation, $\mathrm{v}=16.874 q$

$60750^{\circ}-28-2$ 
The first and second of these are known to be too large. A confirmation of this fact is furnished if we consider the wire to be compared with a charged isolated ellipsoidal conductor, having its greatest dimension the same as that of the wire, and the same central cross section as that of the wire. Using the previous nomenclature, the potential of such a conductor is known to be $v_{0}=\frac{2 q l}{\sqrt{l^{2}-d^{2}}} \cosh ^{-1} \frac{l}{d}$ which, for an ellipsoid equivalent to the wire previously considered, gives a value $(18.420 q)$ which differs by a negligible amount from the potential produced at its middle point by the same charge uniformly distributed on an isolated cylindrical wire. This fact is not surprising, since it is known that on the ellipsoid the charge included between planes perpendicular to the axis and $1 \mathrm{~cm}$ apart is everywhere the same; that is; the ellipsoid, as well as the wire, has a distribution of $q$ units per centimeter of its length. However, the cross section of the ellipsoid is everywhere less than that of the wire, except at the central cross section, and this fact would lead one to expect for it a higher potential, for a given quantity of charge, than for the equivalent cylindrical wire.

\section{METHOD OF SUCCESSIVE NUMERICAL APPROXI- MATIONS}

To obtain an idea of the accuracy of the Howe approximation, a method of successive numerical approximations was employed. Starting with a uniform linear charge density upon the wire and its image, the potential variation over the wire is calculated, as already described. The average, or Howe value, gives a first approximation to the required equilibrium potential. A second approximation to the true charge density is obtained by increasing the values at those points where the potential is low, and decreasing the values where the potential is high, in such a way as to keep the total quantity of charge constant. As a simple method of doing this, the values of the linear charge density were taken as inversely proportional to the calculated potential values (total charge kept constant). With this new distribution of charge the corresponding new potential distribution has to be calculated, and the average taken. This gives a second approximation to the equilibrium potential. Correcting the charge distribution again in the inverse ratio to the potential variation of the potential distribution last found, potential values are again calculated and averaged, and thus a third approximation to the equilibrium potential found, and so on.

The chief difficulty with the method lies in the fact that the expressions for the calculation of the charge density and potentials of the second and higher approximations can not be integrated directly, but methods of mechanical integration and averaging have to be employed, thus requiring the evaluation of many ordinates of the curves of these quantities. Thus the work is very laborious and time consuming. 
The only case for which the author has obtained more than the second approximation to the potential is that of a single vertical wire 50 feet long, 0.01 foot in diameter, with its lower end only 1 foot from the ground. The effect of the earth is in this case very marked, so that this may be regarded as rather a severe test of the simple Howe approximation. The curves of the successive approximations to the equilibrium calculated for this case by the method just outlined are shown in Figure 3. The curve $A$ is for uniform linear charge density on the wire and its image. The average or Howe approximation to the potential is $16.563 q$. Curve $B$ shows that the potential corresponding to the corrected charge density (second approximation) is very uniform over the wire except for the last 0.2 foot at each end. The average of this curve gives $16.42 q$ as the second approximation to the equilibrium potential. Again correcting the charge densities, the potential distribution resulting hardly varies in the fourth figure, except at the extreme end of the wire. The third approximation to the equilibrium potential is $16.41 q$, or about 1 per cent less than the Howe approximation. The convergence of the method appears to be entirely satisfactory. It should be noted that in making these calculations the effect of the charges on the end faces of the cylindrical wire were taken into account. Their effect is found to be inappreciable at distances greater



FIG. 3.-Successive approximations to the potential of a single vertical wire than about the diameter of the cross section of the wire.

A second approximation to the potential of the same wire isolated in space has been calculated. The first or Howe approximation, as has already been mentioned, is $17.807 \mathrm{q}$. The second approximation is only 2 to 3 parts in 1,000 less, which makes it probable that the value $17.75 q$ is correct to perhaps a unit in the last place.

From the nature of the case it is apparent that the method of successive numerical approximations can not give a general estimate of the accuracy of Howe's approximation. Each wire or combination of wires has to be treated as a special case. The fact that the error in the case of a single wire or a vertical wire and its image is small is to be expected, since the cases which they resemble (ellipsoid and hyperboloid of revolution, respectively) are known to be in equi- 
librium with equal charges between equally spaced planes drawn perpendicular to the axis. However, in the case of more complicated wire systems no evidence is yet available as to the error of the Howe

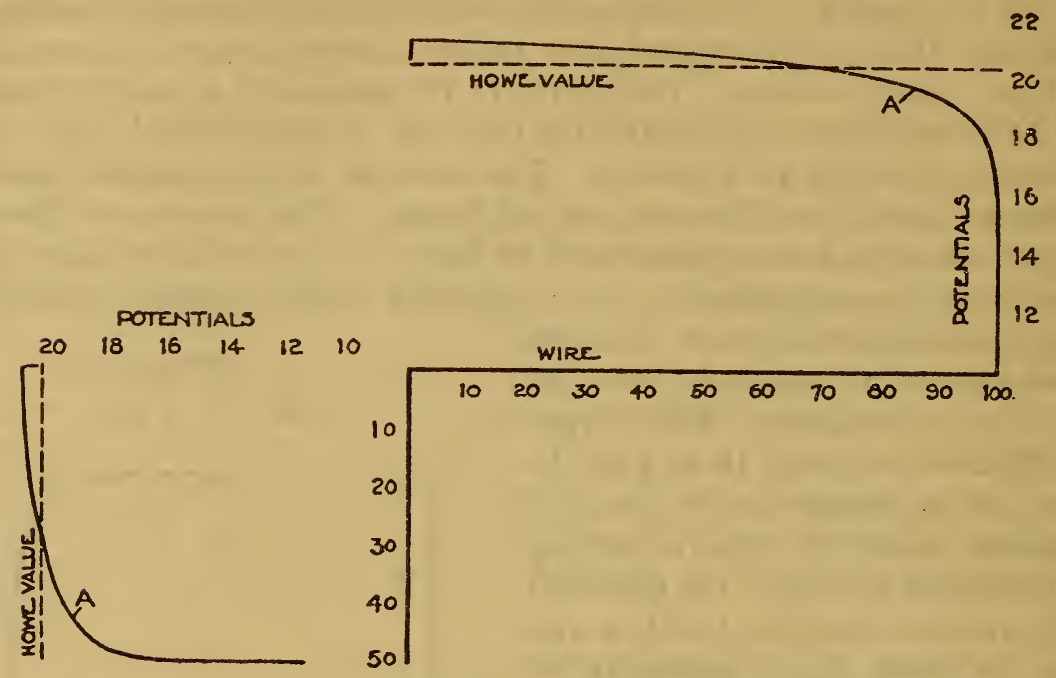

Fig. 4.-Potential variation of uniformly charged isolated $L$ antenna

approximation. Figures 4, 5, 6, and 7 show the potential variation resulting from a uniform linear charge density on two important

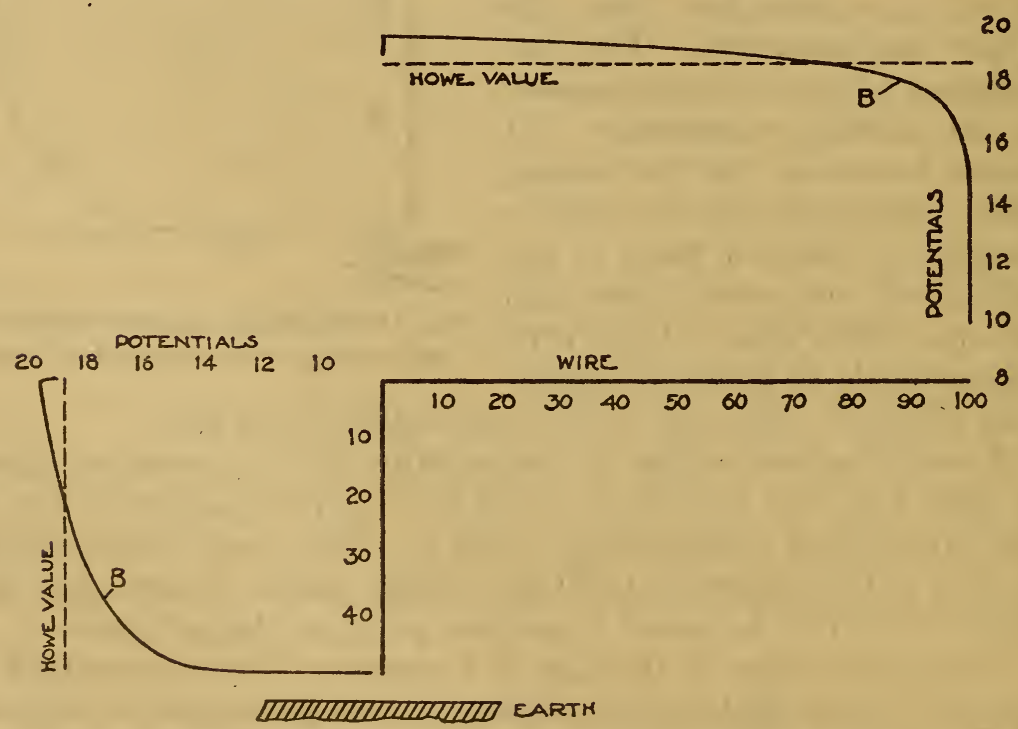

Fig. 5.-Potential variations of uniformly charged $L$ antenna

cases, viz, two wires each 0.01 foot in diameter and of lengths 50 and 100 feet, respectively, joined in the one case to form an inverted $L$ and in the other to form a $T$ antenna. The shorter wire is placed 
vertical with its lower end 5 feet from the ground and the image wires are included. Curve $A$ shows in the case of each combination the potential distribution resulting from the charge of the wires, while curve $B$ in each case shows the potentials as modified by the earth. The Howe values are also indicated in each case. From the potential curve for the $L$ antenna it appears that this case is little different from what would be found for the same wires arranged to form a single vertical antenna. Thus, the Howe approximation is probably as accurate in this case as has been found for a vertical wire by the method of successive approximation. For the $T$ antenna, and still more so in other more complicated antenna systems, nothing can be stated as to the accuracy of Howe's approximation. The author believes it probable that for such long thin wires as are found in practice the error is not important in the light of the uncertainties introduced by errors in the measurements of the dimensions, irregularities in the earth's surface, disturbances due to neighboring objects, effect of imperfect dielectrics, and the like.

Accordingly, the formulas of this paper are based on the Howe approximation, and it remains to show how it may be extended to the treatment of the more complicated forms of antenna. Two general methods are available.

\section{TREATMENT OF COMBINATIONS OF WIRES}

First, we may follow Howe, assuming, first, that a uniform linear charge density $q$ be imparted to the whole system and calculating the potential distribution which would result, average these values over the whole length of wire in the system. This value is taken as an approximation to the true or equilibrium potential.

Thus, denoting by $l$ and $m$ the lengths of two wires joined to form a system, and by $v_{1}$ and $v_{2}$ the values of the potentials at any points of the wires, due to a uniform linear charge density upon the wires and their images, then the approximation to the equilibrium potential is to be talen as equal to

$$
\begin{aligned}
v & =\frac{1}{l+m}\left[\int_{0}^{l} v_{1} d l+\int_{0}^{m} v_{2} d m\right] \\
& =\frac{l}{l+m}\left[\frac{1}{l} \int_{0}^{l} v_{1} d l\right]+\frac{m}{l+m}\left[\frac{1}{m} \int_{0}^{m} v_{2} d m\right]
\end{aligned}
$$

which indicates that the mean is to be taken of the Howe potentials for the two wires, weighting them according to their lengths.

A second, and perhaps more general, treatment of complicated systems is illustrated by the following solution of the problem of a flat-top antenna consisting of four equally spaced parallel wires 


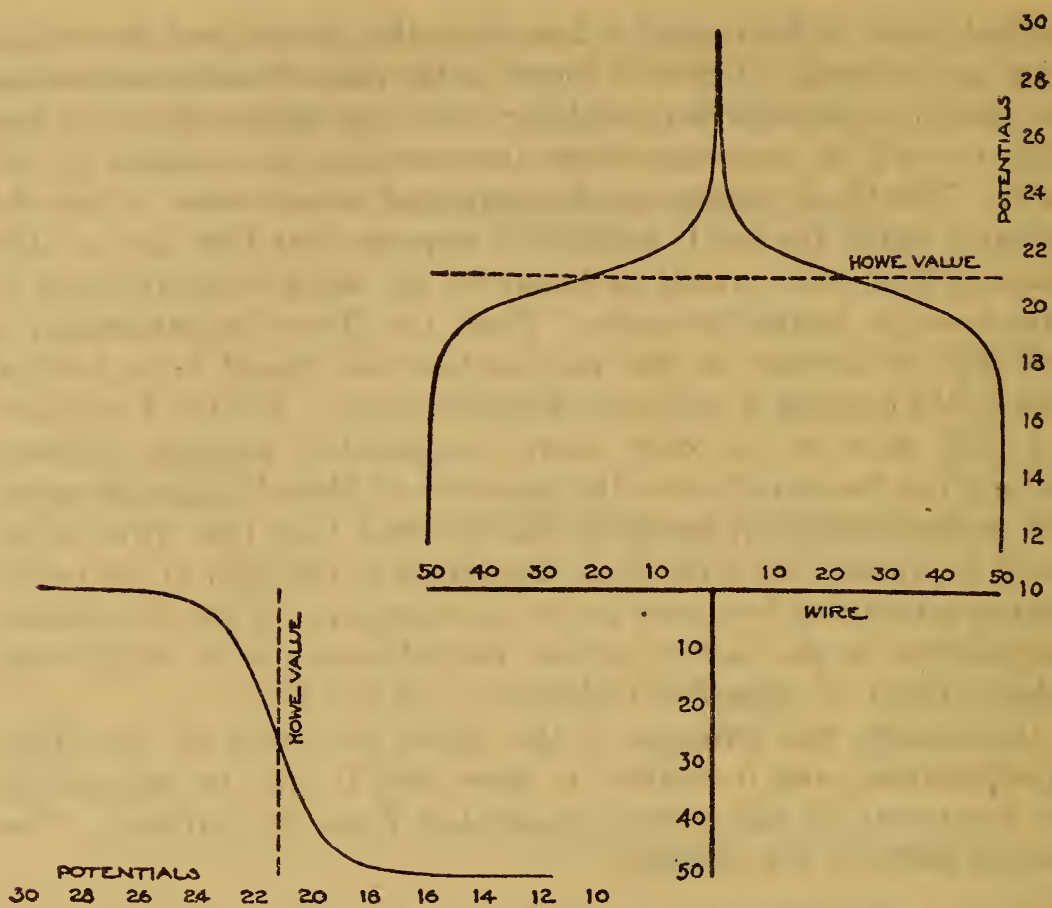

$\begin{array}{lllllllllll}30 & 25 & 26 & 24 & 22 & 20 & 18 & 16 & 14 & 12 & 10\end{array}$

FIG. 6.-Potentials of uniformly charged isolated $\mathrm{T}$ antenna
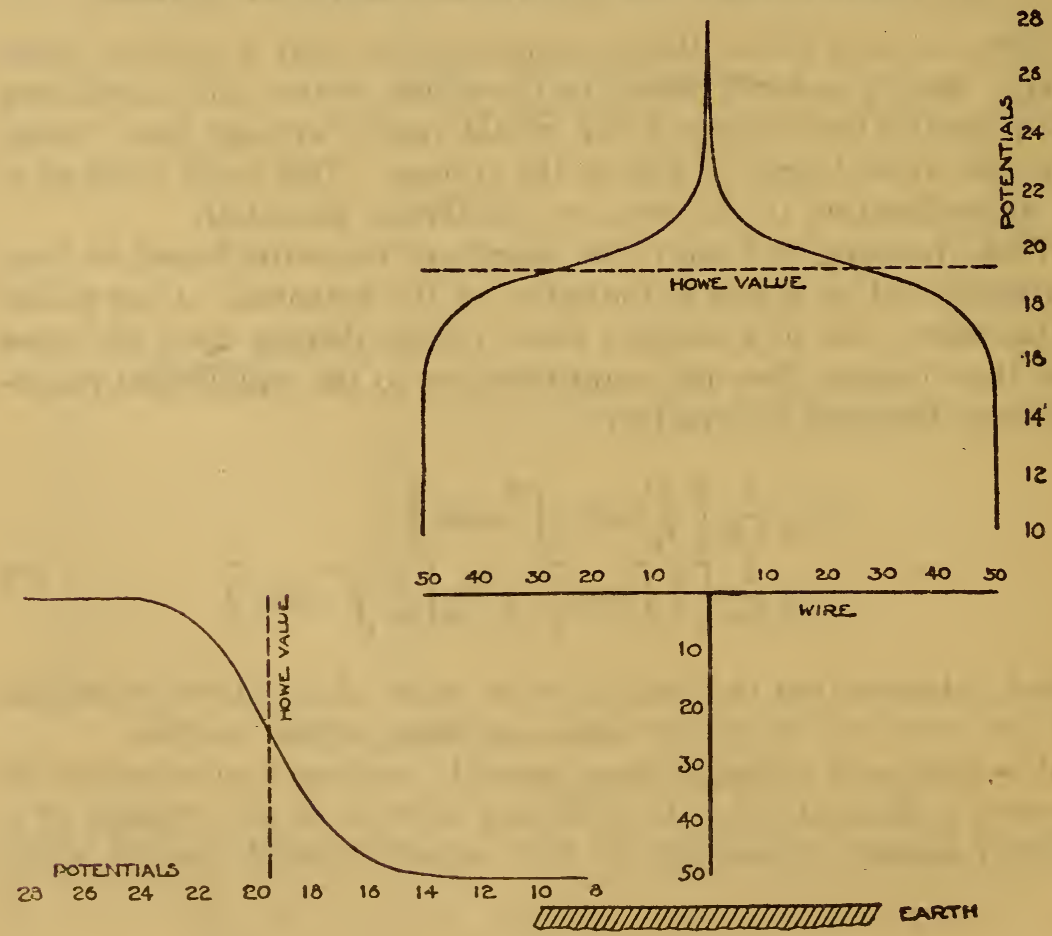

FIG. 7.-Potentials of uniformly charged $T$ antenna 
of equal length and joined at both ends, the whole being placed with the wires all at the same height above the earth.

The general Maxwell potential equations are then

$$
\begin{aligned}
& v_{1}=Q_{1} p_{11}{ }^{\prime}+Q_{2} p_{12}{ }^{\prime}+Q_{3} p_{13}{ }^{\prime}+Q_{4} p_{14}{ }^{\prime} \\
& v_{2}=Q_{1} p_{12}{ }^{\prime}+Q_{2} p_{22}{ }^{\prime}+Q_{3} p_{23}{ }^{\prime}+Q_{4} p_{24}^{\prime}{ }^{\prime} v_{3}=Q_{1} p_{13}{ }^{\prime}+Q_{2} p_{23}{ }^{\prime}+Q_{3} p_{33}+Q_{4} p_{34}{ }^{\prime} \\
& v_{4}=Q_{1} p_{14}{ }^{\prime}+Q_{2} p_{24}{ }^{\prime}+Q_{3} p_{34}{ }^{\prime}+Q_{4} p_{44^{\prime}}
\end{aligned}
$$

The potential coefficient $p_{11}{ }^{\prime}$ refers to the potential of wire 1 due to both its own charge $Q_{1}$ and that on its image wire. Similarly, $p_{12}{ }^{\prime}$ refers to the contribution to the potential of wire 1 by the charge $Q_{2}$ on wire 2 and the equal and opposite charge on the image of wire 2. By symmetry in this problem $Q_{4}=Q_{1}$, and $Q_{3}=Q_{2}, p_{11}{ }^{\prime}=p_{22}{ }^{\prime}=p_{33}{ }^{\prime}=$ $p_{44}{ }^{\prime}, p_{23}{ }^{\prime}=p_{12}{ }^{\prime}=p_{34}{ }^{\prime}, p_{24}{ }^{\prime}=p_{13}{ }^{\prime}$, and the equations for $v_{3}$ and $v_{4}$ are the same as those for $v_{2}$ and $v_{1}$, respectively. To apply Howe's approximation, uniform linear charge densities are assumed to be given to the wires, $q_{1}$ to wire 1 , and $-q_{1}$ to its image, and $q_{2}$ and $-q_{2}$ to wire 2 and its image wire, respectively.

Thus $Q_{1}=q_{1} l, Q_{2}=q_{2} l$, and the general equations are

$$
\begin{aligned}
& v_{1} /=q_{1}\left(p_{11}{ }^{\prime}+p_{14}{ }^{\prime}\right)+q_{2}\left(p_{12}{ }^{\prime}+p_{13}{ }^{\prime}\right) \\
& v_{2} / l=q_{1}\left(p_{12}{ }^{\prime}+p_{13}{ }^{\prime}\right)+q_{2}\left(p_{11}{ }^{\prime}+p_{12}{ }^{\prime}\right)
\end{aligned}
$$

The potential coefficients must be defined in terms of the Howe method of approximation. That is, $p_{12}$ for example, is the average of the potentials contributed to wire 1 by a unit charge distributed uniformly along the axis of wire 2, etc.

Since the wires are all at the same potential when joined together, we will have $v_{2}=v_{1}=v$, so that the potential equations give

where

$$
\begin{aligned}
& q_{1}=\frac{v}{l}\left|\begin{array}{ll}
1 & p_{12}{ }^{\prime}+p_{13}{ }^{\prime} \\
1 & p_{11}{ }^{\prime}+p_{12}^{\prime}
\end{array}\right| \div \Delta \\
& q_{2}=\frac{v}{l}\left|\begin{array}{ll}
p_{11}{ }^{\prime}+p_{14}{ }^{\prime} & 1 \\
p_{12}{ }^{\prime}+p_{13}^{\prime} & 1
\end{array}\right| \div \Delta
\end{aligned}
$$

$$
\Delta=\left|\begin{array}{ll}
p_{11}{ }^{\prime}+p_{14}{ }^{\prime} & p_{12}{ }^{\prime}+p_{13}{ }^{\prime} \\
p_{12}{ }^{\prime}+p_{13}{ }^{\prime} & p_{11}{ }^{\prime}+p_{12}{ }^{\prime}
\end{array}\right|
$$

The capacity is

$$
\begin{aligned}
C & =\frac{2\left(q_{1}+q_{2}\right) l}{v} \\
& =\frac{4}{\Delta}\left[p_{11}{ }^{\prime}-p_{13}{ }^{\prime}-\frac{p_{12}{ }^{\prime}}{2}+\frac{p_{14}{ }^{\prime}}{2}\right]
\end{aligned}
$$

and thus

$$
\frac{1}{C}=\frac{\Delta}{4\left(p_{11^{\prime}}-p_{13}{ }^{\prime}-\frac{p_{12}{ }^{\prime}}{2}+\frac{p_{14}{ }^{\prime}}{2}\right)}
$$


The solution of the problem of finding the inductance of the same four wires joined in parallel with their return circuit through the ground, the resistances of the wires being supposed negligible in comparison with their reactances, leads to the same mathematical expression for their joint inductance if, in the equation for $\frac{1}{C}$, we put for the potential coefficients the corresponding mutual inductances of the wires and their image wires. Cohen derived the expressions for the joint inductance of different numbers of parallel wires up to and including $n=6$. He assumed then that the inductance, divided by the length of the wires, is equal to the reciprocal of the capacity of the same wires, divided by their lengths, and thus obtained capacity formulas for these cases. The identity of the inductance per centimeter and the reciprocal of the capacity per centimeter is, however, exact only in the case of wires of infinite length.

Through the use of a mutual-inductance formula in which the height of the wires above the ground is neglected in comparison with their lengths, and also as the result of an error in the numerical value of a logarithm, Cohen's values for given systems of wires differed considerably from the values found by Howe for the same systems. However, using the appropriate mutual-inductance formula, this inductance method of Cohen agrees exactly with the method of using Howe's approximation sketched above, and we have the striking result that the two methods, each of them inexact, are entirely equivalent for the case of the flat-top antenna. The reason for this agreement and its limitations may be shown as follows:

The potential at any point of a wire $A$, of length $l$, due to a uniform linear charge density $q_{\mathrm{b}}$ along the axis of a wire $B$ of length $m$, is $q_{\mathrm{b}} \int_{0}^{\mathrm{m}} \frac{d m}{r_{\mathrm{ab}}}$ where $r_{\mathrm{ab}}$ is the distance between any two points on the two wires. The average of this potential, taken over the length of the wire $A$ is

$$
v_{\mathrm{ab}}=\frac{q_{\mathrm{b}}}{l} \int_{0}^{1} d l \int_{0}^{\mathrm{m}} \frac{d m}{r_{\mathrm{ab}}}=\frac{q_{\mathrm{b}}}{l} N
$$

The total charge on $B$ is $q_{\mathrm{b}} m$, so that the potential coefficient is $p_{\mathrm{ab}}=\frac{N}{l m}, \quad$ or $\frac{N}{l^{2}}$ if the wires have equal length. From equation (12) it is evident that the reciprocal of the capacity per centimeter of length of the wires $\frac{l}{c}$ is a function of terms of the form $l p_{\mathrm{ab}}$, or of $\frac{N}{l}$.

For the mutual inductances in the solution of the inductance problem we have to put the Neumann integral, which for the wires $A$ and $B$, is $\int_{0}^{1} d l \int_{0}^{m} \frac{\cos \epsilon d m}{r_{\mathrm{ab}}}$ or $N \cos \epsilon, \epsilon$ being the angle made by the two straight wires. Thus for the mutual inductance per centimeter of 
two parallel wires of equal length it becomes $\frac{N}{l} \cos \epsilon$. Thus, since the mutual inductances enter into the expression for the joint inductance in the same way that the potential coefficients do in the expression for the reciprocal of the capacity, the same expression is reached for the inductance per centimeter, as is found for the reciprocal of the capacity per centimeter. This complete equivalence of the solutions of the two problems holds for any system of parallel wires of equal length, both when they are all horizontal, or when they are all vertical. Otherwise the image wires will not be parallel to the antenna wires, and the $\cos \epsilon$ factor is not unity. However, even in this case, the Howe potential coefficients may be obtained from the general Neumann integral for any two straight filaments placed in any desired position, ${ }^{7}$ if only the $\cos \epsilon$ factor be omitted from this.

It will be noticed from equation (9) that the general potential equations for a system of wires involve as coefficients the potentials per unit linear charge density, rather than the potential coefficients themselves. This quantity, which may for convenience be termed the "linear coefficient," depends only upon the ratios of the geometrical dimensions of the system. If we denote by $u_{\mathrm{ab}}$ the linear potential coefficients of wire $A$, length $l$, resulting from a unit linear charge density on wire $B$, length $m$, then a linear charge density $q_{\mathrm{b}}$ on $B$ will give rise to an average potential $v_{\mathrm{ab}}=q_{\mathrm{b}} u_{\mathrm{ab}}$ on $A$. But if $Q=q_{\mathrm{b}} m$ denote the whole charge on $B$, we may write by definition for the average potential of $A, v_{\mathrm{ab}}=Q p_{\mathrm{ab}}=q_{\mathrm{b}} m p_{\mathrm{ab}}$, in which $p_{\mathrm{ab}}$ is the Howe potential coefficient defined on page 581. Thus, $u_{\mathrm{ab}}=m p_{\mathrm{ab}}$. It is well known that the same charge $Q=q_{\mathrm{a}} l$ placed on $A$ will give rise to the same potential $v_{\mathrm{ba}}$ on $B$ as before. Thus, $v_{\mathrm{ba}}=v_{\mathrm{ab}}=q_{\mathrm{b}} u_{\mathrm{ab}}=$ $q_{\mathrm{s}} u_{\mathrm{bs}} . \quad$ But $\frac{q_{\mathrm{a}}}{q_{\mathrm{b}}}=\frac{m}{l}$ and thus

$$
\frac{u_{\mathrm{ab}}}{u_{\mathrm{b} 3}}=\frac{m}{l}
$$

In Appendix 2 are given the linear potential coefficient expressions for certain important special cases. It is to be noted that in the symbol $u_{\mathrm{ab}}$, the charged body appears last in the subscript.

The expression (11) for the capacity of a four-wire flat-top antenna is not simple, and for a greater number of wires the expressions are very complicated. Fortunately a notable simplification may be attained if the division indicated in these expressions is actually carried out. For the four-wire case we find

$$
\frac{1}{C}=\frac{1}{4}\left[p_{11}{ }^{\prime}+\frac{2 p_{14}{ }^{\prime}+4 p_{13}{ }^{\prime}+6 p_{12}{ }^{\prime}}{4}\right]-\frac{1}{16} \frac{\left(p_{12}{ }^{\prime}-p_{13}{ }^{\prime}\right)^{2}}{\left[p_{11}{ }^{\prime}-p_{13}{ }^{\prime}-\frac{\left(p_{12}{ }^{\prime}-p_{14}{ }^{\prime}\right)}{2}\right]}
$$

7 G. A. Campbell, Phys. Rev.; June, 1915.

$60750^{\circ}-28-3$ 
the last or remainder term being small compared with the first or principal term. If the potential coefficients be expressed in terms of one of their number the expression for $n$ equally spaced wires is still simpler. In general, neglecting the remainder term,

$$
\frac{1}{C}=\frac{p_{11}{ }^{\prime}+(n-1) p_{12}^{\prime}}{n}-K_{\mathrm{n}}
$$

where

$$
K_{\mathrm{n}}=\frac{4}{n^{2}}\left[\begin{array}{r}
\log n(n-1)+2 \log n(n-2)+3 \operatorname{logn}(n-3)+\ldots \\
+(n-2) \operatorname{logn} 2
\end{array}\right]
$$

Expressed in terms of the linear potential coefficients, we find for the reciprocal of the capacity per centimeter

$$
\bar{l}=\frac{u_{11}{ }^{\prime}+(n-1) u_{12}{ }^{\prime}}{n}-K_{\mathrm{n}}
$$

an expression which applies equally well when the wires are all vertical, if the appropriate linear potential coefficients be used in each case.

\section{DERIVATION OF WORKING FORMULAS FOR THE CAPACITY}

The derivation of formulas for the capacity of a single horizontal or vertical wire and for systems of parallel wires in a horizontal or in a vertical plane has been fully discussed in the foregoing. Working formulas for these cases and for other types of antenna are given in section 8. All these formulas were obtained by the application of the principles already discussed. The capacities are given throughout in micromicrofarads $\left(10^{=12}\right.$ farad). To make possible the use of tables of common logarithms the denominator of each expression has been divided by 2.303 . Thus, if the velocity of light be taken as $2.998 \times 10^{10} \mathrm{~cm}$ per sec. there is derived the factor 0.2416 which appears in the working formulas. In most cases terms which depend upon the presence of the earth and the mutual effects of the wires have been combined and tabulated. For the usual types of antenna a few tables suffice.

The capacity formulas for the more complex forms of antenna were obtained for the most part by applying the first method of section 6 ; that is, supposing the system to be given a uniform distribution of charge, the potential of each wire is written down as the algebraic sum of the potentials due to its own charge and those on each of the other wires and image wires of the system. The equilibrium potential is taken as the mean of the potentials of the individual wires, each weighted in proportion to the length of the wire to which it applies. The capacity is the quotient of the total charge by the equilibrium potential. In calculating the potential 
the appropriate linear potential coefficients have to be used, and since natural logarithms occur in these, the factor 2.303 has to be divided out to agree with the general system of the calculations.

The effect of supporting masts and other grounded conductors near an antenna may be evaluated by the following general method. Assume that, in addition to the uniform linear density $q$ of the antenna wires, there is a linear charge density of $-q_{1}$ upon the mast and $+q_{1}$ upon its image. The potential equations for the antenna wires thus include terms in $q_{1}$ to take account of the presence of the mast. An additional equation may be written for the potential of the mast itself, and since this is known to be zero, this last equation will be given the value of $q_{1}$ in terms of $q$. Thus $q_{1}$ may be eliminated from the potential equations for the wires and the capacity is then obtained by the methods already discussed.

The calculation of the added capacity given to an antenna system by the lead-in wires is a special case of the general problem of finding the joint capacity of two antenna systems when connected to form one whole, the capacity of each component being given by one of the formulas of section 8. This problem is treated separately in section 10.

\section{WORKING FORMULAS FOR CALCULATING CAPACITY OF VARIOUS PRACTICAL FORMS OF ANTENNAS}

In the following formulas the capacity is in micromicrofarads $\left(10^{-12}\right.$ farad $)$; logarithms are to the base 10 . Ample accuracy in the values of the logarithms will be attained by the use of a fourplace table, although if a five-place table be employed interpolations will be unnecessary. Linear dimensions are given both in centimeters and in feet. The use of subscripts, as explained below, will make clear which system is meant in all cases. However, where the ratio of two dimensions is used as a parameter, either system may be used, as long as both dimensions are expressed in the same system; and this fact will be indicated by the omission of subscripts.

The following nomenclature is common to practically all the formulas. Other symbols are explained where they occur.

$d=$ diameter of wire,

$D=$ distance between centers of parallel wires,

$U=$ potential coefficient for unit charge density per unit length of the antenna,

$C=$ capacity, in micromicrofarads,

$l_{1}=$ length of a horizontal wire, in centimeters,

$m_{1}=$ length of a vertical wire, in centimeters,

$l_{2}=$ length of a horizontal wire, in feet,

$m_{2}=$ length of a vertical wire, in feet,

$h_{1}=$ height of a horizontal wire above earth, in centimeters,

$h_{2}=$ height of a horizontal wire above earth, in feet, 
$h_{1}^{\prime}=$ height of lower end of a vertical wire above earth, in centimeters,

$h_{2}^{\prime}=$ height of lower end of a vertical wire above earth, in feet, $n=$ number of wires joined in parallel.

\section{SINGLE HORIZONTAL WIRE}

$$
C=\frac{0.2416 l_{1}}{\log \frac{4 h}{d}-K}=\frac{7.36 l_{2}}{\log \frac{4 h}{d}-K}
$$

where $K$ is to be taken from Table 1 for either the ratio $\frac{2 h}{l}$ or $\frac{l}{2 h}$, depending upon which is less than unity.

In Table 2 are given values of the capacity of single-wire horizontal antennas of various lengths and heights. This should be useful in certain practical cases.

Example 1.-For a single wire 100 feet long, stretched 50 feet above ground, and assuming the diameter of the wire to be 0.24 inch $=0.02$ foot, we find $\frac{4 h}{d}=\frac{200}{0.02}=10,000$, and thus $\log \frac{4 h}{d}=4.000$. The value of $\frac{2 h}{l}$ is $\frac{100}{100}=1$, and from Table $1, K=0.336$. Thus

$$
C=\frac{7.36(100)}{3.664}=200.9 \mu \mu f
$$

This value is in agreement with that calculated from Howe's tables.

\section{SINGLE VERTICAL WIRE ${ }^{3}$}

The wire is supposed to have a length $m$ and its lower end is at a height $h^{\prime}$ above the surface of the earth.

$$
C=\frac{0.2416 m_{1}}{\log \frac{2 m}{d}-k}=\frac{7.36 m_{2}}{\log \frac{2 m}{d}-k}
$$

in which the constant $k$ is to be obtained from Table 3 for the value of $\frac{h^{\prime}}{m}$ or $\frac{m}{h^{\prime}}$ depending upon which is less than unity.

Example 2.-Suppose a vertical wire 40 feet long, with its lower end 10 feet from the ground. The diameter of the wire will be taken as 0.24 inch as in the preceding example.

\footnotetext{
8 Caution.-The formula for the capacity does not apply for the limiting case where the distance between the lower end of the vertical wire and the earth is vanishingly small, but an error of not more than a fow per cent results if this distance is as small as 1 foot.
} 
Thus. in formula (19) we have $m=40, h^{\prime}=10, \frac{2 m}{d}=4,000$ $\log _{10} \frac{2 m}{d}=3.602$. From Table 3, with $\frac{h^{\prime}}{m}=0.25, k=0.291$, and thus

$$
C=\frac{7.36(40)}{3.602-0.291}=88.9 \mu \mu \mathrm{f}
$$

In Table 4 is given the capacity of vertical wires covering a considerable range of lengths, diameters, and heights above the ground.

\section{SINGLE-WIRE INVERTED L ANTENNA}

Suppose the length of the horizontal portion is $l$, that of the vertical portion $m$, the height of the vertical portion from the ground $h^{\prime}$, and thus the height of the horizontal portion is $h=h^{\prime}+m$. Then the capacity is given by

in which

$$
C=\frac{0.2416\left(l_{1}+m_{1}\right)}{U}=\frac{7.36\left(l_{2}+m_{2}\right)}{U}
$$

$$
U=\frac{l}{l+m}\left[\log \frac{4 h}{d}-K\right]+\frac{m}{l+m}\left[\log \frac{2 m}{d}-k\right]+X
$$

The term $X$ takes into account the mutual effect of the two portions of the antenna. Its value is obtained from Table 5 for different values of the ratios $\frac{l}{m}$ or $\frac{m}{l}$, and $\frac{h^{\prime}}{m}$ or $\frac{m}{h^{\prime}}$. The values of $K$ and $k$ are to be taken from Tables 1 and 3, respectively, as in the preceding examples.

As a first approximation the capacity of the inverted $L$ may be calculated as the sum of the capacities of the component wires taken separately. This approximate method always gives a value larger than the true values.

Example.3.-Let us consider an inverted $L$ antenna made up of the horizontal wire treated in example 1 , and the vertical wire of example 2. Then $l=100, m=40, h^{\prime}=10, d=0.24$ inch, $\frac{l}{l+m}=\frac{100}{140}=\frac{5}{7}, \frac{m}{l+m}=\frac{2}{7}$. With $\frac{m}{l}=0.4, \frac{h^{\prime}}{m}=0.25$ in Table 5 we find $X=0.194$. Thus $U=\frac{5}{7}(3.664)+\frac{2}{7}(3.311)+0.194=3.757$ and

$$
C=\frac{7.36(140)}{3.757}=274.3 \mu \mu \mathrm{f}
$$

The simple sum of the separate capacities of the horizontal and vertical portions is 289.8 , which is more than 5 per cent too large. 


\section{SINGLE-WIRE T ANTENNA}

The antenna consists of a horizontal wire of length $l$ at a height $h$ above the ground. To the center of this is attached a vertical wire of length $m$. The height of the lower end of this, above ground, is denoted by $h^{\prime}$. The capacity is calculated from the formula

$$
C=\frac{0.2416\left(l_{1}+m_{1}\right)}{J^{\prime}}=\frac{7.36\left(l_{2}+m_{2}\right)}{U^{\prime}}
$$

in which

$$
U^{\prime}=\frac{l}{l+m}\left(\log \frac{4 n}{d}-K\right)+\frac{m}{l+m}\left(\log \frac{2 m}{d}-k\right)+\frac{l+2 m}{l+m} \cdot X_{1}
$$

The constants $K, k$, and $X_{1}$ are to be taken from Tables 1, 3, and 5, respectively, the latter for the argument $\frac{m}{l}=$ ratio of $m$ and $\frac{l}{2}$.

Example 4.-Consider a $T$ antenna made up of the horizontal and vertical wires of examples 1 and 2 . Then

$l=100, m=40, h^{\prime}=10, d=0.24$ inch, $\frac{l}{l+m}=\frac{5}{7}, \frac{m}{l+m}=\frac{2}{7}, \frac{l+2 m}{l+m}=\frac{9}{7}$

From Table 5, with the argument

$$
\frac{m}{l}=0.8, \frac{h^{\prime}}{m}=0.25, X_{1}=0.263
$$

Thus $U^{\prime}=3.901$, and therefore

$$
C=\frac{7.36(140)}{3.901}=264.2 \mu \mu \mathrm{f}
$$

If the simple sum of the separate capacities of the component wires had been used the error would have been about 10 per cent.

It is interesting to note that for the given horizontal wire joined to the given vertical wire the capacity is about 3.5 per cent smaller with the wires connected as a $T$ antenna than as an inverted $L$, and for both these cases the capacity is less than the sum of the capacities of the wires taken separately. This follows from the fact that the potential of the charge of each wire is increased by the proximity of the charge on the other wire. On the average, the two wires of the $T$ antenna are closer together than the two parts of the inverted $L$, and the mutual effect of the two wires is therefore greater in the former case.

\section{PARALLEL HORIZONTAL WIRES IN THE SAME HORIZONTAL PLANE (FLAT-TOP ANTENNA)}

The wires are supposed to have a diameter $d$, and to be of equal length $l$. They will be assumed to be $n$ in number, arranged parallel to one another in a horizontal plane, at a height $h$ above the surface of the earth. If the spacing is $D$, the width of the antenna between 
the extreme wires is $(n-1) D$, and this dimension is supposed to be not greater than about one-quarter of the length of the wires. The formula for the capacity is then

$$
C=\frac{0.2416 l_{1}}{F}=\frac{7.36 l_{2}}{F} \mu \mu \mathrm{f}
$$

in which

$$
\begin{aligned}
& F=\frac{P+(n-1) Q}{n}-K_{\mathrm{n}} \\
& P=\log \frac{4 h}{\bar{d}}-K \\
& Q=\log \frac{2 h}{\bar{D}}-K
\end{aligned}
$$

The constant $K_{\mathrm{n}}$, which depends only upon the number of the wires, may be obtained from Table 6 ; the constant $K$ is to be taken from Table 1 , as in preceding examples. The expression for $F$ may also be written

$$
F=\frac{\log \frac{4 h}{d}+(n-1) \log \frac{2 h}{D}}{n}-\left(K+K_{\mathrm{n}}\right)
$$

For the common case of a two-wire flat-top antenna, $K_{\mathrm{n}}=0$, and the general formula (22) becomes

$$
C=\frac{14.73 l_{2}}{\log \frac{4 h}{d}+\log \frac{2 h}{D}-2 K}
$$

In Table 9 will be found the values of the capacity of certain twowire antennas. This should be useful where a moderate accuracy will suffice.

Example 5.-A flat-top antenna is composed of six wires spaced 2 feet apart, the length of the wires being 100 feet, their height 50 feet, and their diameter 0.24 inch as before.

$$
D=2, \frac{4 h}{d}=10,000, \frac{2 h}{D}=50, \frac{2 h}{l}=1
$$

From Table $1, K=0.336$, and from Table $6, K_{\mathrm{n}}=0.252$. Thus, using the last formula (23) for $F$, its value is obtained as follows:

$$
\begin{array}{rlrl}
\log \frac{4 h}{d} & =4.000 & K+K_{\mathrm{n}} & =0.588 \\
5 \log \frac{2 h}{D} & =8.495 & F & =1.494 \\
\text { Sum } \div 6 & =2.082 &
\end{array}
$$

and the capacity is

$$
C=\frac{7.36(100)}{1.494}=492.6 \mu \mu \mathrm{f}
$$


Example 6.-Attention has been called to the small gain from the use of many wires in parallel. Thus Austin states that, for parallel wires of moderate dimensions, a spacing of 1 meter is sufficient to give 90 per cent of the possible capacity. This assumes a certain width of antenna which is kept constant as more wires are added. As an illustration of this point, the capacity was calculated for different numbers of wires, each 100 feet long, 0.24 inch in diameter, placed 50 feet above the earth, the spacing being chosen in each case such that for $n$ wires $n D=15$ feet. The results are given in Table 10 .

TABLE 10

\begin{tabular}{|c|c|c|c|c|c|c|c|c|}
\hline$n$ & $\underset{\mu \mu \mathrm{f}}{C}$ & $\begin{array}{l}\text { Per cent } \\
\text { of maxi- } \\
\text { mum }\end{array}$ & $n$ & $\underset{\mu \mu \mathrm{f}}{C}$ & $\begin{array}{l}\text { Per cent } \\
\text { of maxi- } \\
\text { mum }\end{array}$ & $n$ & $\underset{\mu \mu \mathrm{f}}{C}$ & $\begin{array}{l}\text { Per cent } \\
\text { of maxi- } \\
\text { mum }\end{array}$ \\
\hline $\begin{array}{l}2 \\
3 \\
4 \\
6 \\
6 \\
8 \\
8\end{array}$ & $\begin{array}{l}330.5 \\
408.7 \\
460.6 \\
495.7 \\
520.5 \\
539.6 \\
554.2 \\
565.7\end{array}$ & $\begin{array}{l}51.0 \\
62.9 \\
70.9 \\
76.3 \\
80.2 \\
83.2 \\
85.4 \\
87.2\end{array}$ & $\begin{array}{l}10 \\
112 \\
13 \\
14 \\
15 \\
16 \\
17\end{array}$ & $\begin{array}{l}577.2 \\
582.7 \\
588.8 \\
594.0 \\
598.9 \\
602.8 \\
606.3 \\
609.8\end{array}$ & $\begin{array}{l}89.0 \\
89.8 \\
90.6 \\
91.5 \\
92.3 \\
92.9 \\
93.5 \\
94.0\end{array}$ & $\begin{array}{l}18 \ldots \ldots \\
19 \ldots \ldots \\
20 \ldots \ldots \\
40 \ldots \ldots \\
50 \ldots \ldots \\
100 \ldots\end{array}$ & $\begin{array}{l}611.8 \\
613.8 \\
615.9 \\
626.4 \\
635.0 \\
637.8 \\
643.9\end{array}$ & $\begin{array}{l}94.4 \\
94.7 \\
94.9 \\
96.5 \\
97.9 \\
98.5 \\
99.3\end{array}$ \\
\hline
\end{tabular}

When these values of the capacity are plotted against the reciprocal of the number of the wires, a limiting capacity of about $650 \mu \mu \mathrm{f}$ is indicated. This value has been used in computing the values in the column headed "per cent of maximum." A spacing of 1 meter would be obtained with five or six wires, the capacity being some 80 per cent of the maximum. Even with so few as two wires, the capacity is about 50 per cent of the maximum, and if the two wires were placed 15 feet apart instead of only 7.5, as in the table, the capacity would be 354.4 , or 54 per cent of the maximum.

These conclusions were checked by deriving the formula for the capacity of a horizontal rectangular plate having a length $l$, a width $n D$, and a thickness $d$, situated at a height $h$ above the earth. The treatment of this case was based upon the integration of the Howe expression for a filament of length $l$ over the width of the rectangle. The final formula, which is long and involved, will not be given here. (See Appendix 1.) For the dimensions assumed in the previous example the limiting capacity should be 635 micromicrofarads. The difference of more than 1 per cent between this value and that given above, is probably to be explained by the fact that the ratio of width to length is rather large in this special case, and that the terms neglected in (22) are appreciable. For the more favorable case $n D=5, l=100$, formula (22) gives for a 100 wire antenna $C=455.7$ $\mu \mu f$, while the value for the solid rectangular plate is $454.7 \mu \mu f$. 


\section{ANTENNA OF PARALLEL WIRES EQUALLY SPACED IN A VERTICAL PLANE}

Adopting the same nomenclature as in the preceding case, we find, for an antenna where the extreme width is not greater than, say, one-quarter of the length of the wires

$$
C=\frac{0.2416 l_{1}}{V}=\frac{7.36 l_{2}}{V}
$$

in which

$$
V=\frac{1}{n} \log \frac{2 m}{d}+\frac{n-1}{n} \log \frac{m}{D}-\left(k+K_{\mathrm{n}}\right)
$$

The quantities $k$ and $K_{\mathrm{n}}$ are to be obtained from Tables 3 and 6 , respectively.

Example 7.-For six vertical wires, each 40 feet long, arranged with a spacing of 2 feet, and with the bottom ends of the wires 10 feet above the ground, $m=40, D=2, h^{\prime}=10$. Assume $d=0.02$ foot. As in example 2,

$$
k=0.291, K_{\mathrm{n}}=0.252, \frac{m}{D}=20, \log \frac{m}{D}=1.301, \log \frac{2 m}{d}=3.602,
$$

so that

$$
\begin{gathered}
\frac{1}{n} \log \frac{2 m}{d}=0.600 \quad k+K_{\mathrm{n}}=0.543 \\
\frac{n-1}{n} \log \frac{m}{D}=1.118 \quad V=1.175 \\
C=\frac{7.36(140)}{1.175}=250.6 \mu \mu \mathrm{f} .
\end{gathered}
$$

\section{PARALLEL WIRE INVERTED L ANTENNA}

With the length of the horizontal portion equal to $l$, length of the vertical wires $m$, height of horizontal wires $h$, height of lower ends of the vertical wires $h^{\prime}$, spacing of wires $D$,

in which

$$
C=\frac{0.2416\left(l_{1}+m_{1}\right)}{L}=\frac{7.36\left(l_{2}+m_{2}\right)}{L}
$$

$$
\begin{aligned}
L & =\frac{P^{\prime}+(n-1) Q^{\prime}}{n}-K_{\mathrm{n}}+X \\
P^{\prime} & =\frac{l}{l+m}\left(\log \frac{4 h}{d}-K\right)+\frac{m}{l+m}\left(\log \frac{2 m}{d}-k\right) \\
Q^{\prime} & =\frac{l}{l+m}\left(\log \frac{2 h}{D}-K\right)+\frac{m}{l+m}\left(\log \frac{m}{D}-k\right)
\end{aligned}
$$

$60750^{\circ}-28-1$ 
The constants $K, k, X$, and $K_{\mathrm{n}}$ are to be taken from Tables 1,3 , 5 , and 6 , respectively. This formula is less accurate, the wider the antenna in comparison with its length.

Example 8.- Suppose a parallel wire inverted $L$ antenna composed of the wire systems of examples 5 and 7 , joined to form one conducting system. Then

Therefore

$$
\begin{aligned}
P^{\prime} & =2.617+0.946=3.563 \\
Q^{\prime} & =0.974+0.289=1.263 \\
K_{\mathrm{n}} & =0.252 \quad X=0.194
\end{aligned}
$$

$$
L=1.588, \text { and } C=\frac{7.36(140)}{1.588}=648.9 \mu \mu \mathrm{f}
$$

The sum of the separate capacities of the horizontal and vertical portions is 743.2 , which is more than 14 per cent too large.

\section{PARALLEL WIRE T ANTENNA}

The antenna is supposed to be composed of $n$ similar $T$ 's joined in parallel. Thus, the horizontal wires have the same spacing as the vertical. The total length of the horizontal portion is taken as $l$, the meaning of the other symbols is the same as in the preceding cases.

$$
\begin{aligned}
C & =\frac{0.2416\left(l_{1}+m_{1}\right)}{T}=\frac{7.36\left(l_{2}+m_{2}\right)}{T} \\
T & =\frac{P^{\prime}+(n-1) Q^{\prime}}{n}-K_{\mathrm{n}}+\frac{l+2 m}{l+m} \cdot X \\
P^{\prime} & =\frac{l}{l+m}\left(\log \frac{4 h}{d}-K\right)+\frac{m}{l+m}\left(\log \frac{2 m}{d}-k\right) \\
Q^{\prime} & =\frac{l}{l+m}\left(\log \frac{2 h}{D}-K\right)+\frac{m}{l+m}\left(\log \frac{m}{D}-k\right)
\end{aligned}
$$

The constants $K, k, X$, and $K_{\mathrm{n}}$ are to be obtained from Tables 1, 3, 5, and 6 , respectively, using for $X$ the ratio of $\frac{l}{2}$ to $m$ for $\frac{l}{m}$ in Table 5 .

Example 9.-A $T$ antenna is made by joining the vertical wires of example 7 to the middle points of the horizontal wires of example 5 . The constants are the same as in the preceding example, except that $X=0.263$. The value of $T$ comes out 1.732 , so that

$$
C=\frac{7.36(140)}{1.732}=594.9
$$


which is more than 8 per cent less than the value for the inverted $L$. The following summary presents concisely the results of the examples:

Horizontal parallel portion alone.

Vertical parallel portion alone

Same wires connected as inverted $L$ antenna

\section{HORIZONTAL "CAGE" ANTENNA}

The following formula supposes that the distance between the $n$ wires is small compared with their average distance from the ground. The axis of the cage is at a height $h$ above ground.

in which

$$
C=\frac{0.2416 l_{1} n}{U_{\mathrm{c}}}=\frac{7.36 l_{2} n}{U_{\mathrm{c}}}
$$

$$
U_{\mathrm{c}}=\log \frac{4 h}{d}+\sum_{\mathrm{r}=1}^{\mathrm{r}=\mathrm{n}-1}\left(\log \frac{2 h}{D_{\mathrm{r}}}+0.434 \frac{D_{\mathrm{r}}}{l}\right)-n K
$$

and $D_{\mathrm{r}}$ is the distance between any given wire and another wire. If $\delta=$ the diameter of the circle on whose circumference the wires are arranged, then

$$
D_{\mathrm{r}}=\delta \sin r \frac{\pi}{n}
$$

The quantity $K$ is obtained from Table 1 for the given value of $\frac{l}{2 h}$ or $\frac{2 h}{l}$.

Example 10.-Six wires, each 100 feet long and 0.02 foot in diameter are arranged as elements of a cylinder 5 feet in diameter. The axis of the cylinder lies horizontally 50 feet above the surface of the earth.

Here $n=6, \delta=5, h=50, \frac{2 l}{d}=10,000$. The distances between the wires are then $D_{1}=D_{5}=2.5, D_{2}=D_{4}=\frac{5}{2} \sqrt{3}, D_{3}=5$. From Table 1 for $\frac{2 h}{l}=1, n K=2.016$

$$
\begin{array}{ll}
\log \frac{4 h}{d}=4.000 & 0.434 \frac{D_{1}}{l}=0.011 \\
\log \frac{2 h}{D_{1}}=1.602 & 0.434 \frac{D_{2}}{l}=0.018 \\
\log \frac{2 h}{D_{2}}=1.364 & 0.434 \frac{D_{3}}{l}=0.022
\end{array}
$$




$$
\begin{aligned}
\log \frac{2 h}{D_{3}} & =1.301 \quad \therefore U_{\mathrm{c}}=9.297 \\
C & =\frac{7.36(100) 6}{9.297}=475.0 \mu \mu \mathrm{f}
\end{aligned}
$$

If the same wires had been spaced at the same distance apart in the horizontal plane as the length of the chord of the circle the capacity by formula (22) would have been $520.5 \mu \mu f$. Thus the arrangement in a cage results here in a loss of capacity of about 8 per cent. This is due to the decrease in the average distance between wires brought about by the arrangement in the cage. The advantage of this form of antenna lies, of course, in the saving of space.

Formula (28) was derived on the assumption that the effect of the earth can be evaluated with sufficient accuracy by assuming the charges on the image wires and the charges on the wires of the cage to be situated along the axis of the image and the axis of the cage, respectively. To determine the order of the error committed, an accurate evaluation was made of the effect of the image wires, using the antenna of the preceding example. It was found that, although the potentials contributed by the image wires together differed by as much as 5 per cent for the different wires of the cage, the total effect did not differ as much as 1 part in 10,000 from that calculated by the simplifying assumption used in deriving formula (28).

\section{VERTICAL "CAGE" ANTENNA}

The $n$ wires of diameter $d$ and length $m$ are arranged as elements of a cylinder of diameter $\delta$, whose axis is vertical, and whose lower end is at a height $h^{\prime}$ above the ground.

and

$$
C=\frac{0.2416 n m_{1}}{U^{\prime}}=\frac{7.36 n m_{2}}{U_{c}^{\prime}}
$$

$$
{U^{\prime}}{ }_{\mathrm{c}}=\log \frac{2 m}{d}+\sum_{r=1}^{r=n-1}\left(\log \frac{m}{D_{\mathrm{r}}}+0.434 \frac{D_{\mathrm{r}}}{m}\right)-n k
$$

The value of $k$ is obtained from Table 3 , and the distance $D_{r}$ between any two wires is given by

$$
D_{\mathrm{r}}=\delta \sin r \frac{\pi}{n}
$$

Example 11.-Six vertical wires, each 100 feet long and 0.02 foot in diameter, are arranged as elements of a cylinder, 4 feet in diameter, with their lower ends 25 feet from the ground. Thus

$$
m=100, h^{\prime}=25, \delta=4, d=0.02, \frac{2 m}{d}=10,000 \text {, and } \frac{h^{\prime}}{m}=\frac{1}{4} \text {. }
$$

From Table $3, k=0.291$.

Accordingly $D_{1}=D_{5}=2, D_{2}=D_{4}=2 \sqrt{3}, D_{3}=4$. 


$$
\begin{aligned}
\log \frac{2 m}{d}-n k & =4.000-1.748=2.252 \\
\sum \log \frac{m}{D_{\mathrm{r}}} & =2(1.699+1.460)+1.398=7.716 \\
& 0.434 \sum \frac{D_{\mathrm{r}}}{m}=0.065 \\
\therefore U_{\mathrm{c}}^{\prime} & =10.033
\end{aligned}
$$

and

$$
C=\frac{7.36(600)}{10.033}=440.2 \mu \mu f
$$

\section{SINGLE V ANTENNA}

The antenna is supposed to consist of two wires in a horizontal plane meeting at an angle $\theta$. The lengths of the wires are $l$ and $m$, their diameters $d$ and $d^{\prime}$ and their common height above ground $h$. Then

$$
C=\frac{0.2416\left(l_{1}+m_{1}\right)}{U_{\mathrm{v}}}=\frac{7.36\left(l_{2}+m_{2}\right)}{U_{\mathrm{v}}}
$$

where

$$
U_{\nabla}=\frac{l}{l+m}\left(\log \frac{4 \hbar}{d}-K\right)+\frac{m}{l+m}\left(\log \frac{4 h}{d^{\prime}}-K^{\prime}\right)+Y
$$

The quantities $K$ and $K^{\prime}$ are to be obtained from Table 1 for the values of $\frac{2 h}{l}$ and $\frac{2 h}{m}$, respectively (or their reciprocals if the latter are less than unity).

The quantity $Y$ is the difference of two terms $Y_{1}$ and $Y_{2}$, the first being a function of the angle $\theta$ and the ratio $\frac{m}{l}$ (supposed to be less

than unity), while $Y_{2}$, which refers to the effect of the earth is a function of $\theta, \frac{m}{l}$ and $\frac{2 h}{l}$. Values of $Y_{1}$ and $Y_{2}$ are given in Tables 7 and 8.

If boith wires have the same diameter of cross section, then

$$
U_{\mathrm{v}}=\log \frac{4 h}{d}-\frac{l}{l+m} K-\frac{m}{l+m} K^{\prime}+Y
$$

and if, further, $m=l$ (an important case)

$$
U_{\mathrm{v}}=\log \frac{4 h}{d}-K+Y
$$


Since in the case of existing antennas, the distance between the free ends of the $V$ will be readily measured, rather than the angle, the distance $s$ thus measured may be used in the formula

$$
\cos \theta=\frac{l^{2}+m^{2}-s^{2}}{2 l m}
$$

to determine the angle $\theta$.

Example 12.-If we suppose the case $l=100, m=50, h=50, \theta=45^{\circ}$, and $\frac{4 h}{d}=10,000$, then $\frac{2 h}{l}=1, \frac{m}{2 h}=\frac{1}{2}$, and from Table $1 K=0.336$, $K^{\prime}=0.541$. From Table 7 , for $\theta=45^{\circ}$, and $\frac{m}{l}=\frac{1}{2}, Y_{1}=0.497$, and from Table 8 , for $\theta=45^{\circ}, \frac{m}{l}=\frac{1}{2}$, and $\frac{2 h}{l}=1, Y_{2}=0.131$. Thus $Y=0,366$. By formula (31)

$$
\begin{aligned}
U_{\mathrm{v}} & =4.000+0.366-\frac{2}{3}(0.336)-\frac{1}{3}(0.541)=3.962 \\
\mathrm{C} & =\frac{7.36(150)}{3.962}=278.6 \mu \mu \mathrm{f}
\end{aligned}
$$

The sum of the capacities of the two wires taken singly is (see example 1) $200.9+106.4=307.3 \mu \mu$. Thus the mutual effect of the two wires is to reduce the capacity of the combination in a $V$ by about 9.3 per cent.

\section{TWO HORIZONTAL WIRES INCLINED TO ONE ANOTHER, BUT NOT INTERSECTING}

The wires are supposed to have lengths $l$ and $m$, diameters $d$ and $d^{\prime}$, and their distances from their point of intersection, if supposed to be produced, $l^{\prime}$ and $m^{\prime}$. (See fig. 8.)

For this case the same formula is used as in the preceding case, except that the value for $Y$ is different. This is obtained as before as the difference of two terms, one applying to the top and the other to the image wires. Tables 7 and 8 are used, but instead of a single entry in the table for each of the two terms $Y_{1}$ and $Y_{2}$, several have to be made for each.

$$
\begin{aligned}
Y & =\frac{l+l^{\prime}+m+m^{\prime}}{l+m} \cdot Y_{1+1^{\prime}, \mathrm{m}+\mathrm{m}^{\prime}}-\frac{\left(l+l^{\prime}+m^{\prime}\right)}{l+m} \cdot Y_{1+1^{\prime}, \mathrm{m}^{\prime}} \\
& -\frac{\left(l^{\prime}+m+m^{\prime}\right)}{l+m} Y_{1^{\prime}, \mathrm{m}+\mathrm{m}^{\prime}}+\frac{l^{\prime}+m^{\prime}}{l+m} Y_{1^{\prime}, \mathrm{m}^{\prime}}
\end{aligned}
$$

In this the foliowing abbreviated nomenclature is used: $Y_{1+1^{\prime}, m+m^{\prime}}$ is used for the difference between the value of $Y_{1}$ for the wires $\left(l+l^{\prime}\right)$ and $\left(m+m^{\prime}\right)$ and the quantity $Y_{2}$ for the same wires, etc. For $\boldsymbol{b}^{\prime}=m^{\prime}=n$ 


$$
\begin{aligned}
Y & =\frac{l+m+2 n}{l+m} Y_{1+\mathrm{n}, \mathrm{m}+\mathrm{n}}-\frac{(l+2 n)}{l+m} Y_{1+\mathrm{n}, \mathrm{n}}-\frac{(m+2 n)}{l+m} Y_{\mathrm{n}, \mathrm{m}+\mathrm{n}} \\
& +\frac{2 n}{l+m} Y_{\mathrm{n}, \mathrm{n}}
\end{aligned}
$$

and for the specially important case that $l^{\prime}=m^{\prime}=n$, and $l=m$,

$$
Y=\frac{l+2 n}{l}\left(Y_{\mathrm{n}, \mathrm{n}}-Y_{1+\mathrm{n}, \mathrm{n}}\right)
$$

Example 13.-Two wires of equal length 100 feet make an angle of $30^{\circ}$, and if prolonged until they intersect, the point of intersection is 100 feet from the nearer end of each. The wires have each a diameter of cross section of 0.02 foot, and they lie in a horizontal plane 50 feet above the ground.

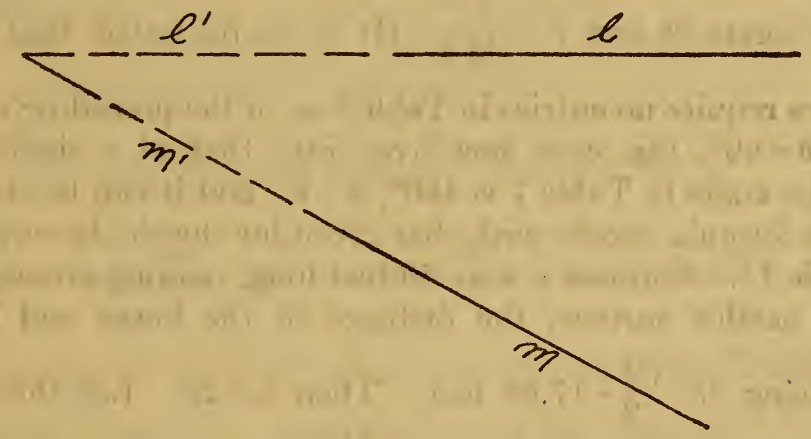

Fig. 8.-Antenna of two nonintersecting wires

Here $l=m=100, h=50, d=0.02, l^{\prime}=m^{\prime}=n=100, \theta=30^{\circ}$. Then for $Y_{\mathrm{n}, \mathrm{n}}$ we have the argument $\left(1,30^{\circ}\right)$ in Table 7 , and $1,30^{\circ}$, and $\frac{2 h}{l}=1$ in Table 8 . Thus $Y_{\mathrm{n}, \mathrm{n}}=0.687-0.197=0.490$. For $Y_{1+\mathrm{n}, \mathrm{n}}$ the argument in Table 7 is $\left(\frac{1}{2}, 30^{\circ}\right)$, and in Table $8\left(\frac{1}{2}, 30, \frac{1}{2}\right)$, so that $Y_{1+\mathrm{n}, \mathrm{n}}=0.601-0.229=0.372$. Thus

and

$$
Y=\frac{l+2 n}{l}\left(Y_{\mathrm{n}, \mathrm{n}}-Y_{1+\mathrm{n}, \mathrm{n}}\right)=3(0.490-0.372)=0.354
$$

and

$$
U_{\mathrm{v}}=\log \frac{4 h}{d}-K+Y=4.000-0.336+0.354=4.018
$$

$$
C=\frac{7.36(200)}{4.018}=366.4 \mu \mu \mathrm{f}
$$

Each of the wires alone has a capacity of $200.9 \mu \mu \mathrm{f}$ (see example 1), so that the sum of their individual capacities is $401.8 \mu \mu \mathrm{f}$. Thus the mutual effect of the wires is to reduce the capacity by about 9 per cent.

If the same wires were so placed as to have their ends in contact, still keeping the angle between them equal to $30^{\circ}$, then $Y=0.687-$ $0.197=0.490, U_{\mathrm{v}}=4.154$, and $C=354.4 \mu \mu \mathrm{f}$. The mutual effect here is nearly 12 per cent, or 30 per cent more than in the previous case. 


\section{SINGLE WIRE INCLINED TO THE EARTH'S SURFACE}

The wire is assumed to have a length $l$, a diameter of cross section $d$, and to make an angle $\theta$ with the earth's surface. Let the height of the lower end be $h^{\prime}$ above the ground. Then the capacity is given by

and

$$
C=\frac{0.2416 l_{1}}{U_{\mathrm{B}}}=\frac{7.36 \mathrm{Z}_{2}}{\bar{U}_{\mathrm{B}}}
$$

$$
U_{\mathrm{s}}=\left(\log \frac{2 l}{d}-0.133\right)-\frac{l+2 n}{l}\left(Y_{\mathrm{n}, \mathrm{n}}^{\prime}-Y^{\prime}{ }_{1+\mathrm{n}, \mathrm{n}}\right)
$$

The quantities $Y_{n, n}^{\prime}$ and $Y_{1+n, n}^{\prime}$ are to be taken from Table 7 , using the angle $2 \theta$ and $n=\frac{h^{\prime}}{\sin \theta}$. (It is to be noted that the constants here require no entries in Table 8 as in the preceding example.)

When $\theta=90^{\circ}$, this case goes over into that of a single vertical wire. The angle in Table 7 is $180^{\circ}, n=h^{\prime}$, and it can be shown that the above formula checks with that given for the single vertical wire.

Example 14.- Suppose a wire 50 feet long, making an angle of $45^{\circ}$ with the earth's surface, the distance of the lower end from the ground being $25 \frac{\sqrt{2}}{2}=17.68$ feet. Then $n=25$. Let the diameter of cross section be taken such that $\frac{2 l}{d}=5,000$. Then the first term of $U_{\mathrm{s}}$ is $(3.699-0.133)=3.566$. For $Y_{n, \mathrm{n}}^{\prime}$ the argument in Table 7 is $\left(1,90^{\circ}\right)$ so that $Y_{n, n}^{\prime}=0.383^{\circ}$. For $Y^{\prime}{ }_{1+n, n}$, the argurnent is $\left(\frac{1}{3}, 90^{\circ}\right)$,

and the same table gives $Y^{\prime}{ }_{1+n, \mathrm{n}}=0.304$. Thus the second term in $U_{\mathrm{B}}$ is $2(0.383-0.304)=2(0.079)=0.158$. Therefore, $U_{\mathrm{s}}=3.408$ and $C=108.0 \mu \mu \mathrm{f}$.

If the same wire were swung about its lower end as center until it reached the vertical position, then we would have to use $\frac{h^{\prime}}{l}=\frac{25}{50} \frac{\sqrt{2}}{2}$ $={ }_{4}^{1} \sqrt{2}=0.354$, and for this Table 3 gives $k=0.269$. The capacity comes out $107.3 \mu \mu \mathrm{f}$.

If the same wire were swung about the lower end into a horizontal position, $h=25 \frac{\sqrt{2}}{2}, \frac{2 h}{l}=\frac{\sqrt{2}}{2}$, and from Table $1, K=0.256$, the resulting capacity being $111.8 \mu \mu \mathrm{f}$. Thus the capacity of the inclined wire lies between the values corresponding to the vertical and horizontal positions, as would be expected. 


\section{PARALLEL WIRE $V$ ANTENNA}

The antenna is supposed to consist of $n^{\prime}$ wires of equal length $l^{\prime}$ and diameter $d^{\prime}$, joined to another set of $n^{\prime \prime}$ wires of equal length $l^{\prime \prime}$ and diameter $d^{\prime \prime}$. Each of these sets of wires is supposed to lie in a horizontal plane at a height $h$ above the ground and the axes of the two sets meet at an angle $\theta$, at a point situated at distances $l_{\circ}^{\prime}$ and $l^{\prime \prime}{ }_{0}$, respectively, from the nearer ends of the sets of wires. Let the spacing of the wires in the two sets be $D^{\prime}$ and $D^{\prime \prime}$.

The capacity is given by

$$
C=\frac{0.2416\left(n^{\prime} l_{1}{ }^{\prime}+n^{\prime \prime} l_{1}{ }^{\prime \prime}\right)}{U^{\prime}{ }^{\prime}}=\frac{7.36\left(n^{\prime} l_{2}{ }^{\prime}+n^{\prime \prime} l^{\prime \prime}{ }_{2}\right)}{U^{\prime}}
$$

in which

$$
\begin{aligned}
U^{\prime} & =\frac{n^{\prime} l^{\prime}}{n^{\prime} l^{\prime}+n^{\prime \prime} l^{\prime \prime}} u^{\prime}+\frac{n^{\prime \prime} l^{\prime \prime}}{n^{\prime} l^{\prime}+n^{\prime \prime} l^{\prime \prime}} u^{\prime \prime}+\frac{n^{\prime} n^{\prime \prime}\left(l^{\prime}+l^{\prime \prime}\right)}{n^{\prime} l^{\prime}+n^{\prime \prime} l^{\prime \prime}} \cdot Y \\
u^{\prime} & =\log \frac{4 h}{d^{\prime}}+\left(n^{\prime}-1\right) \log \frac{2 h}{D^{\prime}}-n^{\prime}\left(K^{\prime}+K_{\mathrm{n}}{ }^{\prime}\right) \\
u^{\prime \prime} & =\log \frac{4 h}{d^{\prime \prime}}+\left(n^{\prime \prime}-1\right) \log \frac{2 h}{D^{\prime \prime}}-n^{\prime \prime}\left(K^{\prime \prime}+K_{\mathrm{n}}^{\prime \prime}\right)
\end{aligned}
$$

The constants $K^{\prime}$ and $K^{\prime \prime}$ are to be obtained from Table 1 for the arguments $\frac{2 h}{l^{\prime}}$ and $\frac{2 h}{l^{\prime \prime}}$, respectively, and the constants $K^{\prime}{ }_{n}$ and $K^{\prime \prime}{ }_{n}$ from Table 6 for the values of $n^{\prime}$ and $n^{\prime \prime}$. The last term in $U^{\prime}$ takes account of the mutual effect between one set of wires and the other set and its image. This is obtained on the assumption that the effect is sensibly the same as though the two sets of wires were replaced by wires along the axes of the parallel sets and carrying the same total charges as the parallel wire sets. The error due to this simplifying assumption will not amount to as much as 1 per cent in most practical cases.

To calculate $Y$ we have the equation

$$
\begin{gathered}
Y=\frac{l^{\prime}+l_{{ }_{0}+l^{\prime \prime}+l^{\prime \prime}{ }_{0}}}{l^{\prime}+l^{\prime \prime}} Y\left(l^{\prime}+l^{\prime}{ }_{0}, l^{\prime \prime}+l^{\prime \prime}{ }_{0}\right)-\frac{\left(l^{\prime}+l^{\prime}{ }_{0}+l^{\prime \prime}{ }_{0}\right)}{l^{\prime}+l^{\prime \prime}} Y\left(l^{\prime}+l^{\prime}{ }_{0}, l^{\prime \prime}{ }_{0}\right) \\
-\frac{\left(l_{0}^{\prime}+l^{\prime \prime}+l^{\prime \prime}{ }_{0}\right)}{l^{\prime}+l^{\prime \prime}} Y\left(l_{0}^{\prime}, l^{\prime \prime}+l^{\prime \prime}{ }_{0}\right)+\frac{l_{0}^{\prime}+l^{\prime \prime}{ }_{0}}{l^{\prime}+l^{\prime \prime}} Y\left(l^{\prime}{ }_{0}, l^{\prime \prime}{ }_{0}\right)
\end{gathered}
$$

each of the terms being the difference of two quantities $Y_{1}$ and $Y_{2}$ taken from Tables 7 and 8 , respectively, for the arguments $\theta$, and the ratio of the lengths which appear in the parentheses which follow the symbol $Y$ in the formula, and for the value of $2 h$ divided by the greater of the two lengths in each case.

In most practical cases, however, there will be simplifying conditions. The following are the most important of these special cases. 
When the wires have all the same diameter, the same spacing, and the number in each leg of the $V$ is the same, then $d^{\prime}=d^{\prime \prime}=d, D^{\prime}=$ $D^{\prime \prime}=D, n^{\prime}=n^{\prime \prime}=n$. The capacity is now

$$
C=\frac{0.2416\left(l_{1}{ }_{1}+l^{\prime \prime}{ }_{1}\right)}{U^{\prime}}=\frac{7.36\left(l^{\prime}{ }_{2}+l^{\prime \prime}{ }_{2}\right)}{U^{\prime}}
$$

with

$$
U^{\prime}=\frac{\log \frac{4 h}{d}+(n-1) \log \frac{2 h}{D}}{n}-\frac{l^{\prime}}{l^{\prime}+l^{\prime \prime}} K_{1}-\frac{l^{\prime \prime}}{l^{\prime}+l^{\prime \prime}} K_{2}-K_{\mathrm{n}}+Y
$$

As the simplest cases of all, we may assume, in addition, that the wires of the two legs of the $V$ have the same length $l$, and that their ends have the same distance from the intersection of their axes; that is, $l^{\prime}=l^{\prime \prime}=l, l_{0}^{\prime}=l^{\prime \prime}{ }_{0}=l_{0}$. Then in formula (39)

$$
U^{\prime}=\frac{\log \frac{4 h}{d}+(n-1) \log \frac{2 h}{D}}{n}-\left(K+K_{n}\right)+Y
$$

and

$$
Y=\frac{l+2 l_{0}}{l}\left[Y\left(l_{0}, l_{0}\right)-Y\left(l+l_{0}, l_{0}\right)\right]
$$

Example 15.-As an illustration of the preceding formulas we may take the case of a parallel-wire $\mathbf{V}$ antenna, each leg consisting of six wires of diameter 0.02 foot, spaced 2 feet apart; the whole antenna is supposed to be in a plane 50 feet above the ground. Suppose further, that the length of the wires in one set is 100 feet and those of the other set 50 feet, and that the point of the intersection of the axes of the two sets is, respectively, 50 and 25 feet from the nearer ends of the two legs, their angle being $45^{\circ}$.

Then $l^{\prime}=100, l^{\prime}{ }_{0}=50, l^{\prime \prime}=50, l^{\prime \prime}{ }_{0}=25, \quad D=2, n=6, d=0.02$, $\theta=45^{\circ}$.

From Table 1 , for $\frac{2 h}{l}=1, K^{\prime}=0.336$, and for $\frac{2 h}{l}=2, K^{\prime \prime}=0.541$, so that

$$
U^{\prime}=\frac{4.000+5(1.699)}{6}-\frac{2}{3}(0.336)-\frac{1}{3}(0.541)-0.252+Y .
$$

To calculate $Y$ we have

$$
\begin{aligned}
& \frac{l^{\prime \prime}+l^{\prime \prime}{ }_{0}}{l^{\prime}+l_{0}^{\prime}}=\frac{75}{150}=\frac{1}{2} \quad \frac{l^{\prime \prime}{ }_{0}}{l^{\prime}+l_{0}^{\prime}}=\frac{25}{150}=\frac{1}{6} \quad \frac{l^{\prime}{ }_{0}}{l^{\prime \prime}+l^{\prime \prime}{ }_{0}}=\frac{50}{75}=\frac{2}{3}
\end{aligned}
$$



$$
\begin{aligned}
& Y_{1}=0.497 \\
& \text { 0. } 286 \\
& 0.535 \\
& \text { 0. } 497 \\
& Y_{2}=.150 \\
& .050 \\
& .117 \\
& .070 \\
& \text { Diff. }=.347 \\
& .236 \\
& .418 \\
& .427
\end{aligned}
$$




$$
\begin{array}{cc}
\frac{l^{\prime}+l^{\prime}{ }_{0}+l^{\prime \prime}+l^{\prime \prime}{ }_{0}}{l^{\prime}+l^{\prime \prime}}=\frac{225}{150}=\frac{3}{2} & \frac{l^{\prime}+l^{\prime}{ }_{0}+l^{\prime \prime}{ }_{0}}{l^{\prime}+l^{\prime \prime}}=\frac{175}{150}=\frac{7}{6} \\
\frac{l^{\prime}{ }_{0}+l^{\prime \prime}+l^{\prime \prime}{ }_{0}}{l^{\prime}+l^{\prime \prime}}=\frac{125}{150}=\frac{5}{6} & \frac{l^{\prime}{ }_{\circ}+l^{\prime \prime}{ }_{0}}{l^{\prime}+l^{\prime \prime}}=\frac{75}{150}=\frac{1}{2} \\
Y=\frac{3}{2}(0.347)-\frac{7}{6}(0.275)-(0.418) \frac{5}{6}+\frac{1}{2}(0.427)=0.112
\end{array}
$$

and finally

$$
U^{\prime}=1.538 \quad C=\frac{7.36(150)}{1.538}=717.3 \mu \mu f
$$

The capacity calculated by simply adding the capacities of the legs taken separately is $778.1 \mu \mu f$, so that the mutual effect of the two legs is to reduce the capacity by about 8 per cent. If the ends of the two legs came together, so that $l^{\prime}{ }_{0}=l^{\prime \prime}{ }_{0}=0$, and we would find from Tables 7 and 8 that $Y_{1}=0.497, Y_{2}=0.131$, so that $Y=0.366$, and the capacity comes out $616.1 \mu \mu f$.

\section{ANTENNA OF PARALLEL WIRES IN A PLANE INCLINED TO GROUND}

The antenna is supposed to consist of $n$ wires spaced a distance $D$ apart, the whole set being situated in a plane making an angle $\theta$ with the surface of the earth. The wires have each a diamater $d$ and are of equal length $l$, while the lower ends of the wires are at a height $h^{\prime}$ above the ground.

The capacity is calculated by the formula

$$
C=\frac{0.2416 \eta_{1}}{U_{1}}=\frac{7.36 l_{2}}{U_{1}}
$$

in which

$$
U_{1}=\frac{\log \frac{2 l}{d}+(n-1) \log \frac{l}{D}}{n}-\left(0.133+K_{\mathrm{n}}\right)-Y^{\prime}
$$

The term $Y^{\prime}$, which takes into account the effect of the charges upon the earth, is calculated on the assumption that its value is closely given by supposing the wire charges and image charges to be concentrated along the axes of the set of wires and the images, respectively. Its value is obtained by formula (35), using Table 7 .

Example 16.-Suppose six wires spaced 2 feet apart, in a plane inclined $45^{\circ}$ to the ground. The wires are of diameter 0.02 foot, and 50 feet long, and their lower ends are 50 feet above the ground.

Then $\frac{2 l}{d}=5,000, \frac{l}{D}=25, K_{\mathrm{n}}=0.252$. To calculate $Y^{\prime}$ we use formula (35). The distance $l^{\prime}=50 \sqrt{2}, \frac{l^{\prime}}{l+l^{\prime}}=0.586$. Then from Table 7 for 
the argument $\left(1,90^{\circ}\right)$ we find $Y\left(l^{\prime}, l^{\prime}\right)=0.383$, and for the argument $\left(0.586,90^{\circ}\right)$ we find $Y\left(l^{\prime}, l+l^{\prime}\right)=0.361$, so that

Then

$$
Y^{\prime}=\frac{(50+100 \sqrt{2} \overline{)}}{50}(0.022)=0.084
$$

$$
U_{1}=\frac{3.699+5(1.398)}{6}-(0.133+0.252)-0.084=1.313
$$

and the capacity is

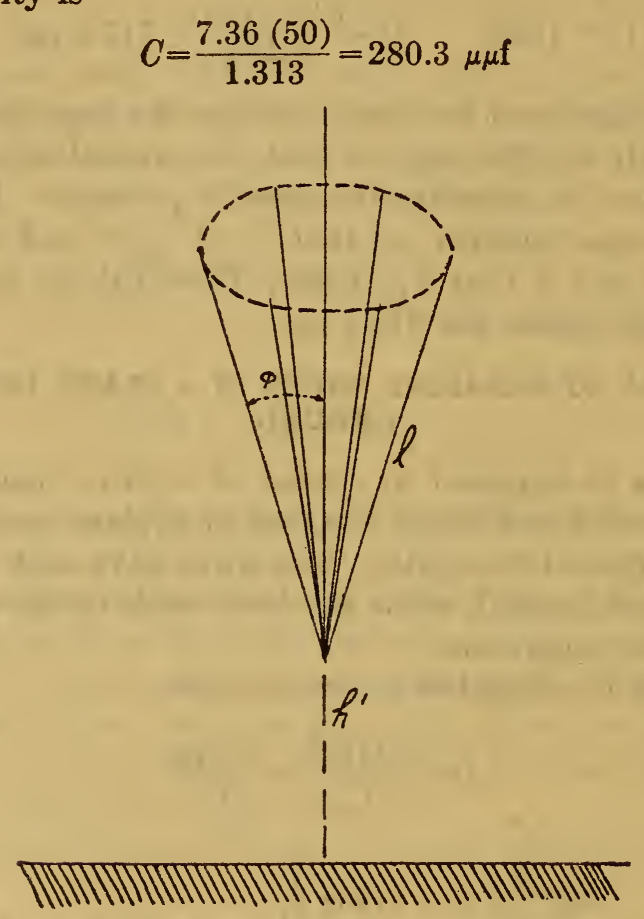

Fig. 9.-Conical form of antenna

If the same wires were placed in a horizontal plane 50 feet above the ground, the capacity would be $285.5 \mu \mu f$, and if they were placed vertical with their lower ends 50 feet above the ground, the capacity would be $278.2 \mu \mu \mathrm{f}$.

16. CONICAL ANTENNA

Let the conical antenna consist of $n$ wires of length $l$, and of diameter of cross section $d$, spaced at equal angles as elements of a cone whose half angle is $\varphi$, and whose point is a distance of $h^{\prime}$ from the ground, the axis of the cone extending vertically above the apex. (See fig. 9.)

The capacity is found by the formula

$$
C=\frac{0.2416 l_{1} n}{U_{\mathrm{k}}}=\frac{7.36 l_{2} n}{U_{\mathrm{k}}}
$$


Here

$$
U_{\mathbf{k}}=\log \frac{2 l}{d}-0.133+\Sigma Y^{\prime}-\frac{n}{\cos \varphi}(k-0.133)
$$

the constant $k$ being obtained from Table 3 for the argument $\frac{h}{l \cos \varphi}$. The term $\Sigma Y^{\prime}$ is the sum of the $Y_{1}$ terms for any wire and the remaining wires, the values being taken from Table 7 for arguments $\theta$ given by the angles between the wires. The lengths of the wires being the same, the length ratio in Table 7 is unity in each case.

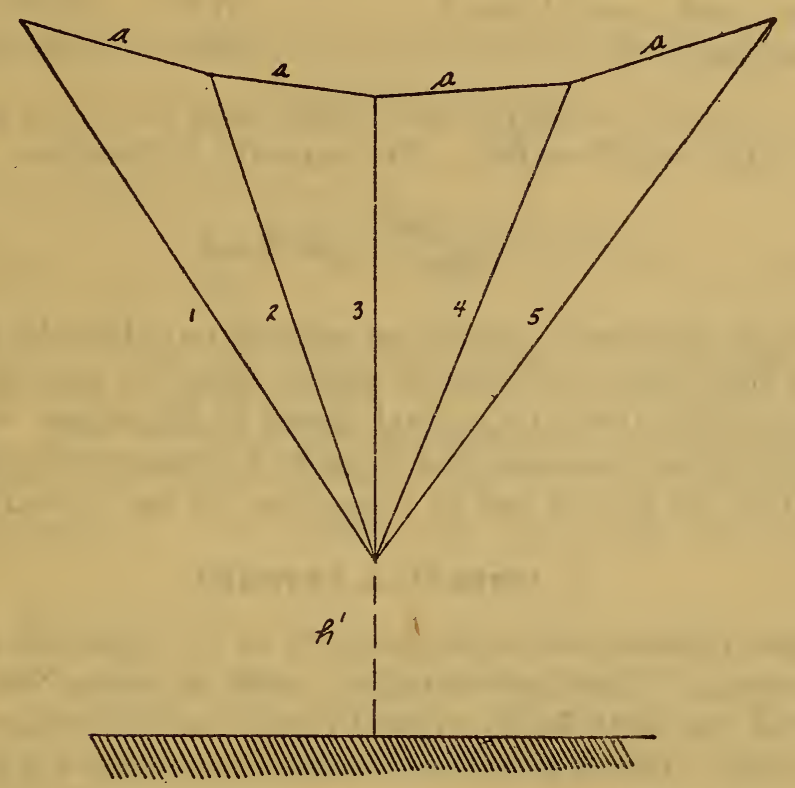

FIG. 10.-Fan form of antenna

The last term in $U_{\mathrm{k}}$ takes into account the effect of the earth. The expression for this is not exact, but the error in practical cases will be only a few per cent in the value of this term which is not more than about one-tenth of the whole quantity $U_{\mathrm{k}}$. To calculate exactly the effect of the earth necessitates in this case the use of complicated formulas. The approximation here employed in obtaining formula (43) is to replace the antenna and image wires each by a single wire along the axis of the cone, the distance between the nearer ends of these two vertical wires being $2 h^{\prime}$, their lengths each being $l \cos \varphi$, and the linear charge density on each being taken as $\frac{q}{\cos \varphi}$, where $q$ is the actual linear density originally assumed upon each wire in obtaining the capacity formula.

Example 17.-Suppose the wires composing a conical antenna are six in number, spaced at equal intervals upon a cone of half angle 
$30^{\circ}$, with its apex 50 feet above the ground. Each wire has a length of 100 feet, and a diameter of 0.02 foot. Then $\frac{2 l}{d}=10,000, \varphi=30^{\circ}$, $h^{\prime}=50, l \cos \varphi=86.6$, and thus in Table 3 we have to take the value of $k$ corresponding to the argument $\frac{50}{86.6}=0.583$; that is, $k=0.238$. To obtain the second term in $U_{\mathrm{k}}$ we find that the angles between the wires are as follows:

Wires 1 and 2, and 1 and $6 \ldots 28.96^{\circ} \quad Y^{\prime}=0.705$

Wires 1 and 3 , and 1 and $5 \ldots \ldots . .51 .3^{\circ} \quad Y^{\prime}=.520$

Wires 1 and $4 \ldots \ldots 0^{\circ} \quad Y^{\prime}=.477$

Thus $\Sigma Y^{\prime}=2(0.705+0.520)+0.477=2.927$, and for $U_{\mathrm{k}}$ we have 4.000 $-0.133+2.927-0.727=6.066$. The capacity is therefore

$$
C=\frac{7.36(600)}{6.066}=728.0 \mu \mu \mathrm{f} \text {. }
$$

With such an antenna it should be pointed out that the gain from increasing the number of wires is largely offset by the reduction in capacity resulting from the mutual effects of the wires. Compared with a vertical cage antenna, the capacity is greater with the conical antenna, but the gain is not in proportion to the amount of space occupied.

\section{UMBRELLA ANTENNA}

The same formula for the capacity is to be employed as for the conical antenna. The approximation made in taking into account the effect of the earth in the conical case is not so accurate for the umbrella type. However, the error in practical cases will not exceed 1 per cent in the value of the capacity.

\section{FAN OR HARP ANTENNA}

This is made up of $n$ wires joined together at their lower ends. From this junction the wires are carried upward and are attached at equal intervals along a horizontal guy rope. (See fig. 10.)

The dimensions required are the lengths of the different wires $l_{\mathrm{s}}$, the distances between their points of attachment on the guy rope $a$, and the distance of the point of junction from the ground $h^{\prime}$. Then the angles between the various wires are to be calculated. Thus for any two consecutive wires of lengths $l_{\mathrm{r}}$ and $l_{\mathrm{s}}$, whose points of attachment are separated by a distance $a$, the angle $\theta$ is found from the relation $\cos \theta=\frac{l_{\mathrm{r}}{ }^{2}+l_{\mathrm{s}}{ }^{2}-a^{2}}{2 l_{\mathrm{r}} l_{\mathrm{s}}}$.

The potential of any one of the wires is that due to its own charge, plus that due to the charges on each of the other wires of the fan, minus that due to the image charges. The effects of the other wires 
are evaluated by the constants given in Table 7 which hold for wires intersecting at an angle $\theta$. The effect of the image may be accurately enough taken into account by supposing both antenna top and images to be replaced by vertical wires having a length equal to the average vertical component of the lengths of the wires, the charge upon these equivalent wires being taken to have a density equal to the sum of the densities on the individual wires. The equivalent wires are supposed to lie in the same straight line with their nearer ends separated by twice the height of the lowest point of the fan from the ground.

Carrying through these operations we find for the capacity formula

$$
C=\frac{0.2416 \Sigma l_{1}}{U_{\mathrm{f}}}=\frac{7.36 \Sigma l_{2}}{\bar{U}_{\mathrm{f}}}
$$

in which the quantity $U_{1}$ is given by

$$
U_{\mathrm{f}}=\frac{1}{\Sigma l}\left[\sum_{s} l_{\mathrm{s}} \log \frac{l_{\mathrm{B}}}{d}+\sum_{r, s} \frac{\left(l_{\mathrm{r}}+l_{\mathrm{s}}\right)}{2} Y_{r \mathrm{r}}^{\prime}\right]-0.133-\frac{\Sigma l_{\mathrm{B}}}{\lambda}(k-0.133)
$$

The constants $Y^{\prime}{ }_{\mathrm{r}}$ are to be taken from Table 7 for the angle between the pairs of wires $r$ and $s$, and for the ratio of the smaller length to the greater. The constant $\lambda$ is the average of the vertical components of the lengths of the wires of the fan, and $k$ is to be taken from Table 3 for the argument $\frac{h}{\lambda}$. An example will make clear the use of the formula.

Example 18.-Suppose in Figure 10 that there are five wires meeting at a point 50 feet above the ground, and that the wires are fastened to a horizontal wire at points 10 feet apart. The middle wire is vertical and has a length of 100 feet and the diameter of the wires is 0.02 foot.

The lengths of the wires are then found to be $l_{1}=l_{5}=102.5, l_{2}=l_{4}=$ 100.5 , and $l_{3}=100$, so that $\Sigma l=505$. The mean value of $\log _{10} \frac{l_{\mathrm{g}}}{d}$, weighted according to the lengths of the wires, is 4.004 . The angles between the wires are as follows:



By rather rough interpolation from Table 7 the constants, corresponding to these angles and the ratios of the lengths of the wires of

\begin{tabular}{|c|c|c|}
\hline$Y^{\prime}$ & Pair & \\
\hline $4,5 \ldots 1.323$ & 2,5 or $1,4 \ldots 0.882$ & ¿, 3 or $3,4 \ldots-1.31$ \\
\hline 3,5 or $1,3 \ldots 1.034$ & 1,5 & 2,4 \\
\hline
\end{tabular}
the pairs, were found to be 
Thus, the terms $\sum_{r, s} \frac{l_{\mathrm{r}}+l_{s}}{2} Y_{\mathrm{rs}}^{\prime}$ give a final result of 4.372 . The average vertical component of the lengths of the wires is $\lambda=100$, and from Table 3 for $\frac{h}{\lambda}=\frac{50}{100}=0.5, k=0.247$, so that the image term is $\frac{505}{100} \times 0.114=0.576$, and the capacity is $C=\frac{7.36(505)}{7.667}=484.6 \mu \mu \mathrm{f}$.

\section{USE OF TABLES FOR THREE COMMON FORMS OF ANTENNAS}

The capacities of certain common forms of antennas may be obtained without calculation from Tables 2, 4, and 9. These tables are, respectively, for single-wire horizontal, single-wire vertical, and two-wire horizontal antennas. The length of each horizontal wire is denoted by $l$ and of the vertical wire by $m$.

In each case there is given the capacity, $C$, in micromicrofarads, and the capacity per unit length in micromicrofarads per foot. It will be noted that the capacity per unit length varies but slowly with the length and the height above the ground. Thus, accurate interpolation of the capacity per unit length may be made for antennas not included in the tables, and so by multiplication by the length, the capacity of the antenna.

In addition to the capacity and linear capacity, the tables include the potential coefficient of the antenna for unit charge density per unit length of the antenna. This quantity $U$ is useful in calculating the capacity of combinations of horizontal and vertical wires, such as, for example, the calculation of the effect of lead-in wires. This point will be illustrated in the succeeding section.

Four different sizes of wires $(0.005,0.01,0.015$, and 0.02 foot in diameter) are included in each table. These sizes, it is believed, cover the majority of antennas met in practice. Interpolation in the tables may be made for sizes lying between these values. The table for two-wire horizontal antennas covers three spacings of the wires, viz, 1 foot, 2 feet, and 3 feet. It is hoped that the range here covered will suffice for the large majority of practical cases.

Example 19.- Suppose the capacity of a two-wire antenna of 0.0125 -foot wires, 125 feet long, spaced 2 feet apart, at a distance of 75 feet from the ground, is to be found from Table 9 .

The following values of the linear capacity were interpolated from the table, using second differences, for the required length of 125 feet:

$\begin{array}{rrrr}\hbar & d=0.01 & 0.015 & 0.02 \\ 60 & 2.675 & 2.764 & 2.831 \\ 80 & 2.629 & 2.714 & 2.778 \\ 100 & 2.601 & 2.684 & 2.746\end{array}$


Interpolating from these for the length 75 feet the resulting values are

$$
\begin{array}{rrr}
d=0.01 & 0.015 & 0.02 \\
2.638 & 2.724 & 2.788
\end{array}
$$

and interpolating, finally, for the given diameter of wire we find for the capacity per foot, 2.684 , so that the capacity of the antenna is $335 \mu \mu \mathrm{f}$. The complicated case just considered is purposely taken to illustrate what is possible with the table. In general, it will be well to use formula (24) directly, when more than two interpolations have to be made in the table. For this case the formula gives $334.9 \mu \mu \mathrm{f}$.

\section{CALCULATION OF CAPACITY OF LEAD-IN WIRES}

A problem frequently met is the calculation of the capacity of the combination of two sets of wires joined together, each of the elements being readily calculable singly by methods and formulas already given. A first approximation is to add the capacities of the elements, but this takes no account of the mutual effect of the elements upon one another and gives a value which is too high.

In general, the simplest method for obtaining the accurate value of the capacity of the combination is to obtain the unit potential coefficients of the separate elements either from Tables 2, 4, or 9 . Likewise the mutual unit potential coefficients are to be obtained. With these values the linear charge density ratios for the elements are to be so determined as to make the potentials equal for all the elements. The process is illustrated in the next example, which has been so chosen as to employ the tabulated values of linear potential coefficients in Tables 2, 4, and 9.

Example 20.-A two-wire horizontal antenna, 200 feet long and 80 feet above the earth, has joined to one of its ends as a lead-in a single vertical wire 60 feet long. The diameter of all the wires will be assumed as 0.02 foot and the spacing of the wires of the horizontal portion as 2 feet.

From Table 9 the linear potential coefficient of the horizontal portion is found to be 2.771, and from Table 4, with $m=60$ and $h^{\prime}=20$, we find $U_{22}=3.505$. The mutual potential coefficient will be obtained with sufficient accuracy if we assume that the charge upon the horizontal portion is concentrated upon a single wire halfway between the actual wires. Then from Table 5 , for the argument

$$
\frac{m}{l}=\frac{60}{200}=0.3 \text { and for } \frac{h^{\prime}}{m}=\frac{1}{3}, \text { there is found } X=0.168
$$

To obtain the linear mutual potential coefficients from the constant $X$ which is useful in calculations with wires at right angles, we note that we may write 
so that

$$
X=\frac{x}{2.303(l+m)}, U_{12}=\frac{x}{4.605 l}, U_{21}=\frac{x}{4.605 m}
$$

$$
U_{12}=\frac{l+m}{2 l} \cdot X, U_{21}=\frac{l+m}{2 m} \cdot X
$$

are the general relations connecting these linear potential coefficients and the tabulated quantity. Thus for the present case

$$
U_{12}=0.109, U_{21}=0.364
$$

If we assume the linear charge densities upon the horizontal and vertical portions as $q_{1}$ and $q_{2}$, respectively, then we may write for the potentials of the two portions

$$
\begin{aligned}
& v_{1}=q_{1} U_{11}+q_{2} U_{12} \\
& v_{2}=q_{1} U_{21}+q_{2} U_{22}
\end{aligned}
$$

and the condition that these may be equal is

$$
\frac{q_{2}}{q_{1}}=\frac{U_{11}-U_{21}}{U_{22}-U_{12}}=\frac{2.407}{3.396}=0.709
$$

Thus the common potential is

$$
v=q_{1}[2.771+0.709(0.109)]=2.848 q_{1}
$$

the total charge

$$
Q=q_{1}[200+60(0.709)]=242.5 q_{1}
$$

and the capacity

$$
C=\frac{7.36(242.5)}{2.848}=625.2 \mu \mu \mathrm{f}
$$

The sum of the capacities of the separate portions is from Tables 4 and $9,531.1+126.0=657.1 \mu \mu \mathrm{f}$, which is thus seen to be about 5 per cent too large.

It is evident that this method is applicable in the general case of the calculation of the capacity of lead-in wires. To go into all the types of lead-in wires which occur in practice would take us too far afield. It is clear, however, that the formulas already given should cover usual arrangements in so far as the capacity of the lead-in wires in themselves are concerned. To take into account their effect upon the other parts of the antenna system it will usually suffice to make some simplifying assumption as was done in the preceding example, since this mutual effect is a relatively small part of the whole capacity. 


\section{TABLES FOR ANTENNA CAPACITY CALCULATION}

Three of the following tables give directly the capacities of three simple forms of antennas; they are Tables 2, 4, and 9. The other tables are auxiliary to certain of the formulas.

TABLE 1.-Values of the constant $K$ for use in formula (18) and for horizontal wires in general

[The argument to be used is either $\frac{2 h}{l}$ or $\frac{l}{2 h}$, according to which is less than unity]

\begin{tabular}{|r|r||r|r|r|r|}
\hline \multicolumn{1}{|c|}{$\frac{2 h}{l}$} & \multicolumn{1}{|c|}{$K$} & $\frac{l}{2 h}$ & \multicolumn{1}{|c|}{$K$} & $\frac{l}{2 h}$ & \multicolumn{1}{|c|}{$K$} \\
\hline 0 & 0 & 1.00 & 0.336 & 0.50 & 0.541 \\
0.1 & 0.042 & .95 & .350 & .45 & .576 \\
.2 & .082 & .90 & .364 & .40 & .617 \\
.3 & .121 & .85 & .379 & .35 & .664 \\
.4 & .157 & .80 & .396 & .30 & .721 \\
.5 & .191 & .75 & .414 & .25 & .790 \\
.6 & .223 & .70 & .435 & .20 & .874 \\
.7 & .254 & .65 & .457 & .15 & .990 \\
.8 & .283 & .60 & .482 & .10 & 1.155 \\
.9 & .310 & .55 & .510 & .05 & 1.445 \\
1.0 & .336 & .50 & .541 & $\ldots$ \\
\hline
\end{tabular}

Further values may be calculated from the formulas

$$
K=\frac{\frac{2 h}{l}-\left(\sqrt{1+\left(\frac{2 h}{l}\right)^{2}}-1\right)}{2.303}+\log _{10} \frac{1+\sqrt{1+\left(\frac{2 h}{l}\right)^{2}}}{2} \text { for } \frac{2 h}{l} \risingdotseq 1
$$

and

$$
K=\frac{0.3069-\frac{2 h}{l}\left(\sqrt{1+\left(\frac{l}{2 h}\right)^{2}}-1\right)}{2.303}+\log _{10} \frac{\frac{l}{2 h}+\sqrt{1+\left(\frac{l}{2 h}\right)^{2}}}{\frac{l}{2 h}} \text { for } \frac{l}{2 h} \risingdotseq 1
$$

TABLE 2.-Constants for single-wire horizontal antennas

[Symbols used above columns, etc., are defined on p. 606]

\begin{tabular}{|c|c|c|c|c|c|c|c|c|c|c|c|c|c|c|c|}
\hline \multirow{2}{*}{$l$ feet } & \multicolumn{3}{|c|}{$h=10$ feet } & \multicolumn{3}{|c|}{$h=15$ feet } & \multicolumn{3}{|c|}{$h=20$ feet } & \multicolumn{3}{|c|}{$h=25$ feet } & \multicolumn{3}{|c|}{$h=30$ feet } \\
\hline & $U$ & $C$ & $C / l$ & $U$ & $C$ & $C / l$ & $U$ & $C$ & $C / l$ & $U$ & $C$ & $C / l$ & $U$ & $C$ & $C / l$ \\
\hline & $\begin{array}{l}\text { 3. } 362 \\
3.567 \\
3.660 \\
3.712 \\
3.746\end{array}$ & \begin{tabular}{|l|}
21.89 \\
41.27 \\
60.30 \\
79.31 \\
98.24
\end{tabular} & $\begin{array}{l}2.189 \\
2.064 \\
2.011 \\
1.983 \\
1.965\end{array}$ & $\begin{array}{l}3.397 \\
3.629 \\
3.743 \\
3.810 \\
3.856\end{array}$ & \begin{tabular}{|l|}
21.67 \\
40.56 \\
58.99 \\
77.27 \\
95.44
\end{tabular} & $\begin{array}{l}2.167 \\
2.028 \\
1.966 \\
1.932 \\
1.909\end{array}$ & $\begin{array}{l}3.414 \\
3.663 \\
3.790 \\
3.868 \\
3.921\end{array}$ & \begin{tabular}{|l|}
22.57 \\
40.18 \\
58.26 \\
76.11 \\
93.85
\end{tabular} & $\begin{array}{l}2.257 \\
2.009 \\
1.942 \\
1.903 \\
1.877\end{array}$ & $\begin{array}{l}3.427 \\
3.684 \\
3.819 \\
3.905 \\
3.965\end{array}$ & $\begin{array}{l}21.48 \\
39.96 \\
57.82 \\
75.39 \\
92.88\end{array}$ & $\begin{array}{l}2.148 \\
1.998 \\
1.927 \\
1.885 \\
1.858\end{array}$ & $\begin{array}{l}3.434 \\
3.698 \\
3.839 \\
3.930 \\
3.995\end{array}$ & $\begin{array}{l}21.30 \\
39.81 \\
57.57 \\
74.91 \\
92.1\end{array}$ & $\begin{array}{l}2.130 \\
1.990 \\
1.919 \\
1.873 \\
1.842\end{array}$ \\
\hline & $\begin{array}{l}3.770 \\
3.801 \\
3.821 \\
3.848 \\
3.861\end{array}$ & $\begin{array}{l}117.1 \\
154.9 \\
192.6 \\
286.9 \\
381.3\end{array}$ & $\begin{array}{l}1.952 \\
1.936 \\
1.926 \\
1.913 \\
1.906\end{array}$ & $\begin{array}{l}3.888 \\
3.931 \\
3.958 \\
3.997 \\
4.017\end{array}$ & $\begin{array}{l}113.6 \\
149.8 \\
186.0 \\
276.2 \\
366.4\end{array} \mid$ & $\begin{array}{l}1.893 \\
1.872 \\
1.860 \\
1.841 \\
1.832\end{array}$ & $\begin{array}{l}3.961 \\
4.013 \\
4.047 \\
4.096 \\
4.122\end{array}$ & $\begin{array}{l}111.5 \\
146.7 \\
181.9 \\
269.5 \\
357.1\end{array}$ & $\begin{array}{l}1.858 \\
1.834 \\
1.819 \\
1.797 \\
1.786\end{array}$ & $\begin{array}{l}\text { 4. } 009 \\
4.070 \\
4.110 \\
4.168 \\
4.199\end{array}$ & $\begin{array}{l}110.2 \\
144.7 \\
179.1 \\
264.9 \\
350.6\end{array}$ & $\begin{array}{l}1.836 \\
1.809 \\
1.791 \\
1.766 \\
1.753\end{array}$ & $\begin{array}{l}4.044 \\
4.111 \\
4.157 \\
4.223 \\
4.259\end{array}$ & $\begin{array}{l}109.2 \\
143.2 \\
177.0 \\
261.4 \\
345.6\end{array}$ & $\begin{array}{l}1.820 \\
1.790 \\
1.770 \\
1.743 \\
1.728\end{array}$ \\
\hline & \multicolumn{3}{|c|}{$h=40$ feet } & \multicolumn{3}{|c|}{$h=50$ feet } & \multicolumn{3}{|c|}{$h=60$ feet } & \multicolumn{3}{|c|}{$h=80$ feet } & \multicolumn{3}{|c|}{$h=100$ feet } \\
\hline & $\begin{array}{l}3.442 \\
3.715 \\
3.862 \\
3.964 \\
4.036\end{array}$ & $\begin{array}{l}21.38 \\
39.64 \\
57.17 \\
74.27 \\
91.2\end{array}$ & $\begin{array}{l}2.138 \\
1.982 \\
1.906 \\
1.856 \\
1.824\end{array}$ & $\begin{array}{l}3.447 \\
3.728 \\
3.881 \\
3.985 \\
4.061\end{array}$ & \begin{tabular}{|l|}
21.35 \\
39.5 \\
56.9 \\
73.9 \\
90.6
\end{tabular} & $\begin{array}{l}2.135 \\
1.974 \\
1.896 \\
1.847 \\
1.812\end{array}$ & $\begin{array}{l}3.451 \\
3.735 \\
3.891 \\
3.999 \\
4.078\end{array}$ & \begin{tabular}{|l|}
21.3 \\
39.4 \\
56.75 \\
73.6 \\
90.2
\end{tabular} & $\begin{array}{l}2.135 \\
1.970 \\
1.892 \\
1.840 \\
1.805\end{array}$ & $\begin{array}{l}3.455 \\
3.743 \\
3.905 \\
4.016 \\
4.100\end{array}$ & \begin{tabular}{|l|}
21.3 \\
39.3 \\
56.5 \\
73.3 \\
89.8
\end{tabular} & $\begin{array}{l}2.130 \\
1.966 \\
1.885 \\
1.833 \\
1.795\end{array}$ & $\begin{array}{l}3.458 \\
3.748 \\
3.913 \\
4.029 \\
4.113\end{array}$ & $\begin{array}{l}21.3 \\
39.3 \\
56.4 \\
73.1 \\
89.5\end{array}$ & $\begin{array}{l}2.128 \\
1.964 \\
1.881 \\
1.827 \\
1.789\end{array}$ \\
\hline $\begin{array}{l}1 . \\
20\end{array}$ & $\begin{array}{l}4.091 \\
4.169 \\
4.222 \\
4.303 \\
4.348\end{array}$ & $\begin{array}{l}107.9 \\
141.2 \\
174.3 \\
256.6 \\
338.5\end{array}$ & $\begin{array}{l}1.799 \\
1.765 \\
1.743 \\
1.711 \\
1.692\end{array}$ & $\begin{array}{l}\text { 4. } 120 \\
4.206 \\
4.266 \\
4.358 \\
4.411\end{array}$ & $\begin{array}{l}107.2 \\
140.0 \\
172.5 \\
253.3 \\
333.7\end{array}$ & $\begin{array}{l}1.787 \\
1.750 \\
1.725 \\
1.687 \\
1.668\end{array}$ & $\begin{array}{l}\text { 4. } 140 \\
4.232 \\
4.290 \\
4.398 \\
4.458\end{array}$ & $\begin{array}{l}106.7 \\
139.1 \\
171.3 \\
251.0 \\
330.2\end{array}$ & $\begin{array}{l}1.778 \\
1.739 \\
1.713 \\
1.673 \\
1.651\end{array}$ & $\begin{array}{l}4.167 \\
4.265 \\
4.337 \\
4.453 \\
4.523\end{array}$ & $\left|\begin{array}{l}169.7 \\
247.9 \\
325.4\end{array}\right|$ & $\begin{array}{l}1.767 \\
1.726 \\
1.697 \\
1.653 \\
1.627\end{array}$ & $\begin{array}{l}4.182 \\
4.286 \\
4.362 \\
4.489 \\
4.567\end{array}$ & $\begin{array}{l}105.6 \\
137.4 \\
168.7 \\
245.9 \\
322.3\end{array}$ & $\begin{array}{l}1.760 \\
1.718 \\
1.687 \\
1.639 \\
1.612\end{array}$ \\
\hline
\end{tabular}

DIAMETER OF WIRE $=0.06$ INCH $=0.005$ FOOT 
TABLE 2.-Constants for single-wire horizontal antennas-Continued DIAMETER OF WIRE $=0.12$ INCH $=0.01$ FOOT

\begin{tabular}{|c|c|c|c|c|c|c|c|c|c|c|c|c|c|c|c|}
\hline \multirow{2}{*}{$l$ feet } & \multicolumn{3}{|c|}{$h=10$ feet } & \multicolumn{3}{|c|}{$h=15$ feet } & \multicolumn{3}{|c|}{$h=20$ feet } & \multicolumn{3}{|c|}{$h=25$ feet } & \multicolumn{3}{|c|}{$h=30$ feet } \\
\hline & $U$ & $C$ & $C / l$ & $U$ & $C$ & $C / l$ & $U$ & $C$ & $C / l$ & $U$ & $C$ & $C / l$ & $U$ & $C$ & $C / l$ \\
\hline & $\begin{array}{l}3.061 \\
3.266 \\
3.359 \\
3.411 \\
3.445\end{array}$ & $\begin{array}{r}24.0 \\
45.1 \\
65.7 \\
86.3 \\
106.8\end{array}$ & $\begin{array}{l}2.404 \\
2.254 \\
2.191 \\
2.158 \\
2.136\end{array}$ & $\begin{array}{l}3.096 \\
3.328 \\
3.442 \\
3.509 \\
3.555\end{array}$ & $\begin{array}{r}23.8 \\
44.2 \\
64.2 \\
83.9 \\
103.5\end{array}$ & $\begin{array}{l}2.377 \\
2.212 \\
2.138 \\
2.098 \\
2.070\end{array}$ & $\begin{array}{l}3.113 \\
3.362 \\
3.489 \\
3.567 \\
3.620\end{array}$ & $\begin{array}{r}23.6 \\
43.8 \\
63.3 \\
82.5 \\
101.6\end{array}$ & $\begin{array}{l}2.364 \\
2.189 \\
2.109 \\
2.064 \\
2.033\end{array}$ & $\begin{array}{l}3.126 \\
3.383 \\
3.518 \\
3.304 \\
3.684\end{array}$ & $\begin{array}{r}23.5 \\
43.5 \\
62.8 \\
81.7 \\
100.4\end{array}$ & $\begin{array}{l}2.354 \\
2.176 \\
2.091 \\
2.042 \\
2.008\end{array}$ & $\begin{array}{l}3.133 \\
3.397 \\
3.536 \\
3.629 \\
3.694\end{array}$ & \begin{tabular}{l|}
23.5 \\
43.3 \\
62.4 \\
81.1 \\
99.6
\end{tabular} & $\begin{array}{l}2.349 \\
2.166 \\
2.080 \\
2.028 \\
1.992\end{array}$ \\
\hline \multirow[t]{2}{*}{$\begin{array}{l}60 \\
80 \\
100 \\
150 \\
200\end{array}$} & $\begin{array}{l}3.469 \\
3.500 \\
3.520 \\
3.547 \\
\text { 3. } 560\end{array}$ & $\begin{array}{l}127.3 \\
168.2 \\
209.1 \\
311.2 \\
413.5\end{array}$ & $\begin{array}{l}2.122 \\
2.102 \\
2.091 \\
2.075 \\
2.068\end{array}$ & $\begin{array}{l}\text { 3. } 587 \\
\text { 3. } 630 \\
3.657 \\
\text { 3. } 659 \\
\text { 3. } 716\end{array}$ & $\begin{array}{l}123.1 \\
162.2 \\
201.3 \\
298.7 \\
396.1\end{array}$ & $\begin{array}{l}2.052 \\
2.028 \\
2.013 \\
1.991 \\
1.980\end{array}$ & \begin{tabular}{|}
3.660 \\
3.712 \\
3.754 \\
3.795 \\
3.821
\end{tabular} & $\begin{array}{l}120.7 \\
158.6 \\
196.1 \\
290.9 \\
385.3\end{array}$ & $\begin{array}{l}2.012 \\
1.982 \\
1.961 \\
1.939 \\
1.926\end{array}$ & $\begin{array}{l}3.708 \\
3.769 \\
3.809 \\
3.867 \\
3.898\end{array}$ & $\begin{array}{l}119.1 \\
156.2 \\
193.2 \\
285.5 \\
377.6\end{array}$ & $\begin{array}{l}1.985 \\
1.952 \\
1.932 \\
1.903 \\
1.888\end{array}$ & $\begin{array}{l}3.743 \\
3.810 \\
3.856 \\
3.922 \\
3.958\end{array}$ & $\begin{array}{l}118.0 \\
154.5 \\
190.9 \\
281.5 \\
371.9\end{array}$ & $\begin{array}{l}1.967 \\
1.931 \\
1.909 \\
1.877 \\
1.860\end{array}$ \\
\hline & \multicolumn{3}{|c|}{$h=40$ feet } & \multicolumn{3}{|c|}{$h=50$ feet } & \multicolumn{3}{|c|}{$h=60$ feet } & \multicolumn{3}{|c|}{$h=80$ feet } & \multicolumn{3}{|c|}{$h=100$ feet } \\
\hline & $\begin{array}{l}3.141 \\
3.414 \\
3.561 \\
3.663 \\
3.735\end{array}$ & $\begin{array}{l}23.4 \\
43.1 \\
62.0 \\
80.4 \\
98.5\end{array}$ & $\begin{array}{l}2.343 \\
2.156 \\
2.067 \\
2.009 \\
1.971\end{array}$ & $\begin{array}{l}3.146 \\
3.427 \\
3.580 \\
3.684 \\
3.760\end{array}$ & $\begin{array}{l}23.4 \\
43.0 \\
61.8 \\
79.9 \\
97.8\end{array}$ & $\begin{array}{l}2.339 \\
2.148 \\
2.059 \\
1.998 \\
1.957\end{array}$ & $\begin{array}{l}\text { 3. } 150 \\
\text { 3. 434 } \\
\text { 3. } 590 \\
\text { 3. } 698 \\
\text { 3. 777 }\end{array}$ & $\begin{array}{l}23.4 \\
42.9 \\
61.5 \\
79.6 \\
97.4\end{array}$ & $\begin{array}{l}2.336 \\
2.144 \\
2.050 \\
1.990 \\
1.949\end{array}$ & $\begin{array}{l}3.154 \\
3.442 \\
3.604 \\
3.715 \\
3.801\end{array}$ & $\begin{array}{l}23.3 \\
42.8 \\
61.3 \\
79.2 \\
96.8\end{array}$ & $\begin{array}{l}2.334 \\
2.138 \\
2.042 \\
1.981 \\
1.936\end{array}$ & \begin{tabular}{|l|}
3.157 \\
3.447 \\
3.612 \\
3.728 \\
3.812
\end{tabular} & \begin{tabular}{l|}
23.3 \\
42.7 \\
61.1 \\
79.0 \\
96.5
\end{tabular} & $\begin{array}{l}2.330 \\
2.135 \\
2.038 \\
1.974 \\
1.931\end{array}$ \\
\hline $\begin{array}{l}60 \\
80\end{array}$ & $\begin{array}{l}3.790 \\
3.868 \\
3.921 \\
4.002 \\
4.047\end{array}$ & $\begin{array}{l}116.5 \\
152.2 \\
187.7 \\
275.9 \\
363.7\end{array}$ & $\begin{array}{l}1.942 \\
1.902 \\
1.877 \\
1.839 \\
1.818\end{array}$ & $\begin{array}{l}\text { 3. } 819 \\
\text { 3. } 905 \\
\text { 3. } 965 \\
\text { 4. 057 } \\
4.110\end{array}$ & $\begin{array}{l}115.6 \\
150.8 \\
185.6 \\
272.1 \\
358.2\end{array}$ & \begin{tabular}{|l|}
1.927 \\
1.885 \\
1.856 \\
1.814 \\
1.791
\end{tabular} & $\begin{array}{l}\text { 3. } 839 \\
\text { 3. } 931 \\
3.995 \\
4.097 \\
4.157\end{array}$ & $\begin{array}{l}115.0 \\
149.8 \\
184.2 \\
269.5 \\
354.1\end{array}$ & $\begin{array}{l}1.917 \\
1.872 \\
1.842 \\
1.797 \\
1.770\end{array}$ & $\begin{array}{l}3.866 \\
3.964 \\
4.036 \\
4.152 \\
4.220\end{array}$ & $\begin{array}{l}114.2 \\
148.5 \\
182.4 \\
265.9 \\
348.6\end{array}$ & $\begin{array}{l}1.903 \\
1.856 \\
1.824 \\
1.773 \\
1.743\end{array}$ & $\begin{array}{l}3.881 \\
\text { 3. } 985 \\
4.061 \\
4.188 \\
4.266\end{array}$ & \begin{tabular}{|}
113.8 \\
147.8 \\
181.2 \\
263.6 \\
345.1
\end{tabular} & $\begin{array}{l}1.897 \\
1.847 \\
1.812 \\
1.757 \\
1.726\end{array}$ \\
\hline
\end{tabular}

DIAMETER OF WIRE $=0.18 \mathrm{INCH}=0.015$ FOOT

\begin{tabular}{|c|c|c|c|c|c|c|c|c|c|c|c|c|c|c|c|}
\hline \multirow{2}{*}{$\frac{l \text { feet }}{10}$} & \multicolumn{3}{|c|}{$h=10$ feet } & \multicolumn{3}{|c|}{$h=15$ feet } & \multicolumn{3}{|c|}{$h=20$ feet } & \multicolumn{3}{|c|}{$h=25$ feet } & \multicolumn{3}{|c|}{$h=30$ foet } \\
\hline & $\begin{array}{l}2.885 \\
3.090 \\
3.183 \\
3.235 \\
3.269\end{array}$ & $\begin{array}{r}25.5 \\
47.6 \\
69.4 \\
91.0 \\
112.6\end{array}$ & $\begin{array}{l}2.549 \\
2.382 \\
2.312 \\
2.277 \\
2.252\end{array}$ & $\begin{array}{l}2.920 \\
3.152 \\
3.266 \\
3.333 \\
3.379\end{array}$ & \begin{tabular}{|r|}
25.2 \\
46.7 \\
67.6 \\
88.3 \\
108.9
\end{tabular} & $\begin{array}{l}2.521 \\
2.335 \\
2.253 \\
2.208 \\
2.178\end{array}$ & $\begin{array}{l}2.937 \\
3.186 \\
3.313 \\
3.391 \\
3.444\end{array}$ & \begin{tabular}{|r|}
25.1 \\
46.2 \\
66.6 \\
86.8 \\
106.8
\end{tabular} & $\begin{array}{l}2.506 \\
2.310 \\
2.222 \\
2.170 \\
2.137\end{array}$ & $\begin{array}{l}2.950 \\
3.207 \\
3.342 \\
3.428 \\
3.488\end{array}$ & \begin{tabular}{|}
24.9 \\
45.9 \\
66.1 \\
85.9 \\
105.5
\end{tabular} & $\begin{array}{l}2.495 \\
2.295 \\
2.202 \\
2.147 \\
2.110\end{array}$ & $\begin{array}{l}2.957 \\
\text { 3. } 221 \\
\text { 3. 362 } \\
3.453 \\
3.518\end{array}$ & $\begin{array}{r}24.9 \\
45.7 \\
65.7 \\
85.3 \\
104.6\end{array}$ & $\begin{array}{l}2.489 \\
2.285 \\
2.189 \\
2.132 \\
2.092\end{array}$ \\
\hline \multirow[t]{2}{*}{$\begin{array}{l}60-\ldots \\
80-\ldots \\
100 \\
150 \\
200\end{array}$} & $\begin{array}{l}3.293 \\
3.324 \\
3.344 \\
3.369 \\
3.384\end{array}$ & $\begin{array}{l}134.1 \\
177.1 \\
220.1 \\
327.7 \\
435.0\end{array}$ & $\begin{array}{l}2.235 \\
2.214 \\
2.201 \\
2.185 \\
2.175\end{array}$ & $\begin{array}{l}3.411 \\
\text { 3. } 451 \\
\text { 3. } 481 \\
3.520 \\
3.540\end{array}$ & $\begin{array}{l}129.5 \\
201.4 \\
211.4 \\
313.6 \\
415.0\end{array}$ & $\begin{array}{l}2.158 \\
2.131 \\
2.114 \\
2.091 \\
2.075\end{array}$ & $\begin{array}{l}\text { 3. 484 } \\
\text { 3. 536 } \\
\text { 3. 570 } \\
3.619 \\
3.645\end{array}$ & $\begin{array}{l}126.8 \\
166.5 \\
206.2 \\
305.1 \\
403.8\end{array}$ & $\begin{array}{l}2.112 \\
2.081 \\
2.062 \\
2.034 \\
2.019\end{array}$ & \begin{tabular}{|} 
3. 532 \\
3.592 \\
3.633 \\
3.691 \\
3.722
\end{tabular} & $\begin{array}{l}125.0 \\
163.9 \\
202.6 \\
299.1 \\
395.5\end{array}$ & $\begin{array}{l}2.083 \\
2.049 \\
2.026 \\
1.94 \\
1.978\end{array}$ & $\begin{array}{l}\text { 3. } 567 \\
\text { 3. } 634 \\
\text { 3. } 680 \\
\text { 3. } 746 \\
\text { 3. 782 }\end{array}$ & $\begin{array}{l}123.8 \\
162.0 \\
200.0 \\
294.7 \\
389.2\end{array}$ & $\begin{array}{l}2.063 \\
2.025 \\
2.000 \\
1.965 \\
1.946\end{array}$ \\
\hline & \multicolumn{3}{|c|}{$h=40$ feet } & \multicolumn{3}{|c|}{$h=50$ feet } & \multicolumn{3}{|c|}{$h=60$ feet } & \multicolumn{3}{|c|}{$h=80$ feet } & \multicolumn{3}{|c|}{$h=100$ feet } \\
\hline & $\begin{array}{l}2.965 \\
3.238 \\
3.385 \\
3.487 \\
3.559\end{array}$ & $\begin{array}{r}24.8 \\
45.5 \\
65.2 \\
84.4 \\
103.4\end{array}$ & $\begin{array}{l}2.482 \\
2.273 \\
2.174 \\
2.11 \\
2.068\end{array}$ & $\begin{array}{l}\text { 2. } 970 \\
\text { 3.251 } \\
3.404 \\
3.512 \\
3.584\end{array}$ & \begin{tabular}{|r|}
24.8 \\
45.3 \\
64.9 \\
83.8 \\
102.7
\end{tabular} & $\begin{array}{l}2.476 \\
2.264 \\
2.162 \\
2.096 \\
2.054\end{array}$ & $\begin{array}{l}2.974 \\
3.258 \\
3.414 \\
3.522 \\
3.601\end{array}$ & $\begin{array}{r}24.8 \\
45.2 \\
64.7 \\
83.6 \\
102.2\end{array}$ & $\begin{array}{l}2.475 \\
2.259 \\
2.150 \\
2.090 \\
2.044\end{array}$ & $\begin{array}{l}2.978 \\
3.266 \\
3.428 \\
3.559 \\
3.623\end{array}$ & $\begin{array}{r}24.7 \\
45.1 \\
64.4 \\
82.7 \\
101.6\end{array}$ & $\left|\begin{array}{l}2.472 \\
2.254 \\
2.147 \\
2.068 \\
2.032\end{array}\right|$ & $\begin{array}{l}\text { 2. } 981 \\
\text { 3. } 271 \\
\text { 3. } 436 \\
3.552 \\
3.636\end{array}$ & $\begin{array}{r}24.7 \\
45.0 \\
64.3 \\
82.9 \\
101.2\end{array}$ & $\begin{array}{l}2.469 \\
2.250 \\
2.142 \\
2.072 \\
2.024\end{array}$ \\
\hline $\begin{array}{l}150- \\
200\end{array}$ & $\begin{array}{l}3.614 \\
3.688 \\
3.745 \\
3.826 \\
3.871\end{array}$ & $\begin{array}{l}122.2 \\
159.7 \\
198.5 \\
288.6 \\
380.3\end{array}$ & $\begin{array}{l}2.037 \\
1.996 \\
1.965 \\
1.924 \\
1.902\end{array}$ & $\begin{array}{l}3.643 \\
3.729 \\
\text { 3. } 789 \\
\text { 3. } 881 \\
3.934\end{array}$ & $\begin{array}{l}121.2 \\
157.9 \\
194.2 \\
284.5 \\
374.2 \\
\end{array}$ & $\begin{array}{l}2.002 \\
1.974 \\
1.942 \\
1.897 \\
1.871\end{array}$ & $\begin{array}{l}3.663 \\
3.755 \\
3.819 \\
3.921 \\
3.981\end{array}$ & $\begin{array}{l}120.6 \\
156.8 \\
192.7 \\
281.6 \\
369.8\end{array}$ & $\begin{array}{l}2.010 \\
1.960 \\
1.927 \\
1.877 \\
1.849\end{array}$ & $\begin{array}{l}3.690 \\
3.788 \\
3.860 \\
3.97 \\
4.046\end{array}$ & $\begin{array}{l}119.7 \\
155.4 \\
190.7 \\
277.7 \\
363.8\end{array}$ & \begin{tabular}{|l|}
1.995 \\
1.942 \\
1.907 \\
1.851 \\
1.819 \\
\end{tabular} & $\begin{array}{l}3.705 \\
3.811 \\
3.885 \\
4.012 \\
4.110\end{array}$ & $\begin{array}{l}119.2 \\
154.5 \\
189.4 \\
275.2 \\
358.2\end{array}$ & $\begin{array}{l}1.987 \\
1.932 \\
1.894 \\
1.835 \\
1.791\end{array}$ \\
\hline
\end{tabular}


TABLE 2.-Constants for single-wire horizontal antennas-Continued DIAMETER OF WIRE $=0.24$ INCH $=0.02$ FOOT

\begin{tabular}{|c|c|c|c|c|c|c|c|c|c|c|c|c|c|c|c|}
\hline \multirow{2}{*}{$l$ feet } & \multicolumn{3}{|c|}{$h=10$ feet } & \multicolumn{3}{|c|}{$h=15$ feet } & \multicolumn{3}{|c|}{$h=20$ feet } & \multicolumn{3}{|c|}{$h=25$ feet } & \multicolumn{3}{|c|}{$h=30$ feet } \\
\hline & $U$ & $C$ & $C / l$ & $U$ & $C$ & $C / l$ & $U$ & $C$ & $C /$ & $U$ & $C$ & $C / l$ & $U$ & $C$ & $C / l$ \\
\hline ). & $\begin{array}{l}2.760 \\
2.965 \\
3.058 \\
3.110 \\
3.144\end{array}$ & $\begin{array}{r}26.7 \\
49.6 \\
72.2 \\
94.7 \\
117.0\end{array}$ & $\begin{array}{l}2.667 \\
2.482 \\
2.407 \\
2.366 \\
2.341\end{array}$ & $\begin{array}{l}2.795 \\
3.027 \\
3.141 \\
3.208 \\
3.254\end{array}$ & $\begin{array}{r}26.3 \\
48.6 \\
70.3 \\
91.8 \\
113.1\end{array}$ & $\begin{array}{l}2.634 \\
2.432 \\
2.343 \\
2.294 \\
2.262\end{array}$ & $\begin{array}{l}2.812 \\
3.061 \\
3.188 \\
3.266 \\
3.319\end{array}$ & \begin{tabular}{|r|}
26.2 \\
48.1 \\
69.3 \\
90.1 \\
111.2
\end{tabular} & $\begin{array}{l}2.617 \\
2.404 \\
2.309 \\
2.254 \\
2.224\end{array}$ & $\begin{array}{l}2.825 \\
3,082 \\
3.217 \\
3.303 \\
3.363\end{array}$ & $\begin{array}{r}26.0 \\
47.8 \\
68.6 \\
89.1 \\
109.4\end{array}$ & $\begin{array}{l}2.605 \\
2.388 \\
2.288 \\
2.228 \\
2.188\end{array}$ & $\begin{array}{l}2.832 \\
3.096 \\
3.237 \\
3.328 \\
3.393\end{array}$ & $\begin{array}{r}26.0 \\
47.6 \\
68.2 \\
88.5 \\
108.5\end{array}$ & $\begin{array}{l}2.599 \\
2.378 \\
2.274 \\
2.212 \\
2.170\end{array}$ \\
\hline $200 \ldots$ & $\begin{array}{l}3.168 \\
3.199 \\
3.219 \\
3.246 \\
3.259\end{array}$ & $\begin{array}{l}139.4 \\
184.1 \\
228.6 \\
340.1 \\
451.7\end{array}$ & $\begin{array}{l}2.323 \\
2.301 \\
2.286 \\
2.274 \\
2.258\end{array}$ & $\begin{array}{l}3.286 \\
3.329 \\
3.356 \\
3.395 \\
3.415\end{array}$ & $\begin{array}{l}134.4 \\
176.9 \\
219.3 \\
325.2 \\
431.0\end{array}$ & $\begin{array}{l}2.240 \\
2.212 \\
2.193 \\
2.168 \\
2.155\end{array}$ & $\begin{array}{l}3.359 \\
3.411 \\
3.445 \\
3.494 \\
3.520\end{array}$ & \begin{tabular}{|l|}
131.5 \\
172.6 \\
213.6 \\
316.0 \\
418.2
\end{tabular} & $\begin{array}{l}2.192 \\
2.158 \\
2.136 \\
2.107 \\
2.091\end{array}$ & \begin{tabular}{|l|}
3.407 \\
3.468 \\
3.508 \\
3.566 \\
3.597
\end{tabular} & $\begin{array}{l}129.6 \\
169.8 \\
209.8 \\
309.6 \\
409.2\end{array}$ & \begin{tabular}{|l|}
2.160 \\
2.122 \\
2.098 \\
2.064 \\
2.046
\end{tabular} & $\begin{array}{l}3.442 \\
3.509 \\
3.555 \\
3.621 \\
3.657\end{array}$ & $\begin{array}{l}128.3 \\
167.8 \\
207.0 \\
304.9 \\
402.5\end{array}$ & $\begin{array}{l}2.138 \\
2.098 \\
2.070 \\
2.033 \\
2.012\end{array}$ \\
\hline $200 \ldots$ & \multicolumn{3}{|c|}{$h=40$ feet } & \multicolumn{3}{|c|}{$h=50$ feet } & \multicolumn{3}{|c|}{$h=60$ feet } & \multicolumn{3}{|c|}{$h=80$ feet } & \multicolumn{3}{|c|}{$h=100$ feet } \\
\hline 10. & $\begin{array}{l}2.840 \\
3.113 \\
3.260 \\
3.362 \\
3.434\end{array}$ & $\begin{array}{r}25.9 \\
47.3 \\
67.7 \\
87.6 \\
107.2\end{array}$ & $\begin{array}{l}2.592 \\
2.364 \\
2.258 \\
2.189 \\
2.144\end{array}$ & $\begin{array}{l}2.845 \\
3.126 \\
3.279 \\
3.383 \\
3.459\end{array}$ & $\begin{array}{r}25.9 \\
47.1 \\
67.3 \\
87.1 \\
106.4\end{array}$ & $\begin{array}{l}2.587 \\
2.354 \\
2.245 \\
2.177 \\
2.128\end{array}$ & $\begin{array}{l}2.849 \\
3.133 \\
3.289 \\
3.397 \\
3.476\end{array}$ & $\begin{array}{r}25.8 \\
47.0 \\
67.1 \\
86.7 \\
105.9\end{array}$ & $\begin{array}{l}2.583 \\
2.349 \\
2.238 \\
2.166 \\
2.118\end{array}$ & $\begin{array}{l}2.853 \\
3.141 \\
3.303 \\
3.414 \\
3.502\end{array}$ & $\begin{array}{r}25.8 \\
46.9 \\
66.8 \\
86.2 \\
105.1\end{array}$ & \begin{tabular}{|l|}
2.580 \\
2.343 \\
2.228 \\
2.156 \\
2.102
\end{tabular} & $\begin{array}{l}2.856 \\
3.146 \\
3.311 \\
3.427 \\
3.511\end{array}$ & $\begin{array}{r}25.8 \\
46.8 \\
66.7 \\
85.9 \\
104.8\end{array}$ & $\begin{array}{l}2.577 \\
2.340 \\
2.223 \\
2.148 \\
2.096\end{array}$ \\
\hline $\begin{array}{l}100 \\
150 \\
200\end{array}$ & $\begin{array}{l}3.489 \\
3.567 \\
3.620 \\
3.701 \\
3.746\end{array}$ & $\begin{array}{l}126.6 \\
165.1 \\
203.3 \\
298.3 \\
393.0\end{array}$ & $\begin{array}{l}2.110 \\
2.064 \\
2.033 \\
1.989 \\
1.965\end{array}$ & $\begin{array}{l}3.518 \\
3.604 \\
3.664 \\
3.756 \\
3.809\end{array}$ & $\begin{array}{l}125.5 \\
163.4 \\
200.9 \\
293.9 \\
386.5\end{array}$ & $\begin{array}{l}2.092 \\
2.042 \\
2.009 \\
1.959 \\
1.932\end{array}$ & $\begin{array}{l}3.538 \\
3.630 \\
3.694 \\
3.796 \\
3.856\end{array}$ & \begin{tabular}{|l|}
124.8 \\
162.2 \\
199.2 \\
290.8 \\
381.7
\end{tabular} & $\begin{array}{l}2.080 \\
2.028 \\
1.992 \\
1.939 \\
1.908\end{array}$ & $\begin{array}{l}3.565 \\
3.663 \\
3.735 \\
3.851 \\
3.921\end{array}$ & $\begin{array}{l}123.9 \\
160.7 \\
197.1 \\
286.7 \\
375.4\end{array}$ & $\begin{array}{l}2.065 \\
2.009 \\
1.971 \\
1.911 \\
1.877\end{array}$ & $\begin{array}{l}3.580 \\
3.684 \\
3.760 \\
3.887 \\
3.965\end{array}$ & $\begin{array}{l}123.4 \\
159.8 \\
195.7 \\
284.0 \\
371.3\end{array}$ & $\begin{array}{l}2.056 \\
1.998 \\
1.957 \\
1.893 \\
1.856\end{array}$ \\
\hline
\end{tabular}

TABLE 3.-Values of the constant $k$ used in formula (19) and for vertical wires in general

[The argument is $\frac{h^{\prime}}{m}$ or $\frac{m}{h^{\prime}}$ according to which is less than unity]

\begin{tabular}{|r|r||r|r|r|r|}
\hline$\frac{h^{\prime}}{m}$ & $k$ & $\frac{h^{\prime}}{m}$ & $k$ & $\frac{m}{h^{\prime}}$ & $k$ \\
\hline & & 0.3 & 0.280 & 1.0 & 0.207 \\
0.02 & 0.403 & .4 & .261 & .9 & .202 \\
.04 & .384 & .5 & .247 & .8 & .196 \\
.06 & .369 & .6 & .236 & .7 & .190 \\
.08 & .356 & .7 & .227 & .6 & .184 \\
.10 & .345 & .8 & .219 & .5 & .177 \\
.15 & .323 & .9 & .2125 & .4 & .170 \\
.20 & .305 & 1.0 & .207 & .3 & .162 \\
.25 & .291 & & & .2 & .153 \\
.30 & .280 & & & 0 & .144 \\
& & & & 0.133 \\
\hline
\end{tabular}

Further values may be calculated from the formula

$$
\begin{gathered}
k=0.4343+\frac{h^{\prime}}{m} \log _{10} \frac{4 h^{\prime}}{m}+\left(1+\frac{h^{\prime}}{m}\right) \log _{10}\left(1+\frac{h^{\prime}}{m}\right) \\
-\left(1+\frac{2 h^{\prime}}{m}\right) \log _{10}\left(1+\frac{2 h^{\prime}}{m}\right) \text { for } \frac{h^{\prime}}{m} \equiv 1
\end{gathered}
$$

and

$$
\begin{aligned}
& k=0.1333+\frac{h^{\prime}}{m}\left(1+\frac{m}{h^{\prime}}\right) \log _{10}\left(1+\frac{m}{h^{\prime}}\right) \\
& -\frac{2 h^{\prime}}{m}\left(1+\frac{m}{2 h^{\prime}}\right) \log \left(1+\frac{m}{2 h^{\prime}}\right) \text { for } \frac{m}{h^{\prime}} \equiv 1
\end{aligned}
$$


TABLE 4.-Constants for single-wire vertical antennas

[Symbols used above columns, etc., are defined on p. 606]

DIAMETER OF WIRE $=0.06$ INCH $=0.005$ FOOT

\begin{tabular}{|c|c|c|c|c|c|c|c|c|c|c|c|c|}
\hline \multirow{2}{*}{$m$ feet } & \multicolumn{3}{|c|}{$h^{\prime}=5$ feet } & \multicolumn{3}{|c|}{$h^{\prime}=10$ feet } & \multicolumn{3}{|c|}{$h^{\prime}=20$ feet } & \multicolumn{3}{|c|}{$h^{\prime}=50$ feet } \\
\hline & $U$ & C & $C / m$ & $U$ & C & $C / m$ & $U$ & $C$ & $C / m$ & $U$ & $C$ & $C / m$ \\
\hline $\begin{array}{l}10 \ldots \\
20 \ldots \\
30 \ldots \\
40 \ldots\end{array}$ & $\begin{array}{l}\text { 3. } 355 \\
3.612 \\
3.762 \\
3.872\end{array}$ & $\begin{array}{l}21.9 \\
40.8 \\
58.7 \\
76.0\end{array}$ & $\begin{array}{l}2.194 \\
2.038 \\
1.956 \\
1.901\end{array}$ & $\begin{array}{l}3.395 \\
3.656 \\
3.806 \\
3.913\end{array}$ & $\begin{array}{l}21.7 \\
40.3 \\
58.0 \\
75.2\end{array}$ & $\begin{array}{l}2.168 \\
2.013 \\
1.934 \\
1.881\end{array}$ & $\begin{array}{l}3.425 \\
3.696 \\
3.850 \\
3.957\end{array}$ & $\begin{array}{l}21.5 \\
39.8 \\
57.4 \\
74.4\end{array}$ & $\begin{array}{l}2.149 \\
1.992 \\
1.912 \\
1.860\end{array}$ & $\begin{array}{l}3.449 \\
3.733 \\
3.895 \\
4.008\end{array}$ & \begin{tabular}{l|}
21.3 \\
39.4 \\
56.7 \\
73.4
\end{tabular} & $\begin{array}{l}2.134 \\
1.972 \\
1.890 \\
1.836\end{array}$ \\
\hline $\begin{array}{l}50 \ldots \\
60 \ldots \\
80 \ldots \\
100\end{array}$ & $\begin{array}{l}3.956 \\
4.025 \\
4.138 \\
4.224\end{array}$ & $\begin{array}{r}93.0 \\
109.7 \\
142.3 \\
174.2\end{array}$ & $\begin{array}{l}1.860 \\
1.828 \\
1.779 \\
1.742\end{array}$ & $\begin{array}{l}3.996 \\
4.063 \\
4.173 \\
4.257\end{array}$ & $\begin{array}{r}92.1 \\
108.7 \\
141.1 \\
172.9\end{array}$ & $\begin{array}{l}1.842 \\
1.812 \\
1.764 \\
1.729\end{array}$ & $\begin{array}{l}4.040 \\
4.107 \\
4.214 \\
4.297\end{array}$ & $\begin{array}{r}91.1 \\
107.5 \\
139.7 \\
171.3\end{array}$ & $\begin{array}{l}1.822 \\
1.792 \\
1.746 \\
1.713\end{array}$ & $\begin{array}{l}4.094 \\
4.163 \\
4.272 \\
4.355\end{array}$ & $\begin{array}{r}89.9 \\
106.1 \\
137.8 \\
169.0\end{array}$ & $\begin{array}{l}1.798 \\
1.768 \\
1.722 \\
1.690\end{array}$ \\
\hline
\end{tabular}

DIAMETER OF WIRE $=0.12$ INCH $=0.01$ FOOT

\begin{tabular}{|c|c|c|c|c|c|c|c|c|c|c|c|c|c|c|c|}
\hline \multirow{2}{*}{$m$ feet } & \multicolumn{3}{|c|}{$\dot{h}^{\prime}=0$} & \multicolumn{3}{|c|}{$h^{\prime}=5$ feet } & \multicolumn{3}{|c|}{$h^{\prime}=10$ feet } & \multicolumn{3}{|c|}{$h^{\prime}=20$ feet } & \multicolumn{3}{|c|}{$h^{\prime}=50$ feet } \\
\hline & $U$ & $C$ & $C / m$ & $U$ & $C$ & $C / m$ & $\sigma$ & $C$ & $C / m$ & $U$ & $C$ & $C / m$ & $U$ & $C$ & $C / m$ \\
\hline & $\begin{array}{l}2.867 \\
3.168 \\
3.344 \\
3.469\end{array}$ & $\begin{array}{l}25.7 \\
46.5 \\
66.0 \\
84.9\end{array}$ & $\begin{array}{l}\text { 2. } 567 \\
\text { 2. } 323 \\
2.201 \\
\text { 2. } 122\end{array}$ & $\begin{array}{l}3.054 \\
3.311 \\
3.461 \\
3.571\end{array}$ & \begin{tabular}{l|}
24.1 \\
44.5 \\
63.8 \\
82.4
\end{tabular} & $\begin{array}{l}2.410 \\
2.223 \\
2.127 \\
2.061\end{array}$ & $\begin{array}{l}3.094 \\
3.355 \\
3.505 \\
3.612\end{array}$ & $\begin{array}{l}23.8 \\
43.9 \\
63.0 \\
81.5\end{array}$ & $\begin{array}{l}2.379 \\
2.194 \\
2.100 \\
2.038\end{array}$ & \begin{tabular}{|l|}
3.124 \\
3.395 \\
3.549 \\
3.656
\end{tabular} & $\begin{array}{l}23.6 \\
43.4 \\
62.2 \\
80.5\end{array}$ & \begin{tabular}{|}
2.356 \\
2.168 \\
2.074 \\
2.013
\end{tabular} & $\begin{array}{l}3.148 \\
3.432 \\
3.594 \\
3.707\end{array}$ & $\begin{array}{l}23.4 \\
42.9 \\
61.4 \\
79.4\end{array}$ & $\begin{array}{l}2.338 \\
2.144 \\
2.048 \\
1.983\end{array}$ \\
\hline 50 & $\begin{array}{l}3.566 \\
3.645 \\
3.770 \\
3.867\end{array}$ & $\begin{array}{l}103.2 \\
121.2 \\
156.2 \\
190.3\end{array}$ & $\begin{array}{l}2.064 \\
2.020 \\
1.952 \\
1.903\end{array}$ & $\begin{array}{l}3.665 \\
3.724 \\
3.837 \\
3.923\end{array}$ & $\begin{array}{l}100.7 \\
118.6 \\
153.5 \\
187.6\end{array}$ & $\begin{array}{l}2.014 \\
1.977 \\
1.919 \\
1.876\end{array}$ & $\begin{array}{l}3.695 \\
3.762 \\
3.872 \\
3.956\end{array}$ & $\begin{array}{r}99.6 \\
117.4 \\
152.1 \\
186.0\end{array}$ & $\begin{array}{l}1.992 \\
1.957 \\
1.901 \\
1.860\end{array}$ & $\begin{array}{l}3.739 \\
3.806 \\
3.913 \\
3.996 \\
\end{array}$ & \begin{tabular}{|}
98.4 \\
116.0 \\
150.5 \\
184.2
\end{tabular} & $\begin{array}{l}1.968 \\
1.933 \\
1.881 \\
1.842\end{array}$ & $\begin{array}{l}3.793 \\
3.862 \\
3.970 \\
4.054\end{array}$ & $\begin{array}{r}97.0 \\
114.3 \\
148.3 \\
181.6\end{array}$ & $\begin{array}{l}1.940 \\
1.905 \\
1.854 \\
1.816\end{array}$ \\
\hline
\end{tabular}

DIAMETER OF WIRE $=0.18 \mathrm{INCH}=0.015$ FOOT

\begin{tabular}{|c|c|c|c|c|c|c|c|c|c|c|c|c|}
\hline \multirow{2}{*}{$m$ leet } & \multicolumn{3}{|c|}{$h^{\prime}=5$ feet } & \multicolumn{3}{|c|}{$h^{\prime}=10$ feet } & \multicolumn{3}{|c|}{$h^{\prime}=20$ feet } & \multicolumn{3}{|c|}{$h^{\prime}=50$ feet } \\
\hline & $U$ & $C$ & $C / m$ & $U$ & $C$ & $C / m$ & $U$ & $C$ & $C / m$ & $U$ & $C$ & $C / m$ \\
\hline $\begin{array}{l}10 . \\
20 . \\
30 . \\
40 .\end{array}$ & $\begin{array}{l}2.878 \\
3.135 \\
3.285 \\
3.395\end{array}$ & $\begin{array}{l}25.6 \\
46.9 \\
67.2 \\
86.7\end{array}$ & $\begin{array}{l}2.557 \\
2.348 \\
2.240 \\
2.168\end{array}$ & $\begin{array}{l}2.918 \\
3.179 \\
3.329 \\
3.436\end{array}$ & \begin{tabular}{l|}
25.2 \\
46.3 \\
66.3 \\
85.7
\end{tabular} & $\begin{array}{l}2.522 \\
2.315 \\
2.211 \\
2.142\end{array}$ & $\begin{array}{l}\text { 2. } 948 \\
\text { 3. } 219 \\
\text { 3. } 373 \\
\text { 3. } 480\end{array}$ & \begin{tabular}{l|}
25.0 \\
45.7 \\
65.5 \\
84.6
\end{tabular} & $\begin{array}{l}2.497 \\
2.286 \\
2.182 \\
2.115\end{array}$ & $\begin{array}{l}2.972 \\
3.256 \\
3.418 \\
3.531\end{array}$ & $\begin{array}{l}24.8 \\
45.2 \\
64.6 \\
83.4\end{array}$ & $\begin{array}{l}\text { 2. } 476 \\
2.260 \\
2.153 \\
2.084\end{array}$ \\
\hline $\begin{array}{l}50 \\
60 \\
80 \\
100\end{array}$ & $\begin{array}{l}3.479 \\
3.548 \\
3.661 \\
3.747\end{array}$ & $\begin{array}{l}105.8 \\
124.5 \\
160.8 \\
196.4\end{array}$ & $\begin{array}{l}2.116 \\
2.075 \\
2.010 \\
1.964\end{array}$ & $\begin{array}{l}\text { 3. } 519 \\
3.586 \\
\text { 3. } 696 \\
3.780\end{array}$ & $\begin{array}{l}104.6 \\
123.2 \\
159.3 \\
194.7\end{array}$ & $\begin{array}{l}2.092 \\
2.052 \\
1.981 \\
1.947\end{array}$ & $\begin{array}{l}\text { 3. } 563 \\
3.630 \\
3.737 \\
3.820\end{array}$ & $\begin{array}{l}103.3 \\
121.7 \\
157.6 \\
192.7\end{array}$ & $\begin{array}{l}2.066 \\
2.028 \\
1.970 \\
1.927\end{array}$ & $\begin{array}{l}3.617 \\
3.686 \\
3.794 \\
3.878\end{array}$ & $\begin{array}{l}101.7 \\
119.8 \\
155.2 \\
189.8\end{array}$ & $\begin{array}{l}2.034 \\
1.997 \\
1.940 \\
1.898\end{array}$ \\
\hline
\end{tabular}

DIAMETER OF WIRE $=0.24$ INCH $=0.02$ FOOT

\begin{tabular}{|c|c|c|c|c|c|c|c|c|c|c|c|c|}
\hline \multirow{2}{*}{$m$ feet } & \multicolumn{3}{|c|}{$h^{\prime}=5$ feet } & \multicolumn{3}{|c|}{$h^{\prime}=10$ feet } & \multicolumn{3}{|c|}{$h^{\prime}=20$ feet } & \multicolumn{3}{|c|}{$h^{\prime}=50$ feet } \\
\hline & $U$ & $C$ & $C / m$ & $U$ & $c$ & $C / m$ & $U$ & $C$ & $C / m$ & $U$ & $C$ & $C / m$ \\
\hline $\begin{array}{l}10 . \\
20 . \\
30 . \\
40 .\end{array}$ & $\begin{array}{l}2.753 \\
3.010 \\
3.160 \\
3.270\end{array}$ & $\begin{array}{l}26.7 \\
48.9 \\
69.8 \\
90.0\end{array}$ & $\begin{array}{l}2.673 \\
2.445 \\
2.329 \\
2.251\end{array}$ & $\begin{array}{l}2.793 \\
3.054 \\
3.204 \\
3.311\end{array}$ & $\begin{array}{l}26.4 \\
48.2 \\
68.9 \\
88.9\end{array}$ & $\begin{array}{l}2.635 \\
2.410 \\
2.297 \\
2.223\end{array}$ & $\begin{array}{l}2.823 \\
\text { 3. } 094 \\
3.248 \\
3.355\end{array}$ & $\begin{array}{l}26.1 \\
47.6 \\
68.0 \\
87.8\end{array}$ & $\begin{array}{l}2.607 \\
2.379 \\
2.266 \\
2.194\end{array}$ & $\begin{array}{l}2.847 \\
3.131 \\
3.293 \\
3.406\end{array}$ & $\begin{array}{l}25.8 \\
47.0 \\
67.0 \\
86.4\end{array}$ & $\begin{array}{r}2.585 \\
2.350 \\
2.235 \\
2.161\end{array}$ \\
\hline $\begin{array}{l}50 \\
60 \\
80 \ldots \\
100\end{array}$ & $\begin{array}{l}3.354 \\
3.423 \\
3.536 \\
3.622\end{array}$ & $\begin{array}{l}109.7 \\
129.0 \\
166.5 \\
203.2\end{array}$ & $\begin{array}{l}2.194 \\
2.150 \\
2.081 \\
2.032\end{array}$ & $\begin{array}{l}3.394 \\
3.461 \\
3.571 \\
3.655\end{array}$ & $\begin{array}{l}108.4 \\
127.6 \\
164.9 \\
201.4\end{array}$ & $\begin{array}{l}2.168 \\
2.127 \\
2.061 \\
2.014\end{array}$ & $\begin{array}{l}3.438 \\
3.505 \\
3.612 \\
3.695\end{array}$ & $\begin{array}{l}107.0 \\
126.0 \\
163.0 \\
199.2\end{array}$ & $\begin{array}{l}2.141 \\
2.100 \\
2.038 \\
1.992\end{array}$ & $\begin{array}{l}3.492 \\
3.561 \\
3.670 \\
3.753\end{array}$ & $\begin{array}{l}105.4 \\
124.0 \\
160.4 \\
196.1\end{array}$ & $\begin{array}{l}2.108 \\
2.067 \\
2.005 \\
1.961\end{array}$ \\
\hline
\end{tabular}


TABLE 5.-Values of the constant $X$ for wires at right angles; formula (20)

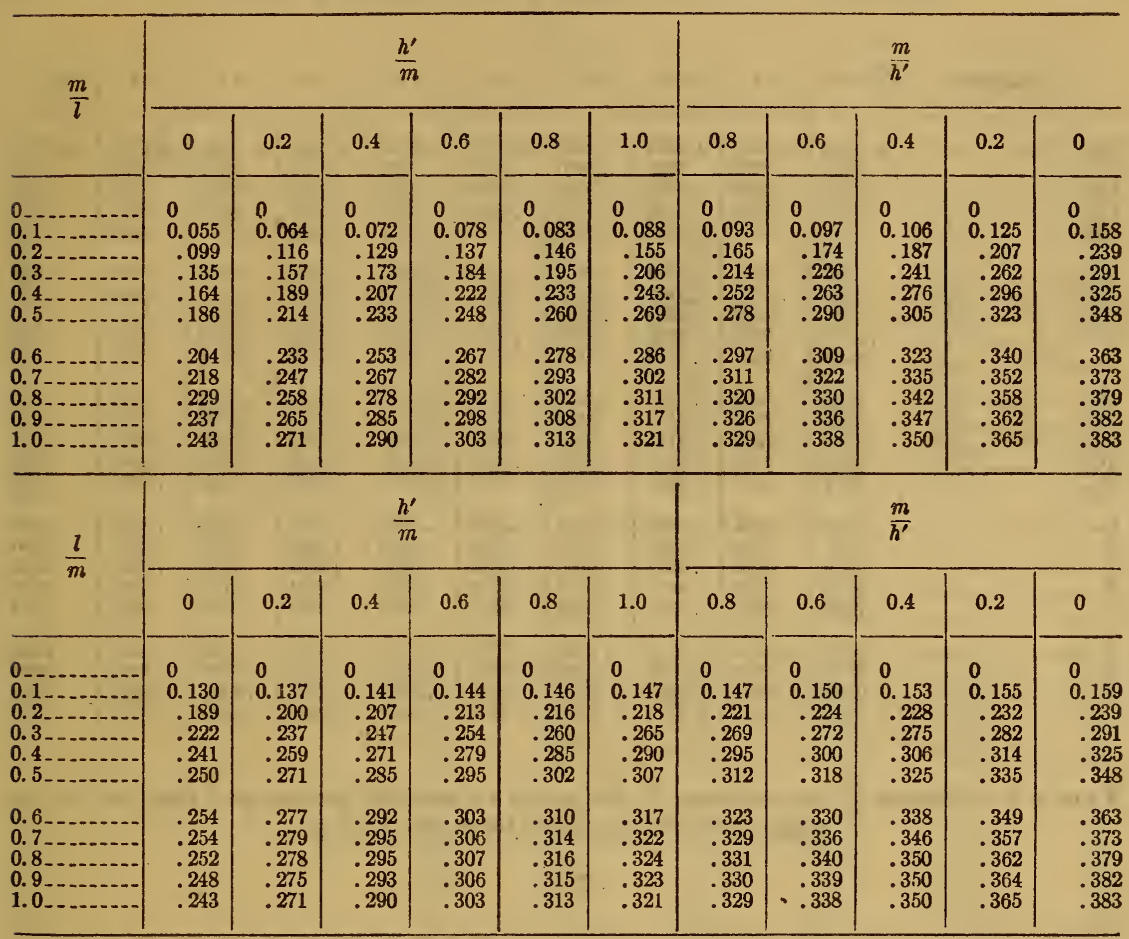

TABLE 6.-Values of the constant $K_{n}$ for use in formula (2Q) and other parallel wire antenna formulas

\begin{tabular}{|c|c|c|c|c|c|c|c|}
\hline$n$ & $K_{n}$ & $n$ & $K_{n}$ & $n$ & $K_{n}$ & $n$ & $K_{\mathrm{n}}$ \\
\hline 2 & ${ }_{0}^{0}$ & 8. & 0.347 & 14 & 0. 550 & & 0.688 \\
\hline 4 & .006 & 10 & $\begin{array}{l}.388 \\
.425\end{array}$ & & $\begin{array}{r}.576 \\
.601\end{array}$ & 40 & $\begin{array}{l}.847 \\
.970\end{array}$ \\
\hline & $\begin{array}{r}.197 \\
252\end{array}$ & 11 & $\begin{array}{r}.460 \\
492\end{array}$ & 17. & $\begin{array}{l}.625 \\
647\end{array}$ & 50 & $\begin{array}{l}1.063 \\
1.357\end{array}$ \\
\hline & .302 & 13 & .522 & 19 & .668 & & \\
\hline
\end{tabular}

The general formula for $K_{\mathrm{n}}$ is

$4.605 K_{\mathrm{n}}=\frac{4}{n^{2}}[\log n(n-1)+2 \operatorname{logn}(n-2)+3 \log n(n-3)+\ldots \cdot$

$$
+(n-2) \log n 2]
$$

or

$$
\begin{aligned}
K_{\mathrm{n}}=\frac{2}{n^{2}}\left[\log _{10}(n-1)\right. & +2 \log _{10}(n-2)+3 \log _{10}(n-3)+\ldots \\
& \left.+(n-2) \log _{10} 2\right]
\end{aligned}
$$


TABLE 7.-Values of the constant $Y_{1}$ for wires intersecting at an angle; formulas (30) $f$

\begin{tabular}{|c|c|c|c|c|c|c|c|c|c|c|}
\hline$\theta$ (degrees) & $\frac{m}{l}=1.0$ & 0.9 & 0.8 & 0.7 & 0.6 & 0.5 & 0.4 & 0.3 & 0.2 & 0.1 \\
\hline 135 & $\begin{array}{r}0.3010 \\
.3029 \\
.3086 \\
.3185 \\
.3334\end{array}$ & $\begin{array}{r}0.3004 \\
.3023 \\
.3080 \\
.3179 \\
.3326\end{array}$ & $\begin{array}{r}0.2983 \\
.3002 \\
.3056 \\
.3156 \\
.3303\end{array}$ & $\begin{array}{r}0.2942 \\
.2960 \\
.3016 \\
.3112 \\
.3255\end{array}$ & $\begin{array}{r}0.2873 \\
.2891 \\
.2944 \\
.3037 \\
.3176\end{array}$ & $\begin{array}{r}0.2764 \\
.2781 \\
.2832 \\
.2920 \\
.3051\end{array}$ & $\begin{array}{r}0.2598 \\
.2613 \\
.2660 \\
.2741 \\
.2860\end{array}$ & $\begin{array}{r}0.2346 \\
.2359 \\
.2400 \\
.2469 \\
.2573\end{array}$ & $\begin{array}{r}0.1957 \\
.1967 \\
.1999 \\
.2053 \\
.2134\end{array}$ & $\begin{array}{r}0.1323 \\
.1329 \\
.1348 \\
.1380 \\
.1427\end{array}$ \\
\hline $\begin{array}{l}85 \ldots \\
80 .- \\
75 .\end{array}$ & $\begin{array}{l}.3542 \\
.3828 \\
.3945 \\
.4075 \\
.4220\end{array}$ & $\begin{array}{l}.3534 \\
.3820 \\
.3936 \\
.4066 \\
.4211\end{array}$ & $\begin{array}{l}.3508 \\
.3790 \\
.3905 \\
.4033 \\
.4176\end{array}$ & $\begin{array}{l}.3457 \\
.3732 \\
.3844 \\
.3970 \\
.4109\end{array}$ & $\begin{array}{l}.3370 \\
.3635 \\
.3743 \\
.3863 \\
.3997\end{array}$ & $\begin{array}{l}.3234 \\
.3483 \\
.3584 \\
.3697 \\
.3823\end{array}$ & $\begin{array}{l}.3028 \\
.3254 \\
.3346 \\
.3448 \\
.3560\end{array}$ & $\begin{array}{l}.2714 \\
.2911 \\
.2989 \\
.3076 \\
.3172\end{array}$ & $\begin{array}{l}.2244 \\
.2393 \\
.2453 \\
.2518 \\
.2591\end{array}$ & $\begin{array}{r}1492 \\
.1578 \\
.1612 \\
.1650 \\
.1691\end{array}$ \\
\hline 50 & $\begin{array}{l}.4383 \\
.4565 \\
.4771 \\
.5004 \\
.5271\end{array}$ & $\begin{array}{l}.4372 \\
.4554 \\
.4759 \\
.4992 \\
.5257\end{array}$ & $\begin{array}{l}.4336 \\
.4515 \\
.4718 \\
.4946 \\
.5208\end{array}$ & $\begin{array}{l}.4265 \\
.4440 \\
.4636 \\
.4859 \\
.5112\end{array}$ & $\begin{array}{l}.4146 \\
.4313 \\
.4501 \\
.4713 \\
.4954\end{array}$ & $\begin{array}{l}.3962 \\
.4118 \\
.4292 \\
.4489 \\
.4712\end{array}$ & $\begin{array}{l}.3686 \\
.3825 \\
.3981 \\
.4156 \\
.4354\end{array}$ & $\begin{array}{l}.3277 \\
.3395 \\
.3526 \\
.3678 \\
.3838\end{array}$ & $\begin{array}{l}.2670 \\
.2759 \\
.2857 \\
.2966 \\
.3089\end{array}$ & $\begin{array}{r}1736 \\
.1786 \\
.1842 \\
.1903 \\
.1971\end{array}$ \\
\hline $\begin{array}{l}35 \\
30 \\
25\end{array}$ & $\begin{array}{l}.5579 \\
.5937 \\
.6360 \\
.6870 \\
.7498\end{array}$ & $\begin{array}{l}.5563 \\
.5920 \\
.6340 \\
.6846 \\
.7470\end{array}$ & $\begin{array}{l}.5509 \\
.5859 \\
.6272 \\
.6767 \\
.7376\end{array}$ & $\begin{array}{l}.5404 \\
.5742 \\
.6140 \\
.6616 \\
.7198\end{array}$ & $\begin{array}{l}.5230 \\
.5550 \\
.5925 \\
.6371 \\
.6915\end{array}$ & $\begin{array}{l}.4966 \\
.5260 \\
.5603 \\
.6009 \\
.6502\end{array}$ & $\begin{array}{r}.4580 \\
.4839 \\
.5139 \\
.5494 \\
.5923\end{array}$ & $\begin{array}{l}.4025 \\
.4239 \\
.4486 \\
.4778 \\
.5128\end{array}$ & $\begin{array}{l}.3227 \\
.3354 \\
.3566 \\
.3780 \\
.4035\end{array}$ & $\begin{array}{r}.2048 \\
.2136 \\
.2236 \\
.2354 \\
.2494\end{array}$ \\
\hline $\begin{array}{l}20 . \\
15 . \\
10 . \\
5 . .\end{array}$ & $\begin{array}{r}.8299 \\
.9376 \\
1.0960 \\
1.3789\end{array}$ & $\begin{array}{r}.8264 \\
.9330 \\
1.0892 \\
1.3663\end{array}$ & $\begin{array}{r}.8148 \\
.9180 \\
1.0681 \\
1.3314\end{array}$ & $\begin{array}{r}.7933 \\
.8909 \\
1.0318 \\
1.2771\end{array}$ & $\begin{array}{r}.7598 \\
.8499 \\
.9793 \\
1.2034\end{array}$ & $\begin{array}{r}.7118 \\
.7926 \\
.9082 \\
1.1079\end{array}$ & $\begin{array}{r}.6457 \\
.7155 \\
.8149 \\
.9863\end{array}$ & $\begin{array}{l}.5563 \\
.6129 \\
.6934 \\
.8320\end{array}$ & $\begin{array}{r}.4351 \\
.4762 \\
.5345 \\
.6346\end{array}$ & $\begin{array}{r}.2668 \\
.2892 \\
.3210 \\
.3757\end{array}$ \\
\hline
\end{tabular}

TABLE 8.-Values of the constant $Y_{2}$ for wires in parallel planes and inclined at an angle with one another; formulas (SO) $f f$

$\frac{m}{l}=1$

\begin{tabular}{|c|c|c|c|c|c|c|}
\hline$\stackrel{\stackrel{\theta}{(d e g r e e s)}}{ }$ & $\frac{2 h}{l}=0$ & 0.2 & 0.5 & 1.0 & 0.5 & $0.2-\frac{l}{2 h}$ \\
\hline 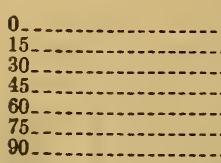 & $\begin{array}{r}0 \\
0.938 \\
.687 \\
.558 \\
.477 \\
.422 \\
.383\end{array}$ & $\begin{array}{r}\mathbf{0 . 6 4 8} \\
.584 \\
.497 \\
.342 \\
.384 \\
.348 \\
.321\end{array}$ & $\begin{array}{r}0.339 \\
.349 \\
.328 \\
.304 \\
.282 \\
.264 \\
.249\end{array}$ & $\begin{array}{r}0.203 \\
.202 \\
.197 \\
.191 \\
.185 \\
.178 \\
.172\end{array}$ & $\begin{array}{l}0.106 \\
.106 \\
.106 \\
.1045 \\
.103 \\
.102 \\
.101\end{array}$ & $\begin{array}{l}0.043 \\
.043 \\
.043 \\
.043 \\
.043 \\
.043 \\
.043\end{array}$ \\
\hline $\begin{array}{l}105 \\
120 \\
135 \\
150 \\
165 \\
180\end{array}$ & $\begin{array}{l}.354 \\
.333 \\
.319 \\
.309 \\
.303 \\
.301\end{array}$ & $\begin{array}{l}.300 \\
.285 \\
.274 \\
.267 \\
.262 \\
.261\end{array}$ & $\begin{array}{l}.237 \\
.228 \\
.221 \\
.216 \\
.213 \\
.212\end{array}$ & $\begin{array}{l}.167 \\
.163 \\
.160 \\
.158 \\
.156 \\
.156\end{array}$ & $\begin{array}{l}.099 \\
.098 \\
.097 \\
.097 \\
.096 \\
.096\end{array}$ & $\begin{array}{l}.043 \\
.0425 \\
.0425 \\
.0425 \\
.0425 \\
.0425\end{array}$ \\
\hline
\end{tabular}

$\frac{m}{l}=0.75$

\begin{tabular}{|c|c|c|c|c|c|c|}
\hline $\begin{array}{l}0 \\
15 \\
45 \\
60\end{array}$ & $\begin{array}{r}\infty \\
0.905 \\
.670 \\
.546 \\
.468 \\
.414\end{array}$ & $\begin{array}{r}0.571 \\
.528 \\
.461 \\
.406 \\
.364 \\
.331\end{array}$ & $\begin{array}{r}0.312 \\
.306 \\
.292 \\
.274 \\
.257 \\
.242\end{array}$ & $\begin{array}{r}0.175 \\
.174 \\
.171 \\
.167 \\
.163 \\
.158\end{array}$ & $\begin{array}{l}0.091 \\
.091 \\
.091 \\
.091 \\
.090 \\
.089\end{array}$ & $\begin{array}{r}0.037 \\
.037 \\
.037 \\
.037 \\
.037 \\
.037\end{array}$ \\
\hline $\begin{array}{l}90 \\
105 \\
120 \\
135 \\
165 \\
180\end{array}$ & $\begin{array}{l}.377 \\
.348 \\
.328 \\
.314 \\
.304 \\
.298 \\
.297\end{array}$ & $\begin{array}{l}.307 \\
.288 \\
.274 \\
.264 \\
.257 \\
.253 \\
.251\end{array}$ & $\begin{array}{l}.230 \\
.220 \\
.212 \\
.206 \\
.202 \\
.199 \\
.198\end{array}$ & $\begin{array}{r}.154 \\
.150 \\
.147 \\
.144 \\
.142 \\
.141 \\
.141\end{array}$ & $\begin{array}{l}.088 \\
.087 \\
.086 \\
.086 \\
.085 \\
.085 \\
.085\end{array}$ & $\begin{array}{l}.037 \\
.037 \\
.037 \\
.037 \\
.037 \\
.037 \\
.037\end{array}$ \\
\hline
\end{tabular}


TABLE 8.-Values of the constant $Y_{2}$ for wires in parallel planes and inclined at an angle with one another; formulas (30) ff-Continued

$\frac{m}{l}=0.5$

\begin{tabular}{|c|c|c|c|c|c|c|}
\hline$\stackrel{\theta}{\text { (degrees) }}$ & $\frac{2 h}{l}=0$ & 0.2 & 0.5 & 1.0 & 0.5 & $0.2 m \frac{l}{2 h}$ \\
\hline 150 & $\begin{array}{r}\infty \\
0.798 \\
.601 \\
.496 \\
.429 \\
.382\end{array}$ & $\begin{array}{r}0.432 \\
.414 \\
.379 \\
.343 \\
.313 \\
.289\end{array}$ & $\begin{array}{r}0.239 \\
.236 \\
.229 \\
.221 \\
.210 \\
.200\end{array}$ & $\begin{array}{l}0.135 \\
.135 \\
.133 \\
.131 \\
.129 \\
.126\end{array}$ & $\begin{array}{l}0.071 \\
.071 \\
.071 \\
.0705 \\
.070 \\
.0695\end{array}$ & $\begin{array}{r}0.029 \\
.029 \\
.029 \\
.029 \\
.029 \\
.029\end{array}$ \\
\hline $\begin{array}{l}90 \\
105 \\
120 \\
150 \\
180\end{array}$ & $\begin{array}{l}.348 \\
.323 \\
.305 \\
.292 \\
.283 \\
.278 \\
.276\end{array}$ & $\begin{array}{l}.270 \\
.255 \\
.244 \\
.235 \\
.230 \\
.225 \\
.223\end{array}$ & $\begin{array}{r}.192 \\
.186 \\
.180 \\
.175 \\
.172 \\
.171 \\
.170\end{array}$ & $\begin{array}{l}.124 \\
.121 \\
.1195 \\
.118 \\
.117 \\
.116 \\
.116\end{array}$ & $\begin{array}{l}.069 \\
.069 \\
.068 \\
.068 \\
.0675 \\
.067 \\
.067\end{array}$ & $\begin{array}{l}.029 \\
.029 \\
.029 \\
.0285 \\
.0285 \\
.0285 \\
.0285\end{array}$ \\
\hline
\end{tabular}

$\frac{m}{l}=0.25$

\begin{tabular}{|c|c|c|c|c|c|c|}
\hline $\begin{array}{l}0 \\
60 \\
65\end{array}$ & $\begin{array}{r}\omega \\
0.550 \\
.432 \\
.366 \\
.322 \\
.291\end{array}$ & $\begin{array}{l}0.238 \\
.235 \\
.226 \\
.215 \\
.204 \\
.194\end{array}$ & $\begin{array}{r}0.136 \\
.136 \\
.134 \\
.131 \\
.128 \\
.125\end{array}$ & $\begin{array}{l}0.079 \\
.079 \\
.079 \\
.078 \\
.0775 \\
.077\end{array}$ & $\begin{array}{r}0.042 \\
.042 \\
.042 \\
.042 \\
.042 \\
.042\end{array}$ & $\begin{array}{r}0.017 \\
.017 \\
.017 \\
.017 \\
.017 \\
.017\end{array}$ \\
\hline 100 & $\begin{array}{l}.270 \\
.251 \\
.238 \\
.228 \\
.222 \\
.162 \\
.217\end{array}$ & $\begin{array}{r}.185 \\
.178 \\
.172 \\
.167 \\
.164 \\
.162 \\
.161\end{array}$ & $\begin{array}{l}.122 \\
.120 \\
.117 \\
.116 \\
.114 \\
.113 \\
.113\end{array}$ & $\begin{array}{l}.076 \\
.075 \\
.074 \\
.074 \\
.073 \\
.073 \\
.073\end{array}$ & $\begin{array}{l}.042 \\
.042 \\
.041 \\
.041 \\
.041 \\
.041 \\
.041\end{array}$ & $\begin{array}{l}.017 \\
.017 \\
.017 \\
.017 \\
.017 \\
.017 \\
.017\end{array}$ \\
\hline
\end{tabular}

$\frac{m}{l}=0.1$

\begin{tabular}{|c|c|c|c|c|c|c|}
\hline $\begin{array}{l}0 \\
15 \\
65\end{array}$ & $\begin{array}{r}\infty \\
0.289 \\
.235 \\
.205 \\
.184 \\
.169\end{array}$ & $\begin{array}{l}0.099 \\
.099 \\
.097 \\
.096 \\
.092 \\
.092\end{array}$ & $\begin{array}{l}0.059 \\
.059 \\
.059 \\
.058 \\
.058 \\
.057\end{array}$ & $\begin{array}{l}0.035 \\
.035 \\
.035 \\
.035 \\
.035 \\
.035\end{array}$ & $\begin{array}{l}0.019 \\
.019 \\
.019 \\
.019 \\
.019 \\
.019\end{array}$ & $\begin{array}{l}0.008 \\
.008 \\
.008 \\
.008 \\
.008 \\
.008\end{array}$ \\
\hline 1050 & $\begin{array}{r}.158 \\
.149 \\
.143 \\
.138 \\
.135 \\
.133 \\
.132\end{array}$ & $\begin{array}{l}.090 \\
.088 \\
.086 \\
.085 \\
.084 \\
.084 \\
.0835\end{array}$ & $\begin{array}{l}.057 \\
.056 \\
.056 \\
.055 \\
.055 \\
.055 \\
.055\end{array}$ & $\begin{array}{l}.035 \\
.035 \\
.034 \\
.034 \\
.034 \\
.034 \\
.034\end{array}$ & $\begin{array}{l}.019 \\
.019 \\
.019 \\
.019 \\
.019 \\
.019 \\
.019\end{array}$ & $\begin{array}{l}.008 \\
.008 \\
.008 \\
.008 \\
.008 \\
.008 \\
.008\end{array}$ \\
\hline
\end{tabular}


TABLE 9.-Constants for two-wire horizontal antennas

[Symbols used above columns, etc., are defined on p. 606]

DIAMETER OF WIRE $=0.06 \mathrm{INCH}=0.005$ FOO'T

\begin{tabular}{|c|c|c|c|c|c|c|c|c|c|}
\hline \multirow{3}{*}{$l$ feet } & \multicolumn{9}{|c|}{ Height $=10$ feet } \\
\hline & \multicolumn{3}{|c|}{$U$} & \multicolumn{3}{|c|}{ Capacity } & \multicolumn{3}{|c|}{ Capacity per foot } \\
\hline & $D=1$ & $D=2$ & $D=3$ & $D=1$ & $D=2$ & $D=3$ & $D=1$ & $D=2$ & $D=3$ \\
\hline $\begin{array}{l}10 \ldots \\
20 \ldots \\
30 \ldots \\
50 \ldots \\
50 \ldots\end{array}$ & $\begin{array}{l}2.082 \\
2.277 \\
2.366 \\
2.416 \\
2.450\end{array}$ & $\begin{array}{l}1.932 \\
2.126 \\
2.216 \\
2.266 \\
2.299\end{array}$ & $\begin{array}{l}1.844 \\
2.038 \\
2.128 \\
2.178 \\
2.211\end{array}$ & $\begin{array}{r}35.3 \\
64.6 \\
93.3 \\
121.9 \\
150.2\end{array}$ & \begin{tabular}{r|}
38.1 \\
69.2 \\
99.7 \\
129.9 \\
160.1
\end{tabular} & $\begin{array}{r}39.9 \\
72.2 \\
103.8 \\
135.2 \\
166.4\end{array}$ & $\begin{array}{l}\text { 3. } 534 \\
\text { 3. } 232 \\
\text { 3. } 111 \\
\text { 3. } 048 \\
\text { 3. } 004\end{array}$ & $\begin{array}{l}3.810 \\
3.460 \\
3.322 \\
3.248 \\
3.202\end{array}$ & $\begin{array}{l}3.991 \\
3.610 \\
3.460 \\
3.380 \\
3.328\end{array}$ \\
\hline $\begin{array}{l}60 . \\
80 . \\
100- \\
150= \\
200 .\end{array}$ & $\begin{array}{l}2.472 \\
2.502 \\
2.522 \\
2.548 \\
2.561\end{array}$ & $\begin{array}{l}2.322 \\
2.352 \\
2.372 \\
2.398 \\
2.410\end{array}$ & $\begin{array}{l}2.234 \\
2.264 \\
2.284 \\
2.310 \\
2.322\end{array}$ & $\begin{array}{l}178.6 \\
235.3 \\
291.8 \\
433.2 \\
574.8\end{array}$ & \begin{tabular}{l|}
190.2 \\
250.3 \\
310.4 \\
460.4 \\
610.7
\end{tabular} & $\begin{array}{l}197.7 \\
260.1 \\
322.3 \\
477.9 \\
633.8\end{array}$ & $\begin{array}{l}2.977 \\
2.941 \\
2.918 \\
2.888 \\
2.874\end{array}$ & $\begin{array}{l}3.170 \\
3.129 \\
3.104 \\
3.069 \\
3.054\end{array}$ & $\begin{array}{l}\text { 3. } 295 \\
\text { 3.251 } \\
\text { 3. } 223 \\
\text { 3. } 186 \\
3.169\end{array}$ \\
\hline & \multicolumn{9}{|c|}{ Height $=15$ feet } \\
\hline & $\begin{array}{l}2.118 \\
2.339 \\
2.449 \\
2.514 \\
2.560\end{array}$ & $\begin{array}{l}1.967 \\
2.188 \\
2.298 \\
2.364 \\
2.409\end{array}$ & $\begin{array}{l}1.879 \\
2.100 \\
2.210 \\
2.276 \\
2.321\end{array}$ & $\begin{array}{r}34.8 \\
62.9 \\
90.2 \\
117.2 \\
143.8\end{array}$ & $\begin{array}{r}37.4 \\
67.3 \\
96.1 \\
124.5 \\
152.8\end{array}$ & $\begin{array}{r}39.1 \\
70.1 \\
99.9 \\
129.4 \\
158.6\end{array}$ & $\begin{array}{l}3.476 \\
3.146 \\
3.005 \\
2.928 \\
2.876\end{array}$ & $\begin{array}{l}3.742 \\
3.363 \\
\text { 3. } 202 \\
3.112 \\
3.056\end{array}$ & $\begin{array}{l}\text { 3. } 914 \\
\text { 3. } 504 \\
\text { 3. } 330 \\
\text { 3. } 235 \\
\text { 3. } 172\end{array}$ \\
\hline $\begin{array}{l}60 \ldots \\
80 \ldots \\
100 \ldots \\
150 \ldots \\
200 \ldots\end{array}$ & $\begin{array}{l}2.590 \\
2.632 \\
2.659 \\
2.698 \\
\text { 2. } 717\end{array}$ & $\begin{array}{l}2.440 \\
2.482 \\
2.508 \\
2.547 \\
2.566\end{array}$ & $\begin{array}{l}2.352 \\
2.394 \\
2.420 \\
2.459 \\
2.478\end{array}$ & $\begin{array}{l}170.5 \\
223.7 \\
276.8 \\
409.3 \\
541.8\end{array}$ & $\begin{array}{l}181.0 \\
237.2 \\
293.4 \\
433.4 \\
573.6\end{array}$ & $\begin{array}{l}187.8 \\
246.0 \\
304.1 \\
449.0 \\
593.9\end{array}$ & $\begin{array}{l}2.842 \\
2.796 \\
2.768 \\
2.729 \\
2.709\end{array}$ & $\begin{array}{l}3.017 \\
2.965 \\
2.934 \\
2.889 \\
2.868\end{array}$ & $\begin{array}{l}3.130 \\
3.074 \\
3.041 \\
2.993 \\
2.970\end{array}$ \\
\hline $200 \ldots$ & \multicolumn{9}{|c|}{ Height $=20$ feet } \\
\hline & $\begin{array}{l}2.134 \\
2.373 \\
2.496 \\
2.572 \\
2.624\end{array}$ & $\begin{array}{l}1.984 \\
\text { 2. } 222 \\
2.346 \\
2.422 \\
2.474\end{array}$ & $\begin{array}{l}1.895 \\
2.134 \\
2.258 \\
2.334 \\
2.386\end{array}$ & $\begin{array}{r}34.5 \\
62.0 \\
88.5 \\
114.4 \\
140.2\end{array}$ & $\begin{array}{r}37.1 \\
66.2 \\
94.1 \\
121.6 \\
148.8\end{array}$ & $\begin{array}{r}38.8 \\
69.0 \\
97.8 \\
126.1 \\
154.2\end{array}$ & $\begin{array}{l}3.448 \\
3.102 \\
2.949 \\
2.860 \\
2.804\end{array}$ & $\begin{array}{l}\text { 3. } 710 \\
3.312 \\
3.138 \\
3.039 \\
2.975\end{array}$ & $\begin{array}{l}3.884 \\
3.448 \\
3.260 \\
3.152 \\
3.084\end{array}$ \\
\hline \multirow[t]{2}{*}{$\begin{array}{l}60 \\
80 \\
100 \\
150 \\
200\end{array}$} & $\begin{array}{l}2.664 \\
2.714 \\
2.748 \\
2.796 \\
2.822\end{array}$ & $\begin{array}{l}2.513 \\
2.564 \\
2.598 \\
2.646 \\
2.672\end{array}$ & $\begin{array}{l}2.425 \\
2.476 \\
2.510 \\
2.558 \\
2.584\end{array}$ & $\begin{array}{l}165.8 \\
216.9 \\
267.8 \\
394.8 \\
521.6\end{array}$ & $\begin{array}{l}175.7 \\
229.6 \\
283.3 \\
417.2 \\
551.0\end{array}$ & $\begin{array}{l}182.1 \\
237.8 \\
293.3 \\
431.6 \\
569.8\end{array}$ & $\begin{array}{l}2.763 \\
2.712 \\
2.678 \\
2.632 \\
2.608\end{array}$ & $\begin{array}{l}2.928 \\
2.870 \\
2.833 \\
2.781 \\
2.755\end{array}$ & $\begin{array}{l}3.035 \\
2.972 \\
2.933 \\
2.877 \\
2.849\end{array}$ \\
\hline & \multicolumn{9}{|c|}{ Height $=25$ feet } \\
\hline & $\begin{array}{l}2.148 \\
2.394 \\
2.525 \\
2.610 \\
2.668\end{array}$ & $\begin{array}{l}1.996 \\
2.243 \\
2.374 \\
2.458 \\
2.518\end{array}$ & $\begin{array}{l}1.909 \\
2.156 \\
2.286 \\
2.371 \\
2.430\end{array}$ & $\begin{array}{r}34.3 \\
61.5 \\
87.4 \\
112.8 \\
137.9\end{array}$ & $\begin{array}{r}36.9 \\
65.6 \\
92.0 \\
119.8 \\
146.2\end{array}$ & $\begin{array}{r}38.6 \\
68.3 \\
96.6 \\
124.2 \\
151.4\end{array}$ & $\begin{array}{l}3.427 \\
3.074 \\
2.915 \\
2.820 \\
2.758\end{array}$ & $\begin{array}{l}\text { 3. } 686 \\
\text { 3. } 282 \\
\text { 3. } 100 \\
\text { 2. } 994 \\
2.924\end{array}$ & $\begin{array}{l}3.855 \\
3.414 \\
3.219 \\
3.105 \\
3.028\end{array}$ \\
\hline \multirow[t]{2}{*}{$\begin{array}{l}60 \\
80 \\
100 \\
150 \\
200\end{array}$} & $\begin{array}{l}2.712 \\
2.772 \\
2.811 \\
2.868 \\
2.899\end{array}$ & $\begin{array}{l}2.560 \\
2.620 \\
2.660 \\
2.718 \\
2.718\end{array}$ & $\begin{array}{l}2.473 \\
2.534 \\
2.572 \\
2.630 \\
2.660\end{array}$ & $\begin{array}{l}162.9 \\
212.4 \\
261.8 \\
384.9 \\
507.8\end{array}$ & $\begin{array}{l}172.5 \\
224.7 \\
276.7 \\
406.3 \\
535.7\end{array}$ & $\begin{array}{l}178.6 \\
232.4 \\
286.1 \\
419.8 \\
553.3\end{array}$ & $\begin{array}{l}2.715 \\
2.656 \\
2.618 \\
2.566 \\
2.539\end{array}$ & $\begin{array}{l}2.875 \\
2.809 \\
2.767 \\
2.709 \\
2.678\end{array}$ & $\begin{array}{l}2.977 \\
2.905 \\
2.861 \\
2.799 \\
2.766\end{array}$ \\
\hline & \multicolumn{9}{|c|}{ Height $=30$ feet } \\
\hline $\begin{array}{l}10- \\
200- \\
30- \\
40- \\
50 .-\end{array}$ & $\begin{array}{l}2.154 \\
2.408 \\
2.545 \\
2.634 \\
2.698\end{array}$ & $\begin{array}{l}2.004 \\
2.258 \\
2.384 \\
2.484 \\
2.548\end{array}$ & $\begin{array}{l}1.916 \\
2.170 \\
2.300 \\
2.396 \\
2.460\end{array}$ & $\begin{array}{r}34.2 \\
61.1 \\
86.8 \\
111.8 \\
136.4\end{array}$ & $\begin{array}{r}36.7 \\
65.2 \\
92.2 \\
118.5 \\
144.4\end{array}$ & $\begin{array}{r}38.4 \\
67.8 \\
95.7 \\
122.9 \\
149.8\end{array}$ & $\begin{array}{l}3.416 \\
3.056 \\
2.892 \\
2.794 \\
2.728\end{array}$ & $\begin{array}{l}3.673 \\
3.260 \\
3.074 \\
2.862 \\
2.888\end{array}$ & $\begin{array}{l}\text { 3. } 841 \\
3.392 \\
3.191 \\
3.072 \\
2.892\end{array}$ \\
\hline $\begin{array}{l}60 \ldots \ldots \\
80-\ldots \\
100 \\
150 \\
200\end{array}$ & $\begin{array}{l}2.746 \\
2.812 \\
2.858 \\
2.924 \\
2.960\end{array}$ & $\begin{array}{l}2.586 \\
2.662 \\
2.708 \\
2.773 \\
2.809\end{array}$ & $\begin{array}{l}2.508 \\
2.574 \\
2.620 \\
2.685 \\
2.721\end{array}$ & $\begin{array}{l}160.8 \\
200.4 \\
257.5 \\
377.6 \\
497.4\end{array}$ & $\begin{array}{l}170.1 \\
221.2 \\
271.8 \\
398.1 \\
524.0\end{array}$ & $\begin{array}{l}176.1 \\
228.8 \\
281.0 \\
411.2 \\
541.0\end{array}$ & $\begin{array}{l}2.880 \\
2.617 \\
2.575 \\
2.517 \\
2.487\end{array}$ & $\begin{array}{l}2.835 \\
2.775 \\
2.718 \\
2.654 \\
2.620\end{array}$ & $\begin{array}{l}2.935 \\
2.859 \\
2.810 \\
2.741 \\
2.705\end{array}$ \\
\hline
\end{tabular}


TABLE 9.-Constants for two-wire horizontal antennas-Continued DIAMETER OF WIRE $=0.06 \mathrm{INCH}=0.005$ FOOT - Continued

\begin{tabular}{|c|c|c|c|c|c|c|c|c|c|}
\hline \multirow{3}{*}{$l$ feet } & \multicolumn{9}{|c|}{ Height $=40$ feet } \\
\hline & \multicolumn{3}{|c|}{$U$} & \multicolumn{3}{|c|}{ Capacity } & \multicolumn{3}{|c|}{ Capacity per foot } \\
\hline & $D=1$ & $D=2$ & $D=3$ & $D=1$ & $D=2$ & $D=3$ & $D=1$ & $D=2$ & $D=3$ \\
\hline $\begin{array}{l}10 \ldots \ldots \\
20 \\
30 \\
40 \\
50 \ldots \ldots .\end{array}$ & $\begin{array}{l}2.162 \\
2.425 \\
2.568 \\
2.668 \\
2.740\end{array}$ & $\begin{array}{l}2.012 \\
2.274 \\
2.418 \\
2.518 \\
2.589\end{array}$ & $\begin{array}{l}1.924 \\
2.186 \\
2.330 \\
2.430 \\
2.501\end{array}$ & $\begin{array}{r}34.0 \\
60.3 \\
86.0 \\
110.3 \\
134.3\end{array}$ & $\begin{array}{r}36.6 \\
64.7 \\
91.3 \\
116.9 \\
142.1\end{array}$ & $\begin{array}{r}38.2 \\
67.3 \\
94.8 \\
121.2 \\
147.1\end{array}$ & \begin{tabular}{l|} 
3. 403 \\
3. 014 \\
2.866 \\
2.758 \\
2.686
\end{tabular} & $\begin{array}{l}3.658 \\
3.236 \\
3.043 \\
2.922 \\
2.842\end{array}$ & $\begin{array}{l}\text { 3. } 825 \\
3.366 \\
3.159 \\
3.029 \\
2.942\end{array}$ \\
\hline \multirow[t]{2}{*}{$\begin{array}{l}60 \\
80 \\
100 \\
150 \\
200\end{array}$} & $\begin{array}{l}2.794 \\
2.870 \\
2.923 \\
3.004 \\
3.049\end{array}$ & $\begin{array}{l}2.643 \\
2.720 \\
2.772 \\
2.853 \\
2.898\end{array}$ & $\begin{array}{l}2.555 \\
2.632 \\
2.684 \\
2.765 \\
2.810\end{array}$ & $\begin{array}{l}158.1 \\
205.1 \\
251.8 \\
367.6 \\
482.8\end{array}$ & $\begin{array}{l}167.1 \\
216.5 \\
265.5 \\
387.0 \\
508.0\end{array}$ & $\begin{array}{l}172.8 \\
223.7 \\
274.2 \\
399.3 \\
523.8\end{array}$ & $\begin{array}{l}2.635 \\
2.564 \\
2.518 \\
2.451 \\
2.414\end{array}$ & $\begin{array}{l}2.785 \\
2.706 \\
2.655 \\
2.580 \\
2.540\end{array}$ & $\begin{array}{l}2.880 \\
2.795 \\
2.742 \\
2.662 \\
2.619\end{array}$ \\
\hline & \multicolumn{9}{|c|}{ Height $=50$ feet } \\
\hline $\begin{array}{l}10 \ldots \\
20 \ldots \\
30 \ldots \\
40 \ldots \\
50 \ldots\end{array}$ & $\begin{array}{l}2.168 \\
2.438 \\
2.587 \\
2.690 \\
2.764\end{array}$ & $\begin{array}{l}2.017 \\
2.288 \\
2.438 \\
2.539 \\
2.614\end{array}$ & $\begin{array}{l}1.929 \\
2.200 \\
2.348 \\
2.451 \\
2.526\end{array}$ & $\begin{array}{r}34.0 \\
60.4 \\
85.4 \\
109.5 \\
133.1\end{array}$ & $\begin{array}{r}36.5 \\
64.4 \\
90.6 \\
116.0 \\
140.8\end{array}$ & $\begin{array}{r}38.2 \\
66.9 \\
94.0 \\
120.1 \\
145.7\end{array}$ & $\begin{array}{l}3.396 \\
3.019 \\
2.845 \\
2.738 \\
2.662\end{array}$ & $\begin{array}{l}\text { 3. } 649 \\
3.218 \\
\text { 3. } 021 \\
\text { 2. } 900 \\
\text { 2. } 816\end{array}$ & $\begin{array}{l}\text { 3. } 818 \\
\text { 3. } 346 \\
\text { 3. } 134 \\
\text { 3. } 002 \\
\text { 2. } 914\end{array}$ \\
\hline \multirow[t]{2}{*}{100} & $\begin{array}{l}2.822 \\
2.908 \\
2.967 \\
3.058 \\
3.112\end{array}$ & $\begin{array}{l}\text { 2. } 672 \\
2.757 \\
2.816 \\
2.908 \\
\text { 2. } 960\end{array}$ & $\begin{array}{l}\text { 2. } 584 \\
2.669 \\
2.728 \\
2.820 \\
\text { 2. } 872\end{array}$ & $\begin{array}{l}156.5 \\
202.5 \\
218.1 \\
361.0 \\
473.1\end{array}$ & $\begin{array}{l}165.3 \\
213.6 \\
261.3 \\
379.6 \\
497.2\end{array}$ & $\begin{array}{l}170.9 \\
220.6 \\
269.8 \\
391.5 \\
512.4\end{array}$ & $\begin{array}{l}2.610 \\
2.531 \\
2.481 \\
2.407 \\
2.366\end{array}$ & $\begin{array}{l}\text { 2. } 755 \\
2.670 \\
2.613 \\
2.531 \\
2.486\end{array}$ & $\begin{array}{l}2.848 \\
2.758 \\
2.608 \\
2.610 \\
2.562\end{array}$ \\
\hline & \multicolumn{9}{|c|}{ Height $=60$ Peet } \\
\hline $\begin{array}{l}10 \ldots \\
20-\ldots \\
30 \ldots \\
40 \ldots \\
50 \ldots\end{array}$ & $\begin{array}{l}2.172 \\
2.445 \\
2.597 \\
2.704 \\
2.782\end{array}$ & $\begin{array}{l}2.021 \\
2.295 \\
2.446 \\
2.553 \\
2.631\end{array}$ & \begin{tabular}{l|}
1.933 \\
2.206 \\
2.358 \\
2.465 \\
2.543
\end{tabular} & \begin{tabular}{r|}
33.9 \\
60.2 \\
85.0 \\
108.9 \\
132.3
\end{tabular} & \begin{tabular}{r|}
36.4 \\
64.1 \\
90.2 \\
115.3 \\
139.9
\end{tabular} & $\begin{array}{r}38.1 \\
66.7 \\
93.6 \\
119.4 \\
144.7\end{array}$ & $\begin{array}{l}\text { 3. } 389 \\
\text { 3. } 010 \\
2.834 \\
2.722 \\
2.646\end{array}$ & $\begin{array}{l}\text { 3. } 642 \\
\text { 3. } 207 \\
\text { 3. } 008 \\
2.882 \\
2.798\end{array}$ & $\begin{array}{l}3.808 \\
3.336 \\
3.120 \\
2.985 \\
2.894\end{array}$ \\
\hline \multirow[t]{2}{*}{$\begin{array}{l}60 \\
80 \\
100 \\
150 \\
200\end{array}$} & $\begin{array}{l}2.842 \\
2.934 \\
2.997 \\
3.098 \\
3.158\end{array}$ & $\begin{array}{l}2.692 \\
2.783 \\
2.846 \\
2.948 \\
3.008\end{array}$ & $\begin{array}{l}2.604 \\
2.695 \\
2.758 \\
2.860 \\
2.920\end{array}$ & $\begin{array}{l}155.4 \\
200.7 \\
245.6 \\
356.3 \\
466.1\end{array}$ & $\begin{array}{l}164.0 \\
211.6 \\
258.6 \\
374.5 \\
489.4\end{array}$ & $\begin{array}{l}169.6 \\
218.5 \\
266.8 \\
386.0 \\
504.2\end{array}$ & \begin{tabular}{l|}
2.590 \\
2.509 \\
2.456 \\
2.375 \\
2.330
\end{tabular} & $\begin{array}{l}2.733 \\
2.645 \\
2.586 \\
2.497 \\
2.447\end{array}$ & $\begin{array}{l}2.827 \\
2.731 \\
2.668 \\
2.573 \\
2.521\end{array}$ \\
\hline & \multicolumn{9}{|c|}{ Height $=80$ feet } \\
\hline $\begin{array}{l}10 \ldots \\
20 \ldots \\
30 \ldots \\
40 \ldots \\
50 \ldots\end{array}$ & $\begin{array}{l}2.176 \\
2.453 \\
2.611 \\
2.720 \\
2.804\end{array}$ & $\begin{array}{l}2.025 \\
2.302 \\
2.458 \\
2.570 \\
2.653\end{array}$ & \begin{tabular}{l|}
1.937 \\
2.214 \\
2.372 \\
2.482 \\
2.565
\end{tabular} & $\begin{array}{r}33.8 \\
60.0 \\
84.6 \\
108.2 \\
131.3\end{array}$ & $\begin{array}{r}36.4 \\
63.9 \\
89.8 \\
114.6 \\
138.7\end{array}$ & $\begin{array}{r}38.0 \\
66,5 \\
93.1 \\
118.6 \\
143.5\end{array}$ & $\begin{array}{l}3.383 \\
3.000 \\
2.829 \\
2.705 \\
2.626\end{array}$ & $\begin{array}{l}3.635 \\
3.196 \\
2.994 \\
2.865 \\
2.774\end{array}$ & $\begin{array}{l}\text { 3. } 800 \\
3.324 \\
3.102 \\
2.965 \\
2.870\end{array}$ \\
\hline \multirow[t]{2}{*}{$\begin{array}{l}60 \\
80 \\
100 \\
150 \\
200\end{array}$} & $\begin{array}{l}2.870 \\
2.966 \\
3.038 \\
3.154 \\
3.223\end{array}$ & $\begin{array}{l}2.720 \\
2.816 \\
2.888 \\
3.003 \\
3.072\end{array}$ & $\begin{array}{l}2.631 \\
2.728 \\
2.800 \\
2.915 \\
2.984\end{array}$ & $\begin{array}{l}153.9 \\
198.5 \\
242.3 \\
350.1 \\
456.7\end{array}$ & $\begin{array}{l}162.4 \\
209.1 \\
254.9 \\
367.6 \\
479.1\end{array}$ & $\begin{array}{l}167.8 \\
215.8 \\
262.9 \\
378.7 \\
493.2\end{array}$ & $\begin{array}{l}2.565 \\
2.481 \\
2.423 \\
2.334 \\
2.284\end{array}$ & $\begin{array}{l}2.706 \\
2.614 \\
2.549 \\
2.451 \\
2.396\end{array}$ & $\begin{array}{l}2.797 \\
2.698 \\
2.629 \\
2.525 \\
2.466\end{array}$ \\
\hline & \multicolumn{9}{|c|}{ Height $=100$ feet } \\
\hline $\begin{array}{l}10 \\
20 \\
30 \\
40 \\
50\end{array}$ & $\begin{array}{l}2.178 \\
2.458 \\
2.619 \\
2.734 \\
2.816\end{array}$ & \begin{tabular}{l|}
2.028 \\
2.308 \\
2.468 \\
2.583 \\
2.666
\end{tabular} & $\begin{array}{l}1.939 \\
2.220 \\
2.380 \\
2.495 \\
2.578\end{array}$ & $\begin{array}{r}33.8 \\
59.9 \\
84.3 \\
107.7 \\
130.7\end{array}$ & \begin{tabular}{r|}
36.3 \\
63.8 \\
89.4 \\
114.0 \\
138.0
\end{tabular} & $\begin{array}{r}38.0 \\
66.3 \\
92.8 \\
118.0 \\
142.8\end{array}$ & $\begin{array}{l}3.378 \\
2.994 \\
2.810 \\
2.692 \\
2.614\end{array}$ & $\begin{array}{l}3.629 \\
3.180 \\
2.982 \\
2.850 \\
2.760\end{array}$ & $\begin{array}{l}\text { 3. } 796 \\
\text { 3. } 316 \\
\text { 3. } 092 \\
2.950 \\
2.855\end{array}$ \\
\hline $\begin{array}{l}60 \\
80 \ldots \ldots \\
160 \\
150 \\
200\end{array}$ & \begin{tabular}{l|}
2.884 \\
2.988 \\
3.063 \\
3.190 \\
3.267
\end{tabular} & \begin{tabular}{l|}
2.734 \\
2.837 \\
2.912 \\
3.039 \\
3. 116
\end{tabular} & $\begin{array}{l}2.640 \\
2.749 \\
2.824 \\
2.951 \\
3.028\end{array}$ & $\begin{array}{l}153.1 \\
197.1 \\
240.3 \\
346.1 \\
450.6\end{array}$ & $\begin{array}{l}161.5 \\
207.5 \\
252.7 \\
363.3 \\
472.3\end{array}$ & $\begin{array}{l}166.8 \\
214.2 \\
260.1 \\
374.1 \\
486.1\end{array}$ & $\begin{array}{l}2.552 \\
2.464 \\
2.403 \\
2.307 \\
2.253\end{array}$ & $\begin{array}{l}2.692 \\
2.594 \\
2.527 \\
2.420 \\
2.362\end{array}$ & $\begin{array}{l}2.780 \\
2.678 \\
2.601 \\
2.490 \\
2.430\end{array}$ \\
\hline
\end{tabular}


TABLE 9.-Constants for two-wire horizontal antennas-Continued

DIAMETER OF WIRE $=0.12$ INCH $=0.01$ FOOT

\begin{tabular}{|c|c|c|c|c|c|c|c|c|c|}
\hline \multirow{3}{*}{$l$ feet } & \multicolumn{9}{|c|}{ Height $=10$ feet } \\
\hline & \multicolumn{3}{|c|}{$\boldsymbol{U}$} & \multicolumn{3}{|c|}{ Capacity } & \multicolumn{3}{|c|}{ Capacity per foot } \\
\hline & $D=1$ & $D=2$ & $D=3$ & $D=1$ & $D=2$ & $D=3$ & $D=1$ & $D=2$ & $D=3$ \\
\hline $\begin{array}{l}10 \ldots \\
20 . \ldots \\
30 . . \\
40 . \\
50 \ldots\end{array}$ & $\begin{array}{l}1.932 \\
2.126 \\
2.216 \\
2.266 \\
2.300\end{array}$ & $\begin{array}{l}1.782 \\
1.976 \\
2.065 \\
2.116 \\
2.148\end{array}$ & $\begin{array}{l}1.694 \\
1.888 \\
1.977 \\
2.028 \\
2.060\end{array}$ & $\begin{array}{r}38.1 \\
69.2 \\
99.7 \\
129.9 \\
160.0\end{array}$ & $\begin{array}{r}41.3 \\
74.5 \\
106.9 \\
139.2 \\
171.3\end{array}$ & $\begin{array}{r}43.5 \\
78.0 \\
111.7 \\
145.2 \\
178.6\end{array}$ & $\begin{array}{l}3.810 \\
3.461 \\
3.322 \\
3.248 \\
3.200\end{array}$ & $\begin{array}{l}4.131 \\
3.724 \\
3.563 \\
3.480 \\
3.426\end{array}$ & $\begin{array}{l}\text { 4. } 346 \\
\text { 3. } 898 \\
\text { 3. } 723 \\
\text { 3. } 630 \\
\text { 3. } 572\end{array}$ \\
\hline \multirow[t]{2}{*}{$\begin{array}{l}60 \\
80 \ldots \ldots \\
100 \\
150 \\
200\end{array}$} & $\begin{array}{l}2.322 \\
2.352 \\
2.372 \\
2.398 \\
2.410\end{array}$ & $\begin{array}{l}2.172 \\
2.202 \\
2.221 \\
2.248 \\
2.260\end{array}$ & $\begin{array}{l}2.084 \\
2.114 \\
2.133 \\
2.160 \\
2.172\end{array}$ & $\begin{array}{l}190.2 \\
250.3 \\
310.4 \\
460.4 \\
610.7\end{array}$ & $\begin{array}{l}203.4 \\
267.5 \\
331.4 \\
491.2 \\
651.3\end{array}$ & $\begin{array}{l}212.0 \\
278.6 \\
345.1 \\
511.2 \\
677.7\end{array}$ & $\begin{array}{l}\text { 3. } 170 \\
\text { 3. } 129 \\
\text { 3. } 104 \\
\text { 3. } 069 \\
\text { 3. } 054\end{array}$ & $\begin{array}{l}3.390 \\
3.344 \\
3.314 \\
3.275 \\
3.256\end{array}$ & $\begin{array}{l}\text { 3. } 532 \\
\text { 3. } 482 \\
\text { 3. } 451 \\
\text { 3. } 408 \\
\text { 3. } 388\end{array}$ \\
\hline & \multicolumn{9}{|c|}{ Height $=15$ feet } \\
\hline $\begin{array}{l}10 \ldots \\
20 \ldots \\
30 \ldots \\
40 \ldots \\
50 \ldots\end{array}$ & $\begin{array}{l}1.967 \\
2.188 \\
2.298 \\
2.364 \\
2.409\end{array}$ & $\begin{array}{l}1.816 \\
2.038 \\
2.148 \\
2.214 \\
2.258\end{array}$ & $\begin{array}{l}1.728 \\
1.950 \\
2.060 \\
2.126 \\
2.170\end{array}$ & $\begin{array}{r}37.4 \\
67.3 \\
96.1 \\
124.5 \\
152.8\end{array}$ & $\begin{array}{r}40.5 \\
72.2 \\
102.8 \\
133.0 \\
162.9\end{array}$ & $\begin{array}{r}42.6 \\
75.5 \\
107.2 \\
138.5 \\
169.5\end{array}$ & $\begin{array}{l}3.742 \\
3.363 \\
3.202 \\
3.112 \\
3.056\end{array}$ & $\begin{array}{l}4.052 \\
3.612 \\
3.427 \\
3.325 \\
3.258\end{array}$ & $\begin{array}{l}\text { 4. } 258 \\
\text { 3. } 774 \\
\text { 3. } 573 \\
3.462 \\
\text { 3. } 390\end{array}$ \\
\hline $\begin{array}{l}60 \ldots \\
800 \ldots \\
100 \ldots \\
200\end{array}$ & $\begin{array}{l}2.440 \\
2.482 \\
2.508 \\
2.547 \\
2.566\end{array}$ & $\begin{array}{l}2.290 \\
2.331 \\
2.358 \\
2.396 \\
2.416\end{array}$ & $\begin{array}{l}2.202 \\
2.244 \\
2.270 \\
2.308 \\
2.328\end{array}$ & $\begin{array}{l}181.0 \\
237.2 \\
294.0 \\
433.4 \\
573.6\end{array}$ & $\begin{array}{l}192.9 \\
252.5 \\
312.1 \\
460.7 \\
609.3\end{array}$ & $\begin{array}{l}200.6 \\
262.4 \\
324.2 \\
478.2 \\
632.3\end{array}$ & $\begin{array}{l}3.017 \\
2.965 \\
2.940 \\
2.890 \\
2.868\end{array}$ & $\begin{array}{l}3.215 \\
3.156 \\
3.121 \\
3.071 \\
3.046\end{array}$ & $\begin{array}{l}\text { 3. } 343 \\
\text { 3. } 281 \\
\text { 3. } 242 \\
\text { 3. } 188 \\
\text { 3. } 162\end{array}$ \\
\hline 200 & \multicolumn{9}{|c|}{ Height $=20$ feet } \\
\hline $\begin{array}{l}10 \ldots \ldots \\
30 \ldots \ldots \\
50 \ldots \ldots\end{array}$ & $\begin{array}{l}1.984 \\
2.222 \\
2.346 \\
2.422 \\
2.474\end{array}$ & $\begin{array}{l}1.834 \\
2.072 \\
2.195 \\
2.272 \\
2.324\end{array}$ & $\begin{array}{l}1,746 \\
1.984 \\
2.107 \\
2.184 \\
2.236\end{array}$ & $\begin{array}{r}37.1 \\
66.2 \\
94.1 \\
121.6 \\
148.8\end{array}$ & $\begin{array}{r}40.1 \\
71.0 \\
100.6 \\
129.6 \\
158.4\end{array}$ & $\begin{array}{r}42.1 \\
74.2 \\
104.8 \\
134.8 \\
164.6\end{array}$ & $\begin{array}{l}3.709 \\
3.312 \\
3.138 \\
3.040 \\
2.975\end{array}$ & $\begin{array}{l}4.013 \\
3.552 \\
3.353 \\
3.240 \\
3.168\end{array}$ & $\begin{array}{l}\text { 4. } 212 \\
3.710 \\
3.493 \\
3.370 \\
\text { 3. } 292\end{array}$ \\
\hline $\begin{array}{l}60 \\
80 \\
100 \ldots \\
150 \ldots \ldots \\
200 \ldots \ldots\end{array}$ & $\begin{array}{l}2.513 \\
2.564 \\
2.602 \\
2.646 \\
2.672\end{array}$ & $\begin{array}{l}2.362 \\
2.414 \\
2.451 \\
2.496 \\
2.521\end{array}$ & $\begin{array}{l}2.274 \\
2.326 \\
2.363 \\
2.408 \\
2.433\end{array}$ & $\begin{array}{l}175.7 \\
229.6 \\
282.9 \\
417.2 \\
550.7\end{array}$ & $\begin{array}{l}186.9 \\
244.0 \\
300.3 \\
442.4 \\
583.9\end{array}$ & $\begin{array}{l}194.2 \\
225.2 \\
311.5 \\
458.6 \\
605.0\end{array}$ & $\begin{array}{l}2.928 \\
2.870 \\
2.829 \\
2.781 \\
2.754\end{array}$ & $\begin{array}{l}3.115 \\
3.050 \\
3.003 \\
2.969 \\
2.920\end{array}$ & $\begin{array}{l}\text { 3. } 236 \\
\text { 3. } 165 \\
\text { 3. } 115 \\
\text { 3. } 057 \\
\text { 3. } 025\end{array}$ \\
\hline 200 & \multicolumn{9}{|c|}{ Height $=25$ feet } \\
\hline $\begin{array}{l}10 \ldots \ldots \\
30 \ldots \\
50 \ldots\end{array}$ & $\begin{array}{l}1.997 \\
2.244 \\
2.374 \\
2.459 \\
2.518\end{array}$ & $\begin{array}{l}1.846 \\
2.092 \\
2.224 \\
2.308 \\
2.367\end{array}$ & $\begin{array}{l}1.758 \\
2.005 \\
2.136 \\
2.220 \\
2.280\end{array}$ & $\begin{array}{r}36.9 \\
65.6 \\
93.0 \\
119.7 \\
146.2\end{array}$ & $\begin{array}{r}39.9 \\
70.4 \\
99.3 \\
127.6 \\
155.5\end{array}$ & $\begin{array}{r}41.8 \\
73.4 \\
103.4 \\
132.6 \\
161.4\end{array}$ & $\begin{array}{l}3.686 \\
3.280 \\
3.100 \\
2.992 \\
2.923\end{array}$ & $\begin{array}{l}\text { 3. } 987 \\
3.518 \\
3.310 \\
3.190 \\
3.110\end{array}$ & $\begin{array}{l}\text { 4. } 185 \\
\text { 3. } 671 \\
\text { 3. } 447 \\
\text { 3. } 315 \\
\text { 3. } 228\end{array}$ \\
\hline $\begin{array}{l}60 \ldots \ldots \\
80, \ldots \\
100 \ldots \ldots \\
200 \ldots \ldots\end{array}$ & $\begin{array}{l}2.561 \\
2.621 \\
2.660 \\
2.718 \\
2.748\end{array}$ & $\begin{array}{l}2.410 \\
2.470 \\
2.510 \\
2.567 \\
2.598\end{array}$ & $\begin{array}{l}2.322 \\
2.383 \\
2.422 \\
2.480 \\
2.510\end{array}$ & $\begin{array}{l}172.4 \\
224.6 \\
276.6 \\
406.2 \\
535.6\end{array}$ & $\begin{array}{l}183.2 \\
238.4 \\
293.3 \\
430.1 \\
566.7\end{array}$ & $\begin{array}{l}190.1 \\
247.1 \\
303.9 \\
45.3 \\
586.5\end{array}$ & $\begin{array}{l}2.873 \\
2.808 \\
2.766 \\
2.708 \\
2.678\end{array}$ & $\begin{array}{l}3.053 \\
2.980 \\
2.933 \\
2.867 \\
2.834\end{array}$ & $\begin{array}{l}\text { 3. } 166 \\
\text { 3. } 089 \\
\text { 3. } 039 \\
2.969 \\
\text { 2. } 932\end{array}$ \\
\hline & \multicolumn{9}{|c|}{ Height $=30$ feet } \\
\hline $\begin{array}{l}10 \ldots \\
20 \ldots \ldots \\
30 \ldots \\
40 \ldots \\
50 \ldots\end{array}$ & $\begin{array}{l}2.004 \\
2.258 \\
2.394 \\
2.484 \\
2.548\end{array}$ & $\begin{array}{l}1.854 \\
2.107 \\
2.244 \\
2.334 \\
2.398\end{array}$ & $\begin{array}{l}1.766 \\
2.019 \\
2.156 \\
2.246 \\
2.310\end{array}$ & \begin{tabular}{r|}
36.7 \\
65.2 \\
92.2 \\
118.5 \\
144.4
\end{tabular} & $\begin{array}{r}39.7 \\
69.9 \\
98.4 \\
126.2 \\
153.5\end{array}$ & $\begin{array}{r}41.7 \\
72.9 \\
102.4 \\
131.1 \\
159.3\end{array}$ & $\begin{array}{l}3.673 \\
3.260 \\
3.074 \\
2.962 \\
2.888\end{array}$ & $\begin{array}{l}\text { 3. } 971 \\
\text { 3. } 493 \\
\text { 3. } 280 \\
3.155 \\
\text { 3. } 070\end{array}$ & $\begin{array}{l}4.169 \\
\text { 3. } 646 \\
3.413 \\
3.278 \\
\text { 3. } 186\end{array}$ \\
\hline $\begin{array}{l}60 \\
800 \\
150 \\
200\end{array}$ & $\begin{array}{l}2.596 \\
2.662 \\
2.708 \\
2.773 \\
2.808\end{array}$ & $\begin{array}{l}2.446 \\
2.512 \\
2.557 \\
2.622 \\
2.658\end{array}$ & $\begin{array}{l}2.358 \\
2.424 \\
2469 \\
2.534 \\
2.570\end{array}$ & $\begin{array}{l}170.1 \\
221.2 \\
271.8 \\
398.1 \\
524.1\end{array}$ & $\begin{array}{l}180.6 \\
234.4 \\
287.8 \\
421.0 \\
553.8\end{array}$ & $\begin{array}{l}187.3 \\
224.9 \\
298.1 \\
435.6 \\
572.8\end{array}$ & $\begin{array}{l}2.835 \\
2.765 \\
2.718 \\
2.654 \\
2.620\end{array}$ & $\begin{array}{l}3.010 \\
2.930 \\
2.878 \\
2.807 \\
2.769\end{array}$ & $\begin{array}{l}3.122 \\
3.036 \\
2.981 \\
2.904 \\
2.864\end{array}$ \\
\hline
\end{tabular}


Grover]

TABLE 9.-Constants for two-wire horizontal antennas-Continued

DIAMETER OF WIRE $=0.12$ inch $=0.01$ foot-Continued

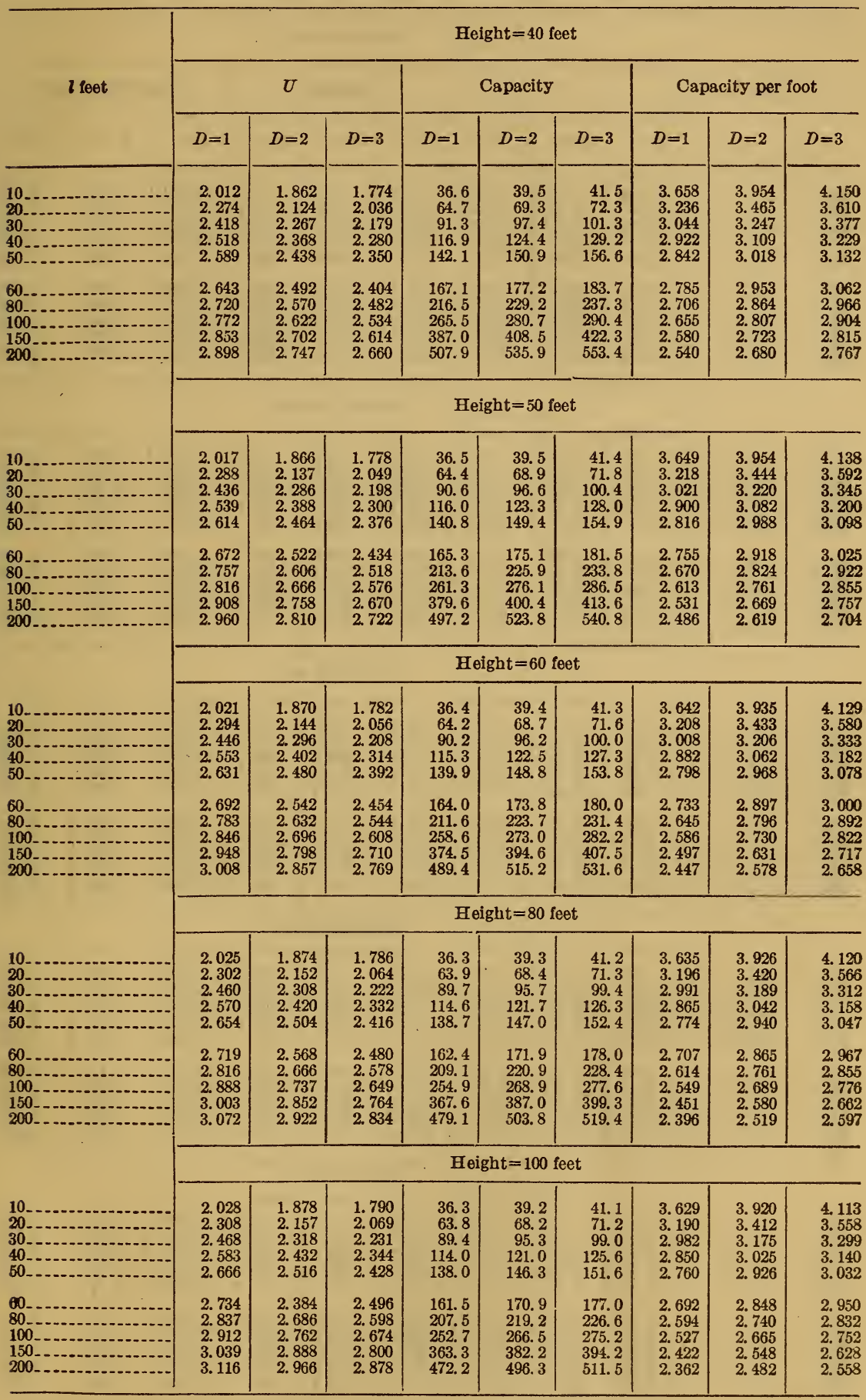


TABLE 9.-Constants for two-wire horizontal antennas-Continued DIAMETER OF WIRE $=0.18$ INCH $=0.015$ FOOT

\begin{tabular}{|c|c|c|c|c|c|c|c|c|c|}
\hline \multirow{3}{*}{ l feet } & \multicolumn{9}{|c|}{ Height $=10$ feet } \\
\hline & \multicolumn{3}{|c|}{$U$} & \multicolumn{3}{|c|}{ Capacity } & \multicolumn{3}{|c|}{ Capacity per foot } \\
\hline & $D=1$ & $D=2$ & $D=3$ & $D=1$ & $D=2$ & $D=3$ & $D=1$ & $D=2$ & $D=3$ \\
\hline $\begin{array}{l}10 \ldots \\
20 \ldots \\
30 \ldots \\
40 \ldots \\
50 \ldots\end{array}$ & $\begin{array}{l}1.844 \\
2.038 \\
2.128 \\
2.178 \\
2.211\end{array}$ & $\begin{array}{l}1.694 \\
1.888 \\
1.977 \\
2.028 \\
2.060\end{array}$ & $\begin{array}{l}1.606 \\
1.800 \\
1.889 \\
1.940 \\
1.972\end{array}$ & $\begin{array}{r}39.9 \\
72.2 \\
103.8 \\
135.2 \\
166.4\end{array}$ & \begin{tabular}{r|}
43.5 \\
78.0 \\
111.7 \\
145.2 \\
178.6
\end{tabular} & $\begin{array}{r}45.8 \\
81.8 \\
116.9 \\
151.8 \\
186.6\end{array}$ & $\begin{array}{l}\text { 3. } 991 \\
\text { 3. } 611 \\
3.460 \\
3.380 \\
\text { 3. } 328\end{array}$ & $\begin{array}{l}4.346 \\
3.898 \\
3.723 \\
3.630 \\
3.572\end{array}$ & $\begin{array}{l}4.584 \\
4.089 \\
3.897 \\
3.795 \\
\text { 3. } 732\end{array}$ \\
\hline \multirow[t]{2}{*}{$\begin{array}{l}60 \\
80 \\
100 \\
200\end{array}$} & $\begin{array}{l}2.234 \\
2.264 \\
2.284 \\
2.309 \\
2.322\end{array}$ & $\begin{array}{l}2.084 \\
2.114 \\
2.133 \\
2.158 \\
2.172\end{array}$ & $\begin{array}{l}1.996 \\
2.206 \\
2.045 \\
2.070 \\
2.084\end{array}$ & $\begin{array}{l}197.7 \\
260.1 \\
322.3 \\
478.1 \\
633.8\end{array}$ & $\begin{array}{l}212.0 \\
278.5 \\
345.1 \\
511.5 \\
677.7\end{array}$ & $\begin{array}{l}221.3 \\
290.7 \\
259.9 \\
533.2 \\
706.3\end{array}$ & $\begin{array}{l}\text { 3. } 295 \\
\text { 3. } 251 \\
\text { 3. } 223 \\
\text { 3. } 187 \\
\text { 3. } 169\end{array}$ & $\begin{array}{l}\text { 3. } 533 \\
\text { 3. } 481 \\
3.451 \\
3.410 \\
3.388\end{array}$ & $\begin{array}{l}3.688 \\
3.634 \\
3.599 \\
3.555 \\
3.532\end{array}$ \\
\hline & \multicolumn{9}{|c|}{ Height $=15$ feet } \\
\hline $\begin{array}{l}10 \ldots \\
20 \ldots \\
30 \ldots \\
40 \ldots \\
50 \ldots\end{array}$ & $\begin{array}{l}1.879 \\
2.100 \\
2.210 \\
2.276 \\
2.321\end{array}$ & $\begin{array}{l}1.728 \\
1.950 \\
2.060 \\
2.126 \\
2.170\end{array}$ & $\begin{array}{l}1.640 \\
1.862 \\
1.972 \\
2.038 \\
2.082\end{array}$ & $\begin{array}{r}39.2 \\
70.1 \\
99.9 \\
129.4 \\
158.6\end{array}$ & $\begin{array}{r}42.6 \\
75.5 \\
107.2 \\
138.5 \\
169.6\end{array}$ & $\begin{array}{r}44.9 \\
79.0 \\
112.0 \\
144.5 \\
176.7\end{array}$ & $\begin{array}{l}\text { 3. } 918 \\
\text { 3. } 505 \\
\text { 3. } 330 \\
\text { 3. } 234 \\
3.171\end{array}$ & $\begin{array}{l}4.258 \\
\text { 3. } 744 \\
3.573 \\
3.462 \\
3.391\end{array}$ & $\begin{array}{l}4.486 \\
\text { 3. } 952 \\
\text { 3. } 733 \\
\text { 3. } 612 \\
\text { 3. } 534\end{array}$ \\
\hline \multirow[t]{2}{*}{$\begin{array}{l}60 \\
100 \\
150 \\
200\end{array}$} & $\begin{array}{l}2.352 \\
2.394 \\
2.420 \\
2.459 \\
2.478\end{array}$ & $\begin{array}{l}\text { 2. } 202 \\
2.244 \\
2.270 \\
2.308 \\
2.328\end{array}$ & $\begin{array}{l}2.114 \\
2.156 \\
2.182 \\
2.220 \\
2.240\end{array}$ & $\begin{array}{l}187.8 \\
246.0 \\
304.1 \\
449.0 \\
593.9\end{array}$ & $\begin{array}{l}200.6 \\
262.4 \\
324.2 \\
478.2 \\
632.3\end{array}$ & $\begin{array}{l}208.9 \\
273.1 \\
337.3 \\
497.2 \\
657.1\end{array}$ & $\begin{array}{l}\text { 3. } 130 \\
\text { 3. } 074 \\
3.041 \\
2.993 \\
2.970\end{array}$ & $\begin{array}{l}\text { 3. } 343 \\
\text { 3. } 282 \\
\text { 3. } 241 \\
\text { 3. } 188 \\
\text { 3. } 162\end{array}$ & $\begin{array}{l}\text { 3. } 482 \\
\text { 3. } 414 \\
\text { 3. 373 } \\
\text { 3. } 315 \\
\text { 3. } 286\end{array}$ \\
\hline & \multicolumn{9}{|c|}{ Height $=20$ feet } \\
\hline $\begin{array}{l}10 \ldots \\
20 \ldots \ldots \\
30 \ldots \ldots \\
40 \ldots \ldots \\
50 \ldots \ldots\end{array}$ & $\begin{array}{l}1.896 \\
2.184 \\
2.258 \\
2.334 \\
2.386\end{array}$ & $\begin{array}{l}1.746 \\
1.984 \\
2.107 \\
2.184 \\
2.236\end{array}$ & $\begin{array}{l}1.658 \\
1.896 \\
2.019 \\
2.096 \\
2.148\end{array}$ & $\begin{array}{r}38.8 \\
69.0 \\
97.8 \\
126.1 \\
154.2\end{array}$ & $\begin{array}{r}42.2 \\
74.2 \\
104.8 \\
134.8 \\
164.6\end{array}$ & $\begin{array}{r}44.4 \\
77.6 \\
109.4 \\
140.5 \\
171.4\end{array}$ & $\begin{array}{l}3.882 \\
3.448 \\
3.260 \\
3.152 \\
3.084\end{array}$ & $\begin{array}{l}4.217 \\
3.710 \\
3.493 \\
3.370 \\
3.292\end{array}$ & $\begin{array}{l}4.440 \\
3.882 \\
3.647 \\
3.512 \\
3.428\end{array}$ \\
\hline \multirow[t]{2}{*}{$\begin{array}{l}60 \\
80 \\
100 \\
1500\end{array}$} & $\begin{array}{l}2.425 \\
2.476 \\
2.510 \\
2.559 \\
2.584\end{array}$ & $\begin{array}{l}\text { 2. } 274 \\
2.326 \\
2.359 \\
2.408 \\
2.433\end{array}$ & $\begin{array}{l}2.186 \\
2.238 \\
2.271 \\
2.320 \\
2.345\end{array}$ & $\begin{array}{l}182.1 \\
237.8 \\
293.3 \\
431.4 \\
569.8\end{array}$ & $\begin{array}{l}194.1 \\
253.2 \\
312.0 \\
458.6 \\
605.0\end{array}$ & $\begin{array}{l}202.0 \\
263.2 \\
324.0 \\
476.0 \\
627.7\end{array}$ & $\begin{array}{l}3.035 \\
2.972 \\
2.933 \\
2.876 \\
2.849\end{array}$ & $\begin{array}{l}3.235 \\
3.165 \\
3.120 \\
3.057 \\
3.025\end{array}$ & $\begin{array}{l}\text { 3. } 367 \\
3.290 \\
3.240 \\
3.173 \\
3.138\end{array}$ \\
\hline & \multicolumn{9}{|c|}{ Height $=25$ feet } \\
\hline $\begin{array}{l}10 \\
20 \\
80 \\
40 \\
50 \\
50 .-\end{array}$ & $\begin{array}{l}1.909 \\
2.157 \\
2.286 \\
2.371 \\
2.430\end{array}$ & $\begin{array}{l}1.758 \\
2.006 \\
2.136 \\
2.220 \\
2.279\end{array}$ & $\begin{array}{l}1.670 \\
1.918 \\
2.048 \\
2.132 \\
2.192\end{array}$ & $\begin{array}{r}38.6 \\
68.2 \\
96.6 \\
124.2 \\
151.4\end{array}$ & \begin{tabular}{r|}
41.9 \\
73.4 \\
103.4 \\
132.6 \\
161.5
\end{tabular} & $\begin{array}{r}44.1 \\
76.7 \\
107.8 \\
138.1 \\
167.9\end{array}$ & $\begin{array}{l}\text { 3. } 855 \\
3.412 \\
3.219 \\
3.105 \\
3.028\end{array}$ & $\begin{array}{l}\text { 4. } 187 \\
\text { 3. } 669 \\
3.447 \\
3.315 \\
\text { 3. } 230\end{array}$ & $\begin{array}{l}4.406 \\
3.836 \\
3.598 \\
3.452 \\
3.358\end{array}$ \\
\hline \multirow[t]{3}{*}{$\begin{array}{l}60 \\
80 \\
100 \\
150 \\
200\end{array}$} & $\begin{array}{l}2.473 \\
2.533 \\
2.572 \\
2.630 \\
2.660\end{array}$ & $\begin{array}{l}\text { 2. } 322 \\
\text { 2. } 382 \\
\text { 2. } 422 \\
\text { 2. } 479 \\
\text { 2. } 510\end{array}$ & $\begin{array}{l}2.234 \\
2.295 \\
2.334 \\
2.392 \\
2.422\end{array}$ & $\begin{array}{l}178.6 \\
232.4 \\
286.1 \\
419.8 \\
553.3\end{array}$ & $\begin{array}{l}190.2 \\
247.2 \\
304.0 \\
445.3 \\
586.6\end{array}$ & $\begin{array}{l}197.6 \\
256.6 \\
315.3 \\
461.6 \\
607.8\end{array}$ & $\begin{array}{l}2.977 \\
2.906 \\
2.861 \\
2.799 \\
2.766\end{array}$ & $\begin{array}{l}\text { 3. } 170 \\
\text { 3. } 090 \\
\text { 3. } 040 \\
2.969 \\
\text { 2. } 933\end{array}$ & $\begin{array}{l}3.293 \\
3.208 \\
3.153 \\
3.077 \\
3.039\end{array}$ \\
\hline & \multicolumn{9}{|c|}{ Height $=30$ feet } \\
\hline & $\begin{array}{l}\text { 1. } 916 \\
2.170 \\
2.306 \\
2.396 \\
2.460\end{array}$ & $\begin{array}{l}\text { 1. } 766 \\
2.019 \\
2.156 \\
2.246 \\
2.310\end{array}$ & $\begin{array}{l}1.678 \\
1.931 \\
2.068 \\
2.158 \\
2.222\end{array}$ & $\begin{array}{r}38.4 \\
67.8 \\
95.7 \\
122.9 \\
149.6\end{array}$ & $\begin{array}{r}41.7 \\
72.9 \\
102.4 \\
131.1 \\
159.3\end{array}$ & $\begin{array}{r}43.9 \\
76.2 \\
106.8 \\
136.5 \\
165.6\end{array}$ & $\begin{array}{l}\text { 3. } 840 \\
3.392 \\
3.191 \\
\text { 3. } 072 \\
\text { 2. } 992\end{array}$ & $\begin{array}{l}\text { 4. } 169 \\
3.646 \\
3.413 \\
\text { 3. } 278 \\
\text { 3. } 186\end{array}$ & $\begin{array}{l}\text { 4. } 388 \\
\text { 3. } 812 \\
\text { 3. } 560 \\
\text { 3. } 412 \\
3.312\end{array}$ \\
\hline $\begin{array}{l}60 \ldots \\
80 \ldots \\
100 . \\
150 \ldots \\
200 .\end{array}$ & $\begin{array}{l}2.508 \\
2.574 \\
2.620 \\
2.685 \\
2.720\end{array}$ & $\begin{array}{l}2.358 \\
2.424 \\
2.460 \\
2.534 \\
2.570\end{array}$ & $\begin{array}{l}2.270 \\
2.336 \\
2.381 \\
2.446 \\
2.482\end{array}$ & $\begin{array}{l}176.1 \\
228.8 \\
280.8 \\
411.2 \\
541.1\end{array}$ & $\begin{array}{l}187.3 \\
243.0 \\
298.1 \\
435.6 \\
572.8\end{array}$ & $\begin{array}{l}194.6 \\
252.1 \\
309.1 \\
451.2 \\
593.1\end{array}$ & $\begin{array}{l}2.935 \\
2.859 \\
2.808 \\
2.741 \\
2.706\end{array}$ & $\begin{array}{l}3.122 \\
3.038 \\
2.981 \\
2.904 \\
2.864\end{array}$ & $\begin{array}{l}3.243 \\
3.151 \\
3.091 \\
3.008 \\
2.966\end{array}$ \\
\hline
\end{tabular}


TABLE 9.-Constants for two-wire horizontal antennas-Continued DIAMETER OF WIRE $=0.18$ INCH $=0.015$ FOOT-Continued

\begin{tabular}{|c|c|c|c|c|c|c|c|c|c|}
\hline \multirow{3}{*}{$l$ feet } & \multicolumn{9}{|c|}{ Height $=40$ feet } \\
\hline & \multicolumn{3}{|c|}{$U$} & \multicolumn{3}{|c|}{ Capacity } & \multicolumn{3}{|c|}{ Capacity per foot } \\
\hline & $D=1$ & $D=2$ & $D=3$ & $D=1$ & $D=2$ & $D=3$ & $D=1$ & $D=2$ & $D=3$ \\
\hline $\begin{array}{l}10 \ldots \\
20 \ldots \\
30 \ldots \\
40 \ldots \\
50 \ldots\end{array}$ & $\begin{array}{l}1.924 \\
2.186 \\
2.330 \\
2.430 \\
2.501\end{array}$ & $\begin{array}{l}1.774 \\
2.036 \\
2.179 \\
2.280 \\
2.350\end{array}$ & $\begin{array}{l}\text { 1. } 686 \\
1.948 \\
2.091 \\
2.192 \\
2.262\end{array}$ & $\begin{array}{r}38.2 \\
67.3 \\
94.8 \\
121.2 \\
147.1\end{array}$ & $\begin{array}{r}41.5 \\
72.3 \\
101.3 \\
129.2 \\
156.6\end{array}$ & $\begin{array}{r}43.7 \\
75.6 \\
105.6 \\
134.3 \\
162.6\end{array}$ & \begin{tabular}{l|} 
3. 825 \\
3. 366 \\
3. 159 \\
3. 030 \\
2. 942
\end{tabular} & $\begin{array}{l}4.150 \\
3.615 \\
3.377 \\
3.229 \\
3.132\end{array}$ & $\begin{array}{l}4.367 \\
3.778 \\
3.520 \\
3.358 \\
3.253\end{array}$ \\
\hline \multirow[t]{2}{*}{$\begin{array}{l}60 \\
80 \\
100 \\
150\end{array}$} & $\begin{array}{l}2.555 \\
2.630 \\
2.684 \\
2.765 \\
2.810\end{array}$ & $\begin{array}{l}2.404 \\
2.480 \\
2.534 \\
2.614 \\
2.659\end{array}$ & $\begin{array}{l}\text { 2. } 316 \\
2.392 \\
2.446 \\
\text { 2. } 526 \\
\text { 2. } 572\end{array}$ & $\begin{array}{l}172.8 \\
223.9 \\
274.2 \\
399.3 \\
523.8\end{array}$ & $\begin{array}{l}183.7 \\
237.5 \\
290.4 \\
422.3 \\
553.6\end{array}$ & $\begin{array}{l}190.6 \\
246.2 \\
307.8 \\
437.0 \\
572.3\end{array}$ & $\begin{array}{l}2.880 \\
2.799 \\
2.742 \\
2.662 \\
2.619\end{array}$ & $\begin{array}{l}\text { 3. } 062 \\
2.969 \\
2.904 \\
2.815 \\
2.768\end{array}$ & $\begin{array}{l}3.177 \\
3.078 \\
3.008 \\
2.913 \\
2.862\end{array}$ \\
\hline & \multicolumn{9}{|c|}{ Height $=50$ feet } \\
\hline $\begin{array}{l}10 \ldots \\
20 \ldots \\
30 \ldots \\
40 \ldots \\
50 \ldots\end{array}$ & $\begin{array}{l}1.929 \\
2.200 \\
2.349 \\
2.452 \\
2.526\end{array}$ & $\begin{array}{l}\text { 1. } 778 \\
2.040 \\
2.198 \\
2.302 \\
2.376\end{array}$ & $\begin{array}{l}1.690 \\
1.961 \\
2.110 \\
2.214 \\
2.288\end{array}$ & $\begin{array}{r}38.2 \\
66.9 \\
94.2 \\
120.1 \\
145.7\end{array}$ & $\begin{array}{r}41.4 \\
71.8 \\
100.4 \\
127.9 \\
154.9\end{array}$ & $\begin{array}{r}43.5 \\
75.1 \\
104.6 \\
132.9 \\
160.9\end{array}$ & $\begin{array}{l}\text { 3. } 816 \\
\text { 3. } 346 \\
\text { 3. } 134 \\
\text { 3. } 002 \\
2.914\end{array}$ & \begin{tabular}{l|} 
4. 138 \\
3. 592 \\
3. 348 \\
3. 198 \\
3. 098
\end{tabular} & $\begin{array}{l}\text { 4. } 354 \\
\text { 3. } 753 \\
\text { 3. } 488 \\
\text { 3. } 322 \\
\text { 3. } 218\end{array}$ \\
\hline $\begin{array}{l}60 \ldots \\
80 \ldots \\
100 \ldots \\
150 \ldots \\
200 \ldots\end{array}$ & $\begin{array}{l}2.584 \\
2.669 \\
2.728 \\
2.820 \\
2.872\end{array}$ & $\begin{array}{l}2.434 \\
2.518 \\
2.580 \\
2.670 \\
2.722\end{array}$ & $\begin{array}{l}2.346 \\
2.430 \\
2.494 \\
2.582 \\
2.634\end{array}$ & $\begin{array}{l}170.9 \\
220.6 \\
269.8 \\
391.5 \\
512.4\end{array}$ & $\begin{array}{l}181.4 \\
233.8 \\
285.3 \\
413.6 \\
540.8\end{array}$ & $\begin{array}{l}188.3 \\
242.3 \\
295.1 \\
427.7 \\
558.8\end{array}$ & $\begin{array}{l}2.848 \\
2.758 \\
2.698 \\
2.610 \\
2.562\end{array}$ & $\begin{array}{l}3.023 \\
2.923 \\
2.853 \\
2.755 \\
2.704\end{array}$ & $\begin{array}{l}3.138 \\
3.029 \\
3.951 \\
2.851 \\
2.794\end{array}$ \\
\hline & \multicolumn{9}{|c|}{ Height $=60$ feet $: \frac{3}{3}$} \\
\hline $\begin{array}{l}10 \ldots \\
20- \\
30- \\
40- \\
50=\end{array}$ & $\begin{array}{l}1.933 \\
2.206 \\
2.358 \\
2.465 \\
2.543\end{array}$ & $\begin{array}{l}1.782 \\
2.056 \\
2.208 \\
2.314 \\
2.392\end{array}$ & $\begin{array}{l}1.694 \\
1.968 \\
2.120 \\
2.226 \\
2.304\end{array}$ & $\begin{array}{r}38.1 \\
66.7 \\
93.6 \\
119.4 \\
144.7\end{array}$ & $\begin{array}{r}41.3 \\
71.6 \\
100.0 \\
127.2 \\
153.8\end{array}$ & $\begin{array}{r}43.4 \\
74.8 \\
104.2 \\
132.2 \\
159.7\end{array}$ & $\begin{array}{l}\text { 3. } 808 \\
\text { 3. } 336 \\
3.121 \\
2.985 \\
2.894\end{array}$ & $\begin{array}{l}\text { 4. } 129 \\
3.580 \\
3.333 \\
3.180 \\
3.076\end{array}$ & $\begin{array}{l}4.343 \\
3.740 \\
3.472 \\
3.305 \\
3.194\end{array}$ \\
\hline \multirow[t]{2}{*}{$\begin{array}{r}60 \\
100 \\
150 \\
200\end{array}$} & $\begin{array}{l}2.604 \\
2.705 \\
2.758 \\
2.860 \\
2.920\end{array}$ & $\begin{array}{l}2.454 \\
2.554 \\
2.608 \\
2.710 \\
2.769\end{array}$ & $\begin{array}{l}2.366 \\
2.466 \\
2.520 \\
2.622 \\
2.681\end{array}$ & $\begin{array}{l}169.6 \\
217.7 \\
266.8 \\
386.0 \\
504.2\end{array}$ & $\begin{array}{l}180.0 \\
230.5 \\
282.2 \\
407.5 \\
531.6\end{array}$ & $\begin{array}{l}186.7 \\
238.7 \\
292.1 \\
421.1 \\
549.0\end{array}$ & $\begin{array}{l}2.827 \\
2.721 \\
2.668 \\
2.573 \\
2.521\end{array}$ & $\begin{array}{l}3.000 \\
2.881 \\
2.822 \\
2.717 \\
2.658\end{array}$ & $\begin{array}{l}3.112 \\
2.984 \\
2.921 \\
2.807 \\
2.745\end{array}$ \\
\hline & \multicolumn{9}{|c|}{ Height $=80$ feet } \\
\hline $\begin{array}{l}10 \ldots \\
20 \ldots \\
30 \ldots \\
40 \ldots \\
50 \ldots\end{array}$ & $\begin{array}{l}1.937 \\
2.214 \\
2.370 \\
2.492 \\
2.565\end{array}$ & $\begin{array}{l}1.786 \\
2.064 \\
2.220 \\
2.342 \\
2.414\end{array}$ & $\begin{array}{l}1.698 \\
1.976 \\
2.132 \\
2.254 \\
2.326\end{array}$ & $\begin{array}{r}38.0 \\
66.5 \\
93.2 \\
118.9 \\
143.5\end{array}$ & $\begin{array}{r}41.2 \\
71.3 \\
99.5 \\
126.6 \\
152.4\end{array}$ & $\begin{array}{r}43.3 \\
74.5 \\
103.6 \\
131.6 \\
158.2\end{array}$ & $\begin{array}{l}3.800 \\
3.324 \\
3.105 \\
2.972 \\
2.870\end{array}$ & $\begin{array}{l}4.120 \\
3.566 \\
3.315 \\
3.165 \\
3.048\end{array}$ & $\begin{array}{l}\text { 4. } 333 \\
\text { 3. } 724 \\
3.453 \\
3.290 \\
\text { 3. } 164\end{array}$ \\
\hline \multirow[t]{2}{*}{$\begin{array}{l}60 \\
80 \\
100 \\
200\end{array}$} & $\begin{array}{l}2.631 \\
2.728 \\
2.800 \\
2.915 \\
2.984\end{array}$ & $\begin{array}{l}2.480 \\
2.578 \\
2.649 \\
2.764 \\
2.834\end{array}$ & $\begin{array}{l}2.392 \\
2.490 \\
2.561 \\
2.676 \\
2.746\end{array}$ & $\begin{array}{l}167.8 \\
215.8 \\
262.9 \\
378.7 \\
493.2\end{array}$ & $\begin{array}{l}178.1 \\
228.4 \\
277.8 \\
399.3 \\
519.4\end{array}$ & $\begin{array}{l}184.6 \\
236.5 \\
287.4 \\
412.5 \\
536.1\end{array}$ & $\begin{array}{l}2.797 \\
2.698 \\
2.629 \\
2.525 \\
2.466\end{array}$ & $\begin{array}{l}2.968 \\
2.855 \\
2.778 \\
2.662 \\
2.597\end{array}$ & $\begin{array}{l}3.077 \\
2.956 \\
2.874 \\
2.750 \\
2.680\end{array}$ \\
\hline & \multicolumn{9}{|c|}{ Height $=100$ feet } \\
\hline $\begin{array}{l}10- \\
20- \\
30- \\
40- \\
50-\end{array}$ & $\begin{array}{l}1.940 \\
2.220 \\
2.380 \\
2.495 \\
2.578\end{array}$ & $\begin{array}{l}1.790 \\
2.069 \\
2.230 \\
2.344 \\
2.428\end{array}$ & $\begin{array}{l}1.702 \\
1.981 \\
2.142 \\
2.256 \\
2.340\end{array}$ & $\begin{array}{r}37.9 \\
66.3 \\
92.8 \\
118.0 \\
142.7\end{array}$ & $\begin{array}{r}41.1 \\
71.2 \\
99.1 \\
125.6 \\
151.6\end{array}$ & \begin{tabular}{r|}
43.3 \\
74.3 \\
103.1 \\
130.5 \\
157.3
\end{tabular} & $\begin{array}{l}\text { 3. } 794 \\
3.316 \\
3.092 \\
2.950 \\
2.855\end{array}$ & $\begin{array}{l}4.113 \\
3.558 \\
3.301 \\
3.140 \\
3.032\end{array}$ & $\begin{array}{l}4.326 \\
3.716 \\
3.437 \\
3.262 \\
3.146\end{array}$ \\
\hline $\begin{array}{l}60 \\
80 \\
100 \\
150 \\
200\end{array}$ & $\begin{array}{l}2.646 \\
2.750 \\
2.824 \\
2.951 \\
3.038\end{array}$ & $\begin{array}{l}2.496 \\
2.600 \\
2.674 \\
2.800 \\
2.888\end{array}$ & $\begin{array}{l}2.408 \\
2.512 \\
2.586 \\
2.713 \\
2.802\end{array}$ & $\begin{array}{l}166.9 \\
214.1 \\
261.6 \\
374.1 \\
484.5\end{array}$ & $\begin{array}{l}177.0 \\
226.5 \\
275.2 \\
394.2 \\
509.7\end{array}$ & $\begin{array}{l}183.4 \\
234.4 \\
284.6 \\
407.0 \\
525.3\end{array}$ & $\begin{array}{l}2.782 \\
2.676 \\
2.616 \\
2.497 \\
2.422\end{array}$ & $\begin{array}{l}2.950 \\
2.831 \\
2.752 \\
2.628 \\
2.548\end{array}$ & $\begin{array}{l}3.057 \\
2.930 \\
2.846 \\
2.713 \\
2.626\end{array}$ \\
\hline
\end{tabular}


TABLE 9.-Constants for two-wire horizontal antennas-Continued DIAMETER OF WIRE $=0.24 \mathrm{INCH}=0.02$ FOOT

\begin{tabular}{|c|c|c|c|c|c|c|c|c|c|}
\hline \multirow{3}{*}{$l$ feet } & \multicolumn{9}{|c|}{ Height $=10$ feet } \\
\hline & \multicolumn{3}{|c|}{$U$} & \multicolumn{3}{|c|}{ Capacity } & \multicolumn{3}{|c|}{ Capacity per foot } \\
\hline & $D=1$ & $D=2$ & $D=3$ & $D=1$ & $D=2$ & $D=3$ & $D=1$ & $D=2$ & $D=3$ \\
\hline $\begin{array}{l}10 \ldots \ldots \\
20 \ldots \ldots \\
30 \\
40 \\
50 \ldots\end{array}$ & $\begin{array}{l}1.782 \\
1.976 \\
2.065 \\
2.116 \\
2.148\end{array}$ & $\begin{array}{l}1.631 \\
1.826 \\
1.914 \\
1.965 \\
1.998\end{array}$ & $\begin{array}{l}1.543 \\
1.738 \\
1.827 \\
1.877 \\
1.910\end{array}$ & $\begin{array}{r}41.3 \\
74.5 \\
106.9 \\
139.2 \\
171.3\end{array}$ & $\begin{array}{r}45.1 \\
80.6 \\
115.3 \\
149.8 \\
184.2\end{array}$ & $\begin{array}{r}47.7 \\
84.7 \\
120.9 \\
156.8 \\
192.7\end{array}$ & $\begin{array}{l}\text { 4. } 131 \\
\text { 3. } 724 \\
\text { 3. } 563 \\
\text { 3. } 480 \\
3.426\end{array}$ & $\begin{array}{l}\text { 4. } 513 \\
\text { 4. } 032 \\
\text { 3. } 843 \\
\text { 3. } 745 \\
\text { 3. } 684\end{array}$ & $\begin{array}{l}4.770 \\
4.236 \\
4.030 \\
3.921 \\
3.854\end{array}$ \\
\hline \multirow[t]{2}{*}{$\begin{array}{l}60 \\
80 \\
100 \\
150\end{array}$} & $\begin{array}{l}2.172 \\
2.202 \\
2.221 \\
2.248 \\
2.260\end{array}$ & $\begin{array}{l}2.021 \\
2.051 \\
2.070 \\
2.097 \\
2.110\end{array}$ & $\begin{array}{l}1.933 \\
1.963 \\
1.982 \\
2.009 \\
2.022\end{array}$ & $\begin{array}{l}203.4 \\
267.6 \\
331.4 \\
491.2 \\
651.3\end{array}$ & $\begin{array}{l}218.5 \\
287.1 \\
355.5 \\
526.5 \\
697.8\end{array}$ & $\begin{array}{l}228.4 \\
300.0 \\
371.3 \\
549.5 \\
728.2\end{array}$ & $\begin{array}{l}\text { 3. } 390 \\
3.345 \\
3.314 \\
\text { 3. } 275 \\
\text { 3. } 256\end{array}$ & $\begin{array}{l}\text { 3. } 642 \\
\text { 3. } 589 \\
\text { 3. } 555 \\
\text { 3. } 510 \\
\text { 3. } 489\end{array}$ & $\begin{array}{l}\text { 3. } 807 \\
\text { 3. } 749 \\
\text { 3. } 713 \\
\text { 3. } 663 \\
\text { 3. } 641\end{array}$ \\
\hline & \multicolumn{9}{|c|}{ Height $=15$ feet } \\
\hline $\begin{array}{l}10 \ldots \ldots \\
20 \ldots \ldots \\
30 \ldots \ldots \\
40 \ldots \ldots\end{array}$ & $\begin{array}{l}1.816 \\
2.038 \\
2.148 \\
2.214 \\
2.258\end{array}$ & $\begin{array}{l}1.666 \\
1.888 \\
1.998 \\
2.063 \\
2.108\end{array}$ & $\begin{array}{l}1.578 \\
1.800 \\
1.910 \\
1.975 \\
2.020\end{array}$ & $\begin{array}{r}40.5 \\
72.2 \\
102.8 \\
133.0 \\
163.0\end{array}$ & $\begin{array}{r}44.2 \\
78.0 \\
110.5 \\
142.7 \\
174.6\end{array}$ & $\begin{array}{r}46.6 \\
81.8 \\
115.6 \\
149.1 \\
182.2\end{array}$ & $\begin{array}{l}\text { 4. } 052 \\
\text { 3. } 612 \\
\text { 3. } 427 \\
\text { 3. } 325 \\
\text { 3. } 260\end{array}$ & $\begin{array}{l}4.418 \\
3.900 \\
3.683 \\
3.568 \\
3.492\end{array}$ & $\begin{array}{l}4.664 \\
\text { 4. } 090 \\
\text { 3. } 853 \\
\text { 3. } 728 \\
\text { 3. } 644\end{array}$ \\
\hline \multirow[t]{2}{*}{$\begin{array}{l}60 \\
8000 \\
150 \\
200\end{array}$} & $\begin{array}{l}2.290 \\
2.332 \\
2.358 \\
2.396 \\
2.416\end{array}$ & $\begin{array}{l}2.139 \\
2.181 \\
2.208 \\
2.246 \\
2.266\end{array}$ & $\begin{array}{l}2.051 \\
2.093 \\
2.120 \\
2.158 \\
2.178\end{array}$ & $\begin{array}{l}192.9 \\
252.5 \\
312.1 \\
460.7 \\
609.3\end{array}$ & $\begin{array}{l}206.4 \\
270.0 \\
333.4 \\
491.5 \\
649.8\end{array}$ & $\begin{array}{l}215.3 \\
281.3 \\
347.3 \\
511.6 \\
676.0\end{array}$ & $\begin{array}{l}3.215 \\
3.156 \\
3.121 \\
3.071 \\
3.046\end{array}$ & $\begin{array}{l}\text { 3. } 441 \\
3.375 \\
\text { 3. } 334 \\
\text { 3. } 277 \\
\text { 3. } 249\end{array}$ & $\begin{array}{l}\text { 3. } 588 \\
\text { 3. } 516 \\
\text { 3. } 473 \\
\text { 3. } 411 \\
3.380\end{array}$ \\
\hline & \multicolumn{9}{|c|}{ Height $=20$ feet } \\
\hline $\begin{array}{l}40 \ldots \\
50 \ldots\end{array}$ & $\begin{array}{l}1.834 \\
2.073 \\
2.195 \\
2.272 \\
2.324\end{array}$ & $\begin{array}{l}1.683 \\
1.922 \\
2.044 \\
2.121 \\
2.173\end{array}$ & $\begin{array}{l}1.595 \\
1.834 \\
1.956 \\
2.033 \\
2.085\end{array}$ & $\begin{array}{r}40.1 \\
71.0 \\
100.6 \\
129.6 \\
158.4\end{array}$ & $\begin{array}{r}43.7 \\
76.6 \\
108.0 \\
138.8 \\
169.4\end{array}$ & $\begin{array}{r}46.1 \\
80.3 \\
112.8 \\
144.8 \\
176.5\end{array}$ & $\begin{array}{l}\text { 4. } 014 \\
3.552 \\
3.353 \\
3.240 \\
3.168\end{array}$ & $\begin{array}{l}4.373 \\
3.830 \\
3.600 \\
3.470 \\
3.387\end{array}$ & $\begin{array}{l}4.614 \\
4.014 \\
3.762 \\
3.620 \\
3.530\end{array}$ \\
\hline \multirow[t]{2}{*}{$\begin{array}{l}60 \\
80 \\
100 \\
150 \\
200\end{array}$} & $\begin{array}{l}2.362 \\
2.414 \\
2.447 \\
2.496 \\
2.521\end{array}$ & $\begin{array}{l}2.212 \\
2.263 \\
2.296 \\
2.345 \\
2.370\end{array}$ & $\begin{array}{l}2.124 \\
2.175 \\
2.208 \\
2.257 \\
2.282\end{array}$ & $\begin{array}{l}186.9 \\
244.0 \\
300.8 \\
442.4 \\
583.9\end{array}$ & $\begin{array}{l}199.6 \\
260.2 \\
320.5 \\
470.8 \\
621.0\end{array}$ & $\begin{array}{l}207.6 \\
270.7 \\
333.3 \\
489.1 \\
644.9\end{array}$ & $\begin{array}{l}3.115 \\
3.050 \\
3.008 \\
2.949 \\
2.920\end{array}$ & $\begin{array}{l}3.327 \\
3.252 \\
3.205 \\
3.139 \\
3.105\end{array}$ & $\begin{array}{l}\text { 3. } 460 \\
\text { 3. } 384 \\
\text { 3. } 333 \\
\text { 3. } 261 \\
\text { 3. } 224\end{array}$ \\
\hline & \multicolumn{9}{|c|}{ Height $=25$ feet } \\
\hline $\begin{array}{l}10 \ldots \\
20 \ldots \\
30 \ldots \\
40 \ldots \\
50 \ldots\end{array}$ & $\begin{array}{l}1.846 \\
2.093 \\
2.224 \\
2.308 \\
2.368\end{array}$ & $\begin{array}{l}1.696 \\
1.942 \\
2.073 \\
2.158 \\
2.217\end{array}$ & $\begin{array}{l}1.608 \\
1.854 \\
1.986 \\
2.070 \\
2.129\end{array}$ & $\begin{array}{r}39.9 \\
70.3 \\
99.3 \\
127.5 \\
155.4\end{array}$ & $\begin{array}{r}43.4 \\
75.8 \\
106.5 \\
136.5 \\
166.0\end{array}$ & $\begin{array}{r}45.8 \\
79.4 \\
111.2 \\
142.2 \\
172.8\end{array}$ & $\begin{array}{l}3.986 \\
3.516 \\
3.309 \\
3.188 \\
3.108\end{array}$ & $\begin{array}{l}4.341 \\
3.790 \\
3.550 \\
3.412 \\
3.320\end{array}$ & $\begin{array}{l}4.577 \\
\text { 3. } 968 \\
\text { 3. } 707 \\
3.550 \\
3.456\end{array}$ \\
\hline \multirow[t]{2}{*}{$\begin{array}{l}60 \\
800 \\
100 \\
200\end{array}$} & $\begin{array}{l}2.410 \\
2.470 \\
2.510 \\
2.568 \\
2.598\end{array}$ & $\begin{array}{l}2.260 \\
2.320 \\
2.359 \\
2.416 \\
2.447\end{array}$ & $\begin{array}{l}2.172 \\
2.232 \\
2.272 \\
2.329 \\
2.360\end{array}$ & $\begin{array}{l}183.2 \\
238.3 \\
293.2 \\
430.0 \\
566.0\end{array}$ & $\begin{array}{l}195.4 \\
253.8 \\
312.0 \\
456.9 \\
601.6\end{array}$ & $\begin{array}{l}203.3 \\
263.8 \\
324.0 \\
474.0 \\
623.9\end{array}$ & $\begin{array}{l}3.053 \\
2.979 \\
2.932 \\
2.867 \\
2.833\end{array}$ & $\begin{array}{l}\text { 3. } 257 \\
\text { 3. } 173 \\
\text { 3. } 120 \\
3.046 \\
3.008\end{array}$ & $\begin{array}{l}\text { 3. } 388 \\
\text { 3. } 297 \\
\text { 3. } 240 \\
\text { 3. } 160 \\
\text { 3. } 120\end{array}$ \\
\hline & \multicolumn{9}{|c|}{ Height $=30$ feet } \\
\hline & $\begin{array}{l}1.854 \\
2.107 \\
2.244 \\
2.334 \\
2.398\end{array}$ & $\begin{array}{l}1.703 \\
1.958 \\
2.094 \\
2.183 \\
2.247\end{array}$ & $\begin{array}{l}1.615 \\
1.868 \\
2.006 \\
2.095 \\
2.159\end{array}$ & $\begin{array}{r}39.7 \\
69.9 \\
98.4 \\
126.2 \\
153.5\end{array}$ & $\begin{array}{r}43.2 \\
75.2 \\
105.5 \\
134.9 \\
163.8\end{array}$ & $\begin{array}{r}45.6 \\
78.8 \\
110.1 \\
140.5 \\
170.4\end{array}$ & $\begin{array}{l}\text { 3. } 971 \\
3.493 \\
3.280 \\
3.155 \\
\text { 3. } 070\end{array}$ & \begin{tabular}{l|}
4.322 \\
3.758 \\
3.517 \\
3.372 \\
3.276
\end{tabular} & $\begin{array}{l}4.557 \\
\text { 3. } 939 \\
3.670 \\
\text { 3. } 512 \\
\text { 3. } 409\end{array}$ \\
\hline $\begin{array}{l}60 \\
80 \\
100 \\
150\end{array}$ & $\begin{array}{l}2.466 \\
2.511 \\
2.557 \\
2.622 \\
2.658\end{array}$ & $\begin{array}{l}2.295 \\
2.361 \\
2.406 \\
2.472 \\
2.506\end{array}$ & $\begin{array}{l}2.207 \\
2.273 \\
2.318 \\
2.384 \\
2.420\end{array}$ & $\begin{array}{l}180.6 \\
234.4 \\
287.8 \\
421.0 \\
553.8\end{array}$ & $\begin{array}{l}192.4 \\
249.4 \\
305.8 \\
446.6 \\
587.4\end{array}$ & $\begin{array}{l}200.1 \\
259.0 \\
317.4 \\
463.1 \\
608.4\end{array}$ & $\begin{array}{l}\text { 3. } 010 \\
2.930 \\
2.878 \\
2.807 \\
2.769\end{array}$ & $\begin{array}{l}3.207 \\
3.118 \\
3.058 \\
2.977 \\
2.937\end{array}$ & $\begin{array}{l}3.335 \\
\text { 3. } 239 \\
3.174 \\
3.087 \\
3.042\end{array}$ \\
\hline
\end{tabular}


TABLE 9.-Constants for two-wire horizontal antennas-Continued DIAMETER OF WIRE $=0.24 \mathrm{INCH}=0.02$ FOOT-Continued

\begin{tabular}{|c|c|c|c|c|c|c|c|c|c|}
\hline \multirow{3}{*}{$l$ feet } & \multicolumn{9}{|c|}{ Height $=40$ feet } \\
\hline & \multicolumn{3}{|c|}{$U$} & \multicolumn{3}{|c|}{ Capacity } & \multicolumn{3}{|c|}{ Capacity per foot } \\
\hline & $D=1$ & $D=2$ & $D=3$ & $D=1$ & $D=2$ & $D=3$ & $D=1$ & $D=2$ & $D=3$ \\
\hline $\begin{array}{l}10 \ldots \\
20 \ldots \\
30 \ldots \\
40 \ldots \\
50 \ldots\end{array}$ & $\begin{array}{l}1.862 \\
2.124 \\
2.267 \\
2.368 \\
2.438\end{array}$ & $\begin{array}{l}1.711 \\
1.974 \\
2.116 \\
2.217 \\
2.289\end{array}$ & $\begin{array}{l}1.623 \\
1.886 \\
2.028 \\
2.129 \\
2.200\end{array}$ & $\begin{array}{r}39.5 \\
69.3 \\
99.7 \\
124.4 \\
150.9\end{array}$ & $\begin{array}{r}43.0 \\
74.6 \\
104.3 \\
132.8 \\
160.7\end{array}$ & $\begin{array}{r}45.4 \\
78.1 \\
108.8 \\
138.3 \\
167.3\end{array}$ & $\begin{array}{l}\text { 3. } 954 \\
3.465 \\
3.324 \\
3.109 \\
3.018\end{array}$ & $\begin{array}{l}\text { 4. } 302 \\
3.730 \\
3.477 \\
3.320 \\
\text { 3. } 214\end{array}$ & $\begin{array}{l}\text { 4. } 535 \\
\text { 4. } 032 \\
\text { 3. } 628 \\
3.458 \\
3.346\end{array}$ \\
\hline \multirow[t]{2}{*}{$\begin{array}{l}60 \\
80 \\
100 \\
150 \\
200\end{array}$} & $\begin{array}{l}2.492 \\
2.570 \\
2.622 \\
2.702 \\
2.748\end{array}$ & $\begin{array}{l}2.342 \\
2.419 \\
2.472 \\
2.552 \\
2.596\end{array}$ & $\begin{array}{l}2.254 \\
2.331 \\
2.384 \\
2.464 \\
2.510\end{array}$ & $\begin{array}{l}177.2 \\
229.2 \\
280.7 \\
408.6 \\
535.7\end{array}$ & $\begin{array}{l}188.6 \\
243.4 \\
297.8 \\
432.6 \\
566.9\end{array}$ & $\begin{array}{l}195.9 \\
252.6 \\
308.8 \\
448.1 \\
586.6\end{array}$ & $\begin{array}{l}2.953 \\
2.864 \\
2.807 \\
2.724 \\
2.678\end{array}$ & $\begin{array}{l}\text { 3. } 143 \\
3.042 \\
2.978 \\
2.884 \\
2.834\end{array}$ & $\begin{array}{l}\text { 3. } 265 \\
3.158 \\
3.088 \\
2.987 \\
2.933\end{array}$ \\
\hline & \multicolumn{9}{|c|}{ Height $=50$ feet } \\
\hline $\begin{array}{l}10 \ldots \\
20 \ldots \\
30 \ldots \\
40 \ldots \\
50 \ldots\end{array}$ & $\begin{array}{l}1.866 \\
2.137 \\
2.286 \\
2.388 \\
2.464\end{array}$ & $\begin{array}{l}1.716 \\
1.986 \\
2.136 \\
2.238 \\
2.313\end{array}$ & $\begin{array}{l}1.628 \\
1.898 \\
2.048 \\
2.150 \\
2.225\end{array}$ & $\begin{array}{r}39.4 \\
68.9 \\
96.6 \\
123.3 \\
149.4\end{array}$ & $\begin{array}{r}42.9 \\
74.1 \\
103.4 \\
131.6 \\
159.1\end{array}$ & $\begin{array}{r}45.2 \\
77.5 \\
107.8 \\
136.9 \\
165.4\end{array}$ & \begin{tabular}{l|} 
3. 943 \\
3. 443 \\
3.220 \\
3.082 \\
2. 988
\end{tabular} & $\begin{array}{l}\text { 4. } 289 \\
3.705 \\
3.447 \\
3.289 \\
3.182\end{array}$ & $\begin{array}{l}4.521 \\
\text { 3. } 877 \\
3.593 \\
3.422 \\
3.308\end{array}$ \\
\hline \multirow[t]{2}{*}{$\begin{array}{l}60 \\
80 \\
100 \\
200\end{array}$} & $\begin{array}{l}2.522 \\
2.606 \\
2.666 \\
2.758 \\
2.810\end{array}$ & $\begin{array}{l}2.371 \\
2.456 \\
2.515 \\
2.607 \\
2.658\end{array}$ & $\begin{array}{l}2.283 \\
2.368 \\
2.428 \\
2.519 \\
2.572\end{array}$ & $\begin{array}{l}175.2 \\
225.9 \\
276.1 \\
400.4 \\
523.8\end{array}$ & $\begin{array}{l}186.3 \\
239.7 \\
292.6 \\
423.5 \\
553.8\end{array}$ & $\begin{array}{l}193.4 \\
248.6 \\
303.2 \\
438.2 \\
572.4\end{array}$ & $\begin{array}{l}2.920 \\
2.824 \\
2.761 \\
2.669 \\
2.619\end{array}$ & $\begin{array}{l}3.105 \\
2.996 \\
2.926 \\
2.827 \\
2.769\end{array}$ & $\begin{array}{l}3.223 \\
3.108 \\
\text { 3. } 032 \\
2.901 \\
2.862\end{array}$ \\
\hline & \multicolumn{9}{|c|}{ Height $=60$ feet } \\
\hline $\begin{array}{l}10 \ldots \\
20 \ldots \\
30 \ldots \\
40 \\
50 \ldots\end{array}$ & $\begin{array}{l}1.870 \\
2.144 \\
2.296 \\
2.402 \\
2.480\end{array}$ & $\begin{array}{l}1.720 \\
1.994 \\
2.146 \\
2.252 \\
2.330\end{array}$ & $\begin{array}{l}1.632 \\
1.906 \\
2.058 \\
2.164 \\
2.242\end{array}$ & $\begin{array}{r}39.3 \\
68.7 \\
96.2 \\
122.5 \\
148.4\end{array}$ & $\begin{array}{r}42.8 \\
53.8 \\
102.9 \\
130.8 \\
157.9\end{array}$ & $\begin{array}{r}45.1 \\
77.2 \\
107.3 \\
136.0 \\
164.1\end{array}$ & $\begin{array}{l}\text { 3. } 932 \\
\text { 3. } 433 \\
3.206 \\
3.062 \\
\text { 2. } 968\end{array}$ & $\begin{array}{l}4.279 \\
3.692 \\
3.430 \\
3.270 \\
3.158\end{array}$ & $\begin{array}{l}4.510 \\
3.862 \\
3.577 \\
3.400 \\
3.282\end{array}$ \\
\hline \multirow[t]{2}{*}{$\begin{array}{l}60 \\
80 \\
100 \\
150 \\
200\end{array}$} & $\begin{array}{l}2.542 \\
2.632 \\
2.697 \\
2.798 \\
2.854\end{array}$ & $\begin{array}{l}2.391 \\
2.482 \\
2.546 \\
2.607 \\
2.702\end{array}$ & $\begin{array}{l}2.303 \\
2.394 \\
2.458 \\
2.559 \\
2.618\end{array}$ & $\begin{array}{l}173.8 \\
223.7 \\
272.9 \\
394.6 \\
515.8\end{array}$ & $\begin{array}{l}184.7 \\
237.2 \\
289.0 \\
417.1 \\
544.9\end{array}$ & $\begin{array}{l}191.8 \\
246.0 \\
299.4 \\
431.4 \\
562.2\end{array}$ & $\begin{array}{l}2.897 \\
2.796 \\
2.729 \\
2.631 \\
2.579\end{array}$ & $\begin{array}{l}3.078 \\
2.965 \\
2.890 \\
2.781 \\
2.724\end{array}$ & $\begin{array}{l}3.197 \\
3.074 \\
2.994 \\
2.876 \\
2.811\end{array}$ \\
\hline & \multicolumn{9}{|c|}{ Height $=80$ feet } \\
\hline & \begin{tabular}{l|}
1.874 \\
2.152 \\
2.310 \\
2.420 \\
2.504
\end{tabular} & $\begin{array}{l}1.724 \\
2.002 \\
2.158 \\
2.269 \\
2.354\end{array}$ & $\begin{array}{l}1.636 \\
1.914 \\
2.072 \\
2.181 \\
2.266\end{array}$ & $\begin{array}{r}39.3 \\
68.4 \\
95.6 \\
121.7 \\
146.9\end{array}$ & $\begin{array}{r}42.7 \\
73.5 \\
102.3 \\
129.8 \\
156.3\end{array}$ & $\begin{array}{r}45.0 \\
76.9 \\
106.6 \\
135.0 \\
162.7\end{array}$ & $\begin{array}{l}\text { 3. } 927 \\
3.420 \\
3.186 \\
\text { 3. } 042 \\
2.938\end{array}$ & $\begin{array}{l}\text { 4. } 269 \\
3.677 \\
3.410 \\
3.244 \\
3.126\end{array}$ & $\begin{array}{l}4.499 \\
3.846 \\
3.553 \\
3.375 \\
3.254\end{array}$ \\
\hline \multirow[t]{2}{*}{$\begin{array}{l}60 \\
8000 \\
150 \\
200\end{array}$} & $\begin{array}{l}2.568 \\
2.666 \\
2.736 \\
2.852 \\
2.922\end{array}$ & $\begin{array}{l}2.418 \\
2.515 \\
2.586 \\
2.702 \\
2.771\end{array}$ & $\begin{array}{l}2.330 \\
2.427 \\
2.498 \\
2.614 \\
2.684\end{array}$ & $\begin{array}{l}171.9 \\
220.9 \\
269.0 \\
387.0 \\
503.8\end{array}$ & $\begin{array}{l}182.6 \\
234.1 \\
296.6 \\
408.6 \\
531.1\end{array}$ & $\begin{array}{l}189.5 \\
242.6 \\
293.6 \\
422.3 \\
548.5\end{array}$ & $\begin{array}{l}2.865 \\
2.761 \\
2.660 \\
2.580 \\
2.519\end{array}$ & $\begin{array}{l}\text { 3. } 043 \\
2.926 \\
2.844 \\
2.724 \\
2.656\end{array}$ & $\begin{array}{l}3.158 \\
3.032 \\
2.946 \\
2.815 \\
2.742\end{array}$ \\
\hline & \multicolumn{9}{|c|}{ Height $=100$ feet } \\
\hline $\begin{array}{l}10 .- \\
20 \ldots \\
30- \\
40 \ldots \\
50 .-\end{array}$ & $\begin{array}{l}1.878 \\
2.156 \\
2.318 \\
2.432 \\
2.516\end{array}$ & $\begin{array}{l}1.727 \\
2.006 \\
2.168 \\
2.282 \\
2.365\end{array}$ & $\begin{array}{l}1.639 \\
1.918 \\
2.080 \\
2.194 \\
2.277\end{array}$ & $\begin{array}{r}39.2 \\
68.3 \\
95.3 \\
121.0 \\
146.3\end{array}$ & $\begin{array}{r}42.6 \\
73.4 \\
101.9 \\
129.0 \\
155.6\end{array}$ & $\begin{array}{r}44.9 \\
76.7 \\
106.2 \\
134.2 \\
161.6\end{array}$ & $\begin{array}{l}\text { 3. } 920 \\
\text { 3. } 414 \\
3.175 \\
\text { 3. } 025 \\
2.926\end{array}$ & $\begin{array}{l}\text { 4. } 262 \\
\text { 3. } 668 \\
\text { 3. } 397 \\
\text { 3. } 222 \\
\text { 3. } 112\end{array}$ & $\begin{array}{l}4.491 \\
3.836 \\
3.540 \\
3.355 \\
3.232\end{array}$ \\
\hline $\begin{array}{l}60 \ldots \\
80 \ldots \\
100 \ldots \\
150 \ldots \\
200 \ldots\end{array}$ & $\begin{array}{l}2.584 \\
2.686 \\
2.752 \\
2.888 \\
2.966\end{array}$ & $\begin{array}{l}2.433 \\
2.536 \\
2.612 \\
2.738 \\
2.816\end{array}$ & $\begin{array}{l}2.345 \\
2.448 \\
2.524 \\
2.650 \\
2.730\end{array}$ & $\begin{array}{l}170.9 \\
219.2 \\
266.5 \\
382.2 \\
496.3\end{array}$ & $\begin{array}{l}181.5 \\
232.2 \\
281.8 \\
403.2 \\
522.8\end{array}$ & $\begin{array}{l}188.3 \\
240.5 \\
291.7 \\
416.6 \\
539.3\end{array}$ & $\begin{array}{l}2.848 \\
2.740 \\
2.665 \\
2.548 \\
2.492\end{array}$ & $\begin{array}{l}3.025 \\
2.902 \\
2.818 \\
2.688 \\
2.614\end{array}$ & $\begin{array}{l}\text { 3. } 138 \\
\text { 3. } 006 \\
2.917 \\
2.777 \\
2.696\end{array}$ \\
\hline
\end{tabular}




\section{APPENDIXES}

\section{APPENDIX 1.-FORMULA FOR THE CAPACITY OF A SOLID-TOP ANTENNA}

The antenna is supposed to consist of a rectangular metal plate of dimensions $l$ by $w$, and to have a thickness of $2 t$. It is placed with its plane at a height $h$ above the ground. The capacity is derived by first assuming a uniform distribution of charge, and from the corresponding potential distribution the equilibrium potential is obtained by Howe's approximation applied to both dimensions. The capacity formula is then

$$
C=\frac{16.95 l_{2} w_{2}}{S-S^{\prime}}
$$

in which the dimensions are supposed to be in feet, and the quantity

$$
\begin{aligned}
S & =w \sinh ^{-1} \frac{l}{\sqrt{w^{2}+t^{2}}}+l \sinh ^{-1} \frac{w^{w}}{\sqrt{l^{2}+t^{2}}}+\frac{t^{2}}{w} \sinh ^{-1} \frac{l}{t}\left(\frac{\sqrt{w^{2}+l^{2}+t^{2}}-\sqrt{l^{2}+t^{3}}}{\sqrt{w^{3}+t^{2}}}\right) \\
& +\frac{t^{2}}{l} \sinh ^{-1} \frac{w}{t}\left(\frac{\sqrt{w^{2}+l^{2}+t^{2}}-\sqrt{w^{2}+t^{2}}}{\sqrt{l^{2}}+t^{2}}\right)-2 t \tan ^{-1} \frac{w l}{t \sqrt{w^{2}+l^{2}+t^{2}}} \\
& +\frac{t^{2}}{l w}\left[\sqrt{w^{2}+l^{2}+t^{2}}-\sqrt{l^{2}+t^{2}}-\sqrt{w^{2}+t^{2}}+t\right] \\
& -\frac{1}{3 l w}\left[\left(w^{2}+l^{2}+t^{2}\right)^{\frac{3}{2}}-\left(l^{3}+t^{2}\right)^{\frac{3}{2}}-\left(w^{3}+t^{2}\right)^{\frac{3}{2}}+t^{3}\right]
\end{aligned}
$$

The value of $S^{\prime}$ is obtained from $S$ by substituting $2 h$ for $t$ in the formula for $S$.

If the width of the antenna is small compared with its length, $S$ and $S^{\prime}$ may be expanded in series, and we may write

$$
C=\frac{0.2416 l_{1}}{p_{1}-p_{2}}=\frac{7.36 l_{2}}{p_{1}-p_{2}}
$$

in which

where

$$
\begin{aligned}
2.303 p_{1} & =\operatorname{logn} \frac{2 l}{w}+\frac{1}{2}+\frac{1}{3} \frac{w}{l}-\frac{1}{24} \frac{w^{2}}{l^{2}}+\frac{1}{480} \frac{w^{4}}{l^{4}}-\ldots \\
2.303 p_{2} & =\sinh ^{-1} \frac{l}{\sqrt{w^{2}+\beta^{2}}}-\left(\frac{\alpha-\beta}{l}\right)+\frac{17}{24} \frac{w^{2}}{\alpha^{2}} \cdot \frac{l}{\alpha}-\frac{1}{8} \frac{w^{2}}{\alpha^{2}} \cdot \frac{\alpha}{l} \\
& +\frac{1}{24} \frac{w^{2}}{\alpha^{2}} \cdot \frac{\beta^{2}}{\alpha l}+\frac{1}{12} \frac{w^{2}}{\beta^{2}} \cdot \frac{\beta}{l}-\frac{1}{4} \frac{w^{2}}{\beta^{2}} \frac{l}{\alpha}+\frac{2}{3} \frac{w^{2}}{\beta^{2}} \cdot \frac{l^{3}}{\alpha^{3}}+\ldots .
\end{aligned}
$$

$$
\beta=2 h, \alpha=\sqrt{l^{2}+\beta^{2}}=\sqrt{l^{2}+4 h^{2}}
$$

\section{APPENDIX 2.-FORMULAS FOR POTENTIAL COEFFICIENTS OF VARI- OUS WIRE COMBINATIONS WITH UNIT CHARGE DENSITY}

In each of the following formulas the length of the charged conductor is taken as $m$, and the potential of the conductor of length $l$, due to unit linear charge density on conductor $m$, is denoted by $U_{\mathrm{lm}}$. The corresponding linear potential coefficient $U_{\mathrm{ml}}$, supposing the conductor $l$ to be charged, may be obtained from the general relation below. The potential coefficient $P_{\mathrm{lm}}=P_{\mathrm{ml}}$, due to unit charge on either conductor, is obtained from the potential coefficient per unit linear charge density by the relation $P_{\mathrm{lm}}=P_{\mathrm{ml}}=\frac{U_{\mathrm{lm}}}{m}=\frac{U_{\mathrm{m} l}}{l}$. Since $U_{\mathrm{lm}}$ is of 
zero dimensions in length, any unit of length may be employed, provided it is used consistently throughout. If $U_{\mathrm{Im}}$ is to be used in the denominator of the general formulas

$$
C=\frac{0.2416 l_{1}}{\Sigma U_{\operatorname{lm}}}=\frac{7.36 l_{2}}{\Sigma U_{\mathrm{Im}}}
$$

the value of $U_{\text {lm }}$ found by any formula of this section must be divided by 4.605 .

SINGLE WIRE.-For a single wire of diameter $d$ and length $l$,

$$
\begin{aligned}
U_{11} & =2\left[\sinh ^{-1} \frac{2 l}{d}-\sqrt{1+\frac{d^{2}}{4 h^{2}}}+\frac{d}{2 l}\right] \\
& =2\left[\sinh ^{-1} \frac{2 l}{d}-1\right] \text { approx. }
\end{aligned}
$$

Two Parallel Wires.-The wires are supposed to be placed as shown in Figure 11.

$$
\begin{gathered}
U_{\mathrm{lm}}=\frac{\alpha}{l} \sinh ^{-1} \frac{\alpha}{D}-\frac{\beta}{l} \sinh ^{-1} \frac{\beta}{D}-\frac{\gamma}{l} \sinh ^{-1} \frac{\cdot \gamma}{D}+\frac{2 h}{l} \sinh ^{-1} \frac{2 h}{D} \\
-\frac{\sqrt{\alpha^{2}+D^{2}}}{l}+\frac{\sqrt{\beta^{2}+D^{2}}}{l}+\frac{\sqrt{\gamma^{2}+D^{2}}}{l}-\frac{\sqrt{4 h^{2}+D^{2}}}{l} \\
\alpha=l+m+2 h, \beta=l+2 h, \gamma=m+2 h
\end{gathered}
$$

As special cases, we have for $D=0$ (wires in the same straight line)

$$
U_{\operatorname{lm}}=\frac{\alpha}{l} \log n \frac{\alpha}{l}-\frac{\beta}{l} \log n \frac{\beta}{l}-\frac{\gamma}{l} \log n \frac{\gamma}{l}+\frac{2 h}{l} \log \frac{2 h}{l}
$$

Wires in contact, $2 h^{\prime}=0, D \neq 0$.

$$
U_{\mathrm{lm}}=\operatorname{logn} \frac{l+m}{l}+\frac{m}{l} \operatorname{logn} \frac{l+m}{m}
$$

Common perpendicular through the centers of the wires (fig. 12).

$$
\begin{gathered}
U_{\mathrm{lm}}=\frac{l+m}{l} \sinh ^{-1} \frac{l+m}{2 D}-\frac{(l-m)}{l} \sinh ^{-1} \frac{l-m}{2 D} \\
-\frac{2}{l} \sqrt{\left(\frac{l+m}{2}\right)^{2}+D^{2}}+\frac{2}{l} \sqrt{\left(\frac{l-m}{2}\right)^{2}+D^{2}}
\end{gathered}
$$

If, further, the lengths are equal, $l=m=l_{1}$

$$
U_{11^{\prime}}=2\left[\sinh ^{-1} \frac{l_{1}}{D}-\sqrt{1+\frac{D^{2}}{l_{1}^{2}}}+\frac{D}{l_{1}}\right]
$$

Common perpendicular through the ends of the wires.- $-(a)$ Wires on the same side of the perpendicular: 


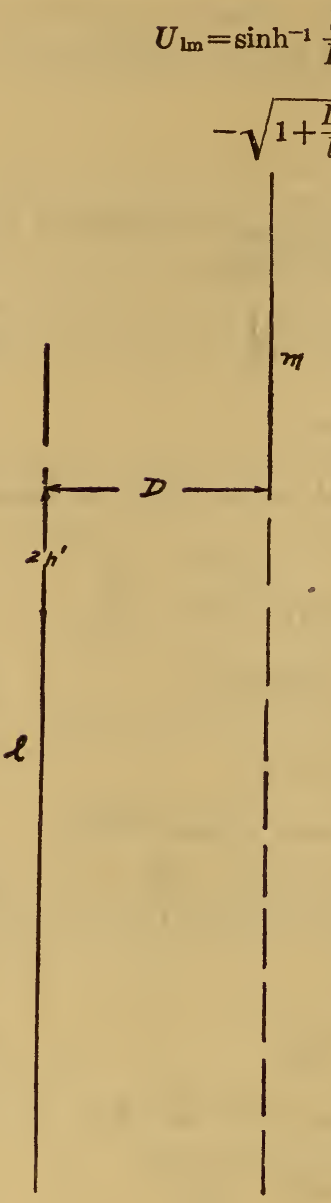

FI G. 11. $-T$ wo parallel wires, general case

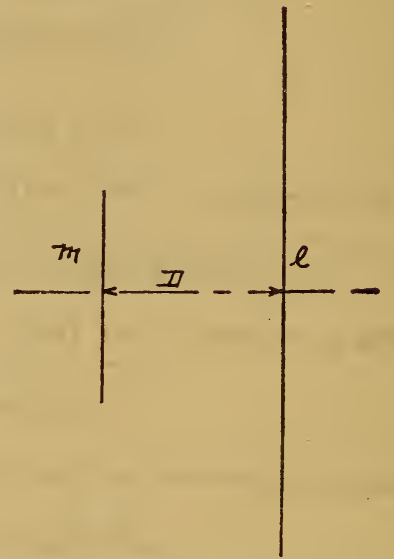

Fig. 12.-Two parallel wires, sym metrically placed

(b) Wires on opposite sides of the perpendicular:

$$
\begin{gathered}
U_{\mathrm{lm}}=\frac{l+m}{l} \sinh ^{-1} \frac{l+m}{D}-\sinh ^{-1} \frac{l}{D}-\frac{m}{l} \sinh ^{-1} \frac{m}{D} \\
-\frac{\sqrt{(l+m)^{2}+D^{2}}}{l}+\frac{\sqrt{l^{2}+D^{2}}}{l}+\frac{\sqrt{m^{2}+D^{2}}}{l}-\frac{D}{l}
\end{gathered}
$$

Wires at Right Angles. - Wires in the same plane intersecting at right angles:

$$
U_{\mathrm{lm}}=\sinh ^{-1} \frac{m}{l}+\frac{m}{l} \sinh ^{-1} \frac{l}{m}
$$


Wires in the same plane with their nearer ends separated by a distance $2 h$ :

$$
U_{l \mathrm{~m}}=\sinh ^{-1} \frac{m+2 h}{l}-\sinh ^{-1} \frac{2 h}{l}+\frac{2 h+m}{l} \sinh ^{-1} \frac{l}{2 h+m}-\frac{2 h}{l} \sinh ^{-1} \frac{l}{2 h}
$$

Wires in parallel planes separated by a distance $D$ and with the end of wire $m$ separated by a distance $2 h$ from the common perpendicular which runs through the end of the wire $l$ :

$$
\begin{gathered}
U_{l \mathrm{~m}}=\sinh ^{-1} \frac{2 h+m}{\sqrt{D^{2}+l^{2}}}-\sinh ^{-1} \frac{2 h}{\sqrt{D^{2}+l^{2}}}+\frac{2 h+m}{l} \sinh ^{-1} \frac{l}{\sqrt{D^{2}+(2 h+m)^{2}}} \\
-\frac{2 h}{l} \sinh ^{-1} \frac{l}{\sqrt{D^{2}+4 h^{2}}}-\frac{D}{l}\left(\tan ^{-1} \frac{l(2 h+m)}{D \sqrt{D^{2}+l^{2}+(2 h+m)^{2}}}-\tan ^{-1} \frac{2 h l}{D \sqrt{D^{2}+l^{2}+4 h^{2}}}\right)
\end{gathered}
$$

Wires in parallel planes separated by a distance $D$, the common perpendicular through the ends of both wires:

$$
U_{l m}=\sinh ^{-1} \frac{m}{\sqrt{l^{2}+D^{2}}}+\frac{m}{l} \sinh ^{-1} \frac{l}{\sqrt{m^{2}+D^{2}}}-\frac{D}{l} \tan ^{-1} \frac{l m}{D \sqrt{l^{2}+m^{2}+D^{2}}}
$$

WrRes Inclined to ONe ANother.-Wires intersecting at an angle $\theta$ :

$$
U_{l m}=\sinh ^{-1} \frac{m-l \cos \theta}{l \sin \theta}+\frac{m}{l} \sinh ^{-1} \frac{l-m \cos \theta}{m \sin \theta}+\frac{l+m}{l} \sinh ^{-1}(\cot \theta)
$$

Wires in the same plane, but not intersecting, the distances of wires $l$ and $m$ from the intersection of their directions being $\mu$ and $\nu$, respectively:

$$
\begin{aligned}
U_{l m} & =\frac{\mu+l}{l}\left[\sinh ^{-1} \frac{(\nu+m)-(\mu+l) \cos \theta}{(\mu+l) \sin \theta}-\sinh ^{-1} \frac{\nu-(\mu+l) \cos \theta}{(\mu+l) \sin \theta}\right] \\
& -\frac{\mu}{l}\left[\sinh ^{-1} \frac{(\nu+m)-\mu \cos \theta}{\mu \sin \theta}-\sinh ^{-1} \frac{\nu-\mu \cos \theta}{\mu \sin \theta}\right] \\
& +\frac{(\nu+m)}{l}\left[\sinh ^{-1} \frac{(\mu+l)-(\nu+m) \cos \theta}{(\nu+m) \sin \theta}-\sinh ^{-1} \frac{\mu-(\nu+m) \cos ^{-} \theta}{\mu \sin \theta}\right] \\
& -\frac{\nu}{l}\left[\sinh ^{-1} \frac{(\mu+l)-\nu \cos \theta}{\nu \sin \theta}-\sinh ^{-1} \frac{\mu-\nu \cos \theta}{\nu \sin \theta}\right]
\end{aligned}
$$

Wires in parallel planes separated by a distance $2 h$. The common perpendicular passes through the ends of the wires, and they are inclined at an angle $\theta$ :

$$
\begin{aligned}
& U_{l m}=2 \tanh ^{-1} \frac{m}{R_{1}+R_{2}}+2 \frac{m}{l} \tanh ^{-1} \frac{l}{R_{1}+R_{4}} \\
& -\frac{2 h}{l \sin \theta}\left[\tan ^{-1} \frac{4 h^{2} \cos \theta+l m \sin ^{2} \theta}{2 h R_{1} \sin \theta}-\tan ^{-1} \frac{2 h \cot \theta}{R_{2}}\right. \\
& \left.-\tan ^{-1} \frac{2 h \cot \theta}{R_{4}}+\tan ^{-1}(\cot \theta)\right] \\
& R_{1}{ }^{2}=4 h^{2}+l^{2}+m^{2}-2 l m \cos \theta \\
& R_{2}{ }^{2}=4 h^{2}+l^{2}, R_{3}{ }^{2}=4 h^{2}, R_{4}{ }^{2}=4 h^{2}+m^{2} .
\end{aligned}
$$

General case of any two straight wires whatever (G. A. Campbell). In Figure 13 the wires are $A B$ and $a b$, their common perpendicular $P p$, and the various distances are given in the figure.

$$
\begin{aligned}
U_{l m} & =\frac{2(\mu+l)}{l} \tanh ^{-1} \frac{m}{R_{1}+R_{2}}-\frac{2 \mu}{l} \tanh ^{-1} \frac{m}{R_{3}+R_{4}} \\
& +\frac{2(\nu+m)}{l} \tanh ^{-1} \frac{l}{R_{1}+R_{4}}-\frac{2 \nu}{l} \tanh ^{-1} \frac{l}{R_{2}+R_{3}}-\frac{d \Omega}{l \sin \epsilon}
\end{aligned}
$$


where

$$
\begin{aligned}
\Omega & =\tan ^{-1}\left[\frac{d^{2} \cos \epsilon+(\mu+l)(\nu+m) \sin ^{2} \epsilon}{d R_{1} \sin \epsilon}\right]+\tan ^{-1}\left[\frac{d^{2} \cos \epsilon+\mu^{2} \sin ^{2} \epsilon}{d R_{3} \sin \epsilon}\right] \\
& -\tan ^{-1}\left[\frac{d^{2} \cos \epsilon+(\mu+l) \nu \sin \epsilon}{d R_{2} \sin \epsilon}\right]-\tan ^{-1}\left[\frac{d^{2} \cos \epsilon+\mu(\nu+m) \sin ^{2} \epsilon}{d R_{4} \sin \epsilon}\right] \\
R_{1} & =\overline{B b}, R_{2}=\overline{B a}, R_{3}=\overline{A a}, R_{4}=\overline{A b} \\
a^{2} & =R_{1}{ }^{2}-R_{2}{ }^{2}+R_{3}{ }^{2}-R_{4}{ }^{2}, \delta_{23}{ }^{2}=R_{2}{ }^{2}-R_{3}{ }^{2}, \delta_{43}{ }^{2}=R_{4}{ }^{2}-R_{3}{ }^{2} \\
d^{2} & =R_{3}{ }^{2}-\mu^{2}-\nu^{2}-\frac{\mu \nu}{l m} \cdot a^{2}, \cos \epsilon=-\frac{a^{2}}{2 l m} \\
\mu & =\frac{2 l^{2}\left(\delta_{23}{ }^{2}-l^{2}\right)-a^{2}\left(\delta_{43}{ }^{2}-m^{2}\right)}{4 l^{2} m^{2}-a^{4}} \cdot l \\
\nu & =\frac{2 l^{2}\left(\delta_{43}{ }^{2}-m^{2}\right)-a^{2}\left(\delta_{23}{ }^{2}-l^{2}\right)}{4 l^{2} m^{2}-a^{4}} \cdot m
\end{aligned}
$$

The quantities $l, m_{1} R_{1}, R_{2}, R_{3}$, and $R_{1}$ are obtained by direct measurement and serve to determine all the others.

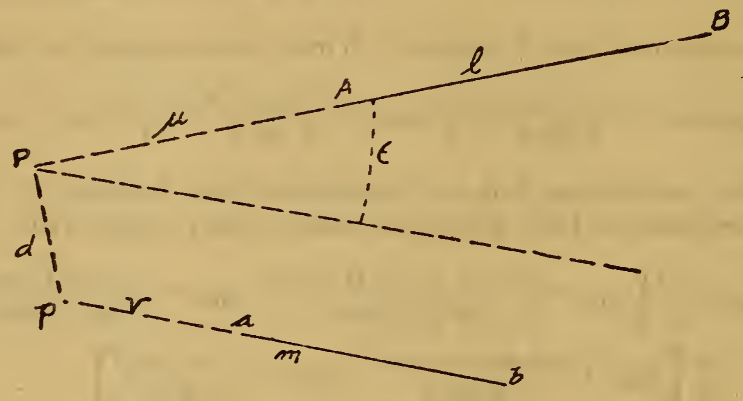

Fic. 13.-Two inclined wires, general case

\section{APPENDIX 3.-AN ALTERNATIVE OR MATHEMATICAL STATEMENT OF HOWE'S ASSUMPTION}

Dr. C. Snow, of this bureau, has developed the following treatment of the limitations of Howe's method. Formulating the question by means of the Newtonian integral for the electrostatic potential, and by taking the surface average and inverting the order of integration, one may arrive at the following alternative statement of Howe's assumption:

Howe's expression for the potential (and hence the capacity) is valid when, and to the same precision as, the following is valid: The sum of the deviations of linear charge density on the antenna differs from their mean value by a negligible amount.

It is obvious that this would apply very well to horizontal wires not too close together, but might not be true in the case of long, vertical wires whose lower end is close to the ground.

The proof may be outlined as follows: Let $z=0$ be the plane of the earth at zero potential, and let $P_{1}\left(x_{1} y_{1} z_{1}\right)$ be any point on the surface of the conducting system constituting the antenna, $\sigma\left(x_{1} y_{1} z_{1}\right)$ the surface density of charge there, and $d S_{1}$ the surface element there. If $P(x y z)$ is any point in space above the ground, then the Newtonian integral for the electrostatic potential at $P$ is

$$
\begin{gathered}
V(x y z)=\int \mathcal{S} d S_{1} \sigma\left(x_{1} y_{1} z_{1}\right)\left\{\frac{1}{\sqrt{\left(x-x_{1}\right)^{2}+\left(y-y_{1}\right)^{2}+\left(z-z_{1}\right)^{2}}}\right. \\
\left.-\frac{1}{\sqrt{\left(x-x_{1}\right)^{2}+\left(y-y_{1}\right)^{2}+\left(z+z_{1}\right)^{2}}}\right\}
\end{gathered}
$$


If $P(x y z)$ is any point on the surface of the conductor (antenna), the distribution of charge will be such as to give the integral on the right of (64) the same constant value, say $V_{1}$, for all positions of $P$ on this conductor. On the other hand, if $\sigma$ has the constant value $\sigma_{\mathrm{o}}$ at all points of this conductor (and $P$ still refers to a point on it) the second member would not be a constant, but would be a function of the position of the point $P$, say $V_{\mathrm{o}}(x y z)$ where

$$
\begin{aligned}
V_{0}(x y z) & =\sigma_{o} \int \mathcal{S} d S_{1}\left\{\frac{1}{\sqrt{\left(x-x_{1}\right)^{2}+\left(y-y_{1}\right)^{2}+\left(z-z_{1}\right)^{2}}}\right. \\
& \left.-\frac{1}{\sqrt{\left(x-x_{1}\right)^{2}+\left(y-y_{1}\right)^{2}+\left(z+z_{1}\right)^{2}}}\right\}
\end{aligned}
$$

Let $S$ represent the entire area of the conductor (antenna). If we multiply both sides of (64) by $d S$ and integrate over the entire surface of the conductor, the first member of the equation gives $V_{1} S$ since $V$ has the constant value $V_{1}$ over its surface. In the second member, we may interchange the order of integrations, and we obtain

$$
\begin{aligned}
& V_{1}=\frac{1}{S} \mathcal{S} \int d S_{1} \sigma\left(x_{1} y_{1} z_{1}\right) \mathcal{S} \mathcal{S} d S\left\{\frac{1}{\sqrt{\left(x_{1}-x\right)^{2}+\left(y_{1}-y\right)^{2}+\left(z_{1}-z\right)^{2}}}\right. \\
& \left.-\frac{1}{\sqrt{\left(x_{1}-x\right)^{2}+\left(y_{1}-y\right)^{2}+\left(z_{1}+z\right)^{2}}}\right\}=\frac{1}{\sigma_{\mathrm{o}} S} \mathcal{S} \mathcal{S} d S_{1} \sigma\left(x_{1} y_{1} z_{1}\right) \phi\left(x_{1} y_{1} z_{1}\right)
\end{aligned}
$$

where

$$
\begin{aligned}
\phi\left(x_{1} y_{1} z_{1}\right) & =\sigma_{o} \mathcal{S} \mathcal{S d S}\left\{\frac{1}{\sqrt{\left(x_{1}-x\right)^{2}+\left(y_{1}-y\right)^{2}+\left(z_{1}-z\right)^{2}}}\right. \\
& \left.-\frac{1}{\sqrt{\left(x_{1}-x\right)^{2}+\left(y_{1}-y\right)^{2}+\left(z_{1}+z\right)^{2}}}\right\}
\end{aligned}
$$

A comparison of (67) and (65) shows that $\phi\left(x_{1} y_{1} z_{1}\right)$ is just $V_{\circ}\left(x_{1} y_{1} z_{1}\right)$; that is, Howe's trial potential, or the potential at any point on the antenna, assuming that its density is uniform and that it is in the presence of the earth at zero potential. Therefore (66) amounts to

$$
V_{1}=\frac{1}{\sigma_{0} S} \int \mathcal{S} d S_{1} \sigma\left(x_{1} y_{1} z_{1}\right) V_{0}\left(x_{1} y_{1} z_{1}\right)
$$

If into (68) we now introduce the explicit assumption stated above, in the form

$$
\sigma\left(x_{1} y_{1} z_{1}\right)=\sigma_{0}+\epsilon\left(x_{1} y_{1} z_{1}\right)
$$

where $\epsilon$ is a variable measuring the deviation from uniformity,

$$
V_{1}=\frac{1}{S}\left\{\mathcal{S} \mathcal{S} V_{0}\left(x_{1} y_{1} z_{1}\right) d S_{1}+\frac{1}{\sigma_{0}} \mathcal{S} \mathcal{S} \in\left(x_{1} y_{1} z_{1}\right) V_{0}\left(x_{1} y_{1} z_{1}\right) d S_{1}\right\}
$$

Now, if the second integral is negligible in this expression, it reduces precisely to Howe's value for the potential. The method of passing from surface integrals to line integrals and regarding the conductors as linear is obvious. The second integral measures the error of his computation of potential $V_{1}$ (and hence of capacity $\left.C=\frac{Q}{V}\right)$. It is to be noticed that this integral accounts for the peculiar form of the alternative statement of Howe's assumption given above, for his method would still be applicable even if the deviation in density $\epsilon$ became infinite at certain places (as ends of wire where it might become logarithmically infinite and still remain integrable). All that is required is that the sum (integral) $\boldsymbol{S} \int \mathcal{S} S_{1} \in\left(x_{1} y_{1} z_{1}\right)$ be small compared to $\sigma_{0}$.

Washington, May 9, 1926. 